Pontifícia Universidade Católica $_{\text {a }}$

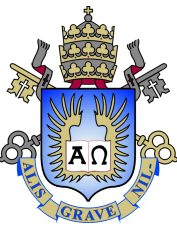

Larissa da Conceição Borges dos Santos

\title{
Teoria de Grafos na Educação Secundária:
}

Uma Proposta

Dissertação de Mestrado

Dissertação apresentada como requisito parcial para obtenção do grau de Mestre pelo Programa de Pós-graduação em Matemática do Departamento de Matemática do Centro Técnico Científico da PUC-Rio.

Orientador: Prof. José Victor Goulart Nascimento 


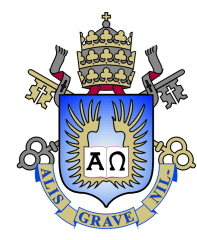

Larissa da Conceição Borges dos Santos

\section{Teoria de Grafos na Educação Secundária: \\ Uma Proposta}

Dissertação apresentada como requisito parcial para obtenção do grau de Mestre pelo Programa de Pós-graduação em Matemática do Departamento de Matemática do Centro Técnico Científico da PUC-Rio. Aprovada pela Comissão Examinadora abaixo assinada.

Prof. José Victor Goulart Nascimento
Orientador
Departamento de Matemática - PUC-Rio

Prof. Sinesio Pesco

Departamento de Matemática - PUC-Rio

Prof. Emilia Carolina Santana Teixeira Alves

Departamento de Matemática - PUC-Rio

Prof. Márcio da Silveira Carvalho

Coordenador Setorial do Centro Técnico Científico - PUC-Rio 
Todos os direitos reservados. É proibida a reprodução total ou parcial do trabalho sem autorização da universidade, do autor e do orientador.

\section{Larissa da Conceição Borges dos Santos}

Graduou-se em Licenciatura pela Universidade Federal do Rio de Janeiro (UFRJ) no ano de 2013. Atualmente é professora do ensino básico pela Secretaria de Educação do Estado do Rio de Janeiro.

Ficha Catalográfica

da Conceição, Larissa

Teoria de Grafos na Educação Secundária: Uma Proposta / Larissa da Conceição Borges dos Santos; orientador: José Victor Goulart Nascimento . - Rio de janeiro: PUC-Rio, Departamento de Matemática , 2017.

v., 108 f: il. color. ; $30 \mathrm{~cm}$

Dissertação (mestrado) - Pontifícia Universidade Católica do Rio de Janeiro, Departamento de Matemática .

Inclui bibliografia

1. Matemática - Teses. 2. demonstrações - Teses. 3. Teoria de Grafos;. 4. Ensino;. I. Goulart Nascimento, José Victor. II. Pontifícia Universidade Católica do Rio de Janeiro. Departamento de Matemática . III. Título. 


\section{Agradecimentos}

Em primeiro lugar, gostaria de agradecer a Deus por estar sempre comigo e ter me conduzido e colocado pessoas tão especiais ao meu lado, sem as quais não teria conseguido mais uma conquista em minha vida.

À minha família, principalmente aos meus pais Marilene e George, que sempre me incentivaram, me apoiaram e acreditaram não só em minha capacidade como também me consideravam a melhor de todas, mesmo eu estando longe disso. Muito Obrigada pelo amor e apoio incondicional que sempre tiveram comigo!

Ao meu noivo Pablo, meu porto seguro e meu companheiro de todas as horas. Sempre ao meu lado, me incentivando, não deixando fraquejar e me fazendo acreditar que tenho capacidade para ir além do que eu imagino. Graças ao apoio, ao amor, a amizade, a paciência e ao seu companheirismo este trabalho pode ser realizado. Agradeço por ter feito desse meu sonho o nosso sonho!

Ao meu orientador, o professor José Victor, por ser um grande guia, por sua paciência, pelos ensinamentos e ajuda nas dicas, indicações e correções durante as orientações e pela disponibilidade de seu precioso tempo a me ajudar sempre que eu precisei.

Aos professores da PUC-Rio, que sempre estavam dispostos a ajudar, fazendo com que eu aproveitasse a cada momento do mestrado e assim contribuíram com a minha formação.

Aos colegas de turma do PROFMAT na PUC-Rio, por todo apoio nos grupos de estudos, debates, conversas que ajudaram nas dificuldades vencidas durante o decorrer do curso.

À CAPES pelo auxílio financeiro que me proporcionou a conclusão desse mestrado.

E por fim, gostaria de agradecer ao PROFMAT e a PUC-Rio pelos auxílios fornecidos, pela oportunidade e por oferecer um curso enriquecedor . 


\section{Resumo}

da Conceição, Larissa; Goulart Nascimento,José Victor. Teoria de Grafos na Educação Secundária: Uma Proposta. Rio de Janeiro, 2017. 108p. Dissertação de Mestrado - Departamento de Matemática, Pontifícia Universidade Católica do Rio de Janeiro.

Este trabalho procura motivar e propor direções para uma abordagem de rudimentos da Teoria de Grafos nos anos finais da educação secundária brasileira. Os conceitos básicos da teoria são apresentados no contexto de desafios lúdicos e situações cotidianas. Procura-se ainda destacar a interdisciplinaridade e a atualidade do tema, apresentando exemplos provenientes de ramos tão diversos como eletrônica, transportes, arqueologia e genética.

\section{Palavras-chave}

Teoria de Grafos; Ensino; 


\section{Abstract}

da Conceição, Larissa; Goulart Nascimento,José Victor (Advisor). Graph Theory in Secondary Education: A Proposal. Rio de Janeiro, 2017. 108p. Dissertação de mestrado - Departamento de Matemática , Pontifícia Universidade Católica do Rio de Janeiro.

This work makes a case for the inclusion of some rudimentary Graph Theory in the final years of secondary education in Brazil, and also puts forward some suggestions of approach. The most basic concepts are presented in a light key, taking advange of puzzles and day to day situations. An effort was made to highlight the connections and applications of the theory to many branches of science and technology, such as electronics, transports, archeology and genetics.

\section{Keywords}

Graph Theory; Education; 


\section{Sumário}

1 Introdução $\quad 14$

2 Alguns problemas $\quad 15$

$\begin{array}{ll}2.1 & \text { O Problema da raposa, da galinha e do milho. } \\ 2.2 & 15\end{array}$

2.2 O Problema das três jarras de água. 21

2.3 O Problema do caixeiro viajante. 26

2.4 O Problema das sete pontes de Königsberg 28

3 Conceitos iniciais de teoria de grafos 33

3.1 Definições 33

$\begin{array}{lll}3.2 & \text { Alguma nomenclatura } & 42\end{array}$

3.3 Caminhos, Trilhas e Passeios 48

4 Problemas resolvíveis por teoria de grafos $\quad 54$

5 Demonstrações de alguns teoremas da teoria de grafos $\quad 96$

6 Considerações Finais 106

$\begin{array}{ll}\text { Referências bibliográficas } & 108\end{array}$ 


\section{Lista de figuras}

Figura 2.1 Raposa, Galinha e Milho. 16

Figura 2.2 Em rosa temos as diagonais das faces do cubo; em verde, as diagonais do cubo; em preto, as arestas.

Figura 2.3 Possibilidades de deslocamentos. Ponto de partida $(0,0,0)$ e ponto de chegada $(1,1,1)$.

Figura 2.4 As arestas $(0,0,0) \rightarrow(0,0,1)$ e $(0,0,0) \rightarrow(0,1,0)$ foram excluídas das possibilidades.

Figura 2.5 O caminho (2), destacado em laranja, e o caminho (2'), destacado em roxo.

Figura 2.6 As arestas $(1,1,0) \rightarrow(1,1,1)$ e $(1,0,1) \rightarrow(1,1,1)$ foram excluídas das possibilidades.

Figura 2.7 O caminho seguindo por (2), destacado em laranja, e o caminho seguindo por (2'), destacado em roxo.

Figura 2.8 Caminhos coincidentes $(\mathbf{5})=\left(5^{\prime}\right):(0,1,1) \rightarrow(1,1,1)$ destacados em azul.

Figura 2.9 Três jarras com capacidade de 8 litros, 5 litros e 3 litros. 21

Figura $2.10 \mathrm{O}$ ponto em rosa indica o ponto de partida e os pontos verdes, as configurações finais desejadas.

Figura 2.11 Neste momento, temos 5 litros de água na jarra (A), 3 litros na jarra $(\mathrm{C})$ e 0 litros na jarra $(\mathrm{B})$.

Figura 2.12 Neste momento, temos 5 litros de água na jarra (A), 3 litros na jarra(B) e 0 litros na jarra $(\mathrm{C})$.

Figura 2.13 Neste momento, temos 2 litros de água na jarra (A), 3 litros na jarra(B) e 3 litros na jarra $(\mathrm{C})$.

Figura 2.14 Neste momento, temos 2 litros de água na jarra (A), 5 litros na jarra(B) e 1 litros na jarra (C).

Figura 2.15 Neste momento, temos 7 litros de água na jarra (A), 0 litros na jarra(B) e 1 litros na jarra $(\mathrm{C})$.

Figura 2.16 Neste momento, temos 7 litros de água na jarra (A), 1 litros na jarra(B) e 0 litros na jarra $(\mathrm{C})$.

Figura 2.17 Neste momento, temos 4 litros de água na jarra (A), 1 litros na jarra(B) e 3 litros na jarra $(\mathrm{C})$.

Figura 2.18 Esquema das cidades. 26

Figura 2.19 Em verde temos o percurso com menor custo. 28

Figura 2.20 Desenho da cidade de Königsberg. Fonte: https://grafos.neocities.org/\#/

Figura 2.21 Esquema da cidade de Königsberg. $\quad 29$

Figura 2.22 Problema para passar pela ponte 5. 30

Figura 2.23 Problema para passar pela ponte $7 . \quad 30$

Figura 2.24 Problema para passar pela ponte 1. 31

Figura 2.25 Problema para passar pelas pontes 2 e 7 . 31

Figura 3.1 Um grafo. 33

Figura 3.2 Grafo das cidades vizinhas da baixada fluminense. $\quad 34$

Figura 3.3 Grafo das palavras da língua portuguesa. 34 
Figura 3.4 Grafo retirado do Estudos de Redes Sociais na Internet feito pela jornalista Raquel Recuero no site: www.raquelrecuero.com.

Figura 3.5 Imagem retirada do Google. 35

Figura 3.6 Grafo da 37º rodada do campeonato de $2016 . \quad 36$

Figura 3.7 Representação gráfica do Grafo $G(V, A, f) . \quad 37$

Figura 3.8 Representação gráfica do Grafo G'(V',A'). 38

Figura 3.9 Um representação só com segmentos, outra com curvas e segmentos, e a terceira somente com curvas.

38

Figura $3.10 \mathrm{O}$ vértice c é vizinho de $a$ e $d, d$ é vizinho de $c$ e $b, b$ é vizinho de $a$ e $d$.

Figura 3.11 Duas arestas paralelas incidindo nos vértices a e b. $\quad 40$

Figura 3.12 Temos o laço aa. $\quad 40$

Figura 3.13 Formado somente por arestas orientadas. 41

Figura 3.14 O grafo (a) é um grafo simples, o grafo (b) é um multigrafo e o grafo (b) é um digrafo.

42

Figura 3.15 Grafo do Mapa do Brasil. 43

Figura 3.16 Grafo do Benzeno. 43

Figura 3.17 Grafo de chamadas telefônicas com 5 telefones. 44

Figura 3.18 Grafo totalmente desconexo. 44

Figura 3.19 Os primeiros cinco grafos completos. 45

Figura 3.20 H é um subgrafo de G.

Figura 3.21 Grafo bipartido. 45

Figura 3.22 Grafo bipartido completo $K_{3,4}$ ou $K_{4,3}$. 46

Figura 3.23 Representações do grafo planar $K_{4}$ : em (1) ocorre cruzamento entre arestas.

46

Figura 3.24 Fonte: http://www.mspc.eng.br/elemag/celetr0220.shtml modificada pela autora. $\quad 47$

Figura 3.25 Três exemplos de placas de circuito impressos. 47

Figura 3.26 No grafo desconexo não existe um A-F passeio. 48

Figura 3.27 Esquema da atividade elétrica num cérebro humano. Fonte: http://news.harvard.edu/gazette/story/2015/09/whyms-symptoms-may-improve-as-days-get-shorter/

Figura 3.28 (1) aedabcdac é um $a-c$ passeio,(2) abcdac é uma $a-c$ trilha e (3) abdc é um $a-c$ caminho.

Figura 3.30 O octaedro é um grafo planar com trilha euleriana fechada $A B C F B D F E C A E D A$.

Figura 3.31 Grafo completo $K_{5}$ com o ciclo hamiltoniano mais óbvio destacado em azul.

Figura 3.32 O cubo como um grafo planar hamiltoniano. 51

$\begin{array}{ll}\text { Figura } 3.33 \text { Uma árvore. } & 52\end{array}$

Figura 3.34 (1):Alcano e (2):Isobutano. $\quad 52$

Figura 3.35 F= frase; $\mathrm{SN}=$ Sintagma Nominal; SV= Sintagma Verbal; $\mathrm{V}=$ Verbo; $\mathrm{Q}=$ Quantificador; $\mathrm{DET}=$ Determinante; $\mathrm{N}=$ nome.

Figura 3.36 H é uma árvore geradora de G. 53

Figura 4.1 Grafo das Movimentações da Galinha,Raposa e Milho. 55 
Figura 4.2 Grafo do Esquema das Cidades a serem percorridas pelo Senhor Tavares.

Figura 4.3 Grafo das 7 pontes da cidade de Königsberg.

Figura 4.4 Imagem da cidade de Königsberg no dias atuais retirada do "Google Maps" .

Figura 4.5 Algumas imagens do jogo "Viagem ao mundo". Fonte: http://principo.org/um-pequeno-histrico-da-teoria-dos-grafos3.html?page $=5$

Figura 4.6 Grafo do jogo "Viagem ao mundo".

Figura 4.7 Em vermelho temos uma solução do jogo "Viagem ao mundo".

Figura 4.8 Conjunto de dominós duplo-seis.

60

Figura 4.9 Grafo do dominó.

Figura 4.10 Planta da casa. Fonte: http://leandro.md.tripod.com 62

Figura 4.11 Grafo da Planta da casa do bilionário Count Van Diamond. 63

Figura 4.12 "Desenho" das duas casas. 64

Figura 4.13 Grafo G da casa 1 e grafo G' da casa 2.

Figura 4.14 Os 7 produtos químicos para serem transportados. $\quad 66$

Figura 4.15 Grafo das reações químicas entre os 7 produtos. $\quad 67$

Figura 4.16 O subgrafos formados. $\quad 67$

Figura 4.17 Grafo das relações de amizades. $\quad 69$

Figura 4.18 Os 4 casais do problema. $\quad 70$

Figura 4.19 Representação parcial no grafo $G$ do problema. $\quad 71$

Figura 4.20 Representação parcial no grafo $G$ do problema: Primeiro casal relacionado $\rightarrow A$ e $D$.

Figura 4.21 Representação parcial no grafo $G$ do problema: Segundo casal relacionado $\rightarrow G$ e $H$.

Figura 4.22 Representação final do grafo $G$ do problema. $\quad 73$

Figura 4.23 Representação inicial do digrafo $G$ do problema. $\quad 74$

Figura 4.24 Representação final do digrafo $G$ do problema. $\quad 75$

$\begin{array}{ll}\text { Figura 4.25 Problemas dos } 3 \text { vizinhos. } & 76\end{array}$

Figura 4.26 Grafo problemas dos 3 vizinhos. 76

Figura 4.27 Segunda representação geométrica do grafo do problemas dos 3 vizinhos.

Figura 4.28 Temos a curva $C$ e $x \in \operatorname{Int}(C)$ e $y \in \operatorname{Ext}(C) . \quad 77$

$\begin{array}{ll}\text { Figura 4.29 A curva } C \text { é o Ciclo AECD. } & 78\end{array}$

Figura 4.30 Regiões $R_{2}, R_{11}$ e $R_{12}$. 78

Figura 4.31 Na figura (1) corta a aresta $A D$, em (2) corta $B D$, em (3) corta $B E$ e em (4) corta $A E$.

Figura 4.32 Problemas dos 3 vizinhos modificado. $\quad 79$

Figura 4.33 Condimínio e as 5 torres. 80

Figura 4.34 Uma representação gráfica do Grafo das cinco Torres. $\quad 80$

Figura 4.35 Desenhando o ciclo. $\quad 80$

Figura 4.36 (1):Acrescentando as arestas $T_{3} T_{1}$ e $T_{3} T_{5}$ e

(2):Acrescentando as arestas $T_{4} T_{1}$ e $T_{4} T_{2} . \quad 81$

Figura 4.37 (1):Cortou a arest a $T_{1} T_{3}$ e (2):Cortou a aresta $T_{4} T_{1} . \quad 81$

Figura 4.38 Grafo das rotas aéreas. $\quad 82$

Figura 4.39 Retirando a aresta Manaus - Curitiba. 83 
Figura 4.40 Árvore geradora do grafo. 83

Figura 4.41 Intervalos de vida de alguns matemáticos. 86

$\begin{array}{ll}\text { Figura } 4.42 \text { grafo de contemporaneidade de alguns matemáticos. } & 86\end{array}$

$\begin{array}{ll}\text { Figura 4.43 Grafo de intervalos? } & 87\end{array}$

Figura 4.44 Duas tentativas fracassadas de associar quatro intervalos ao grafo 4.43. 87

Figura 4.45 Fonte: http://antigoegito.org/visualizando-o-antigoegito-parte-2/. Modificado pela autora. $\quad 88$

$\begin{array}{ll}\text { Figura } 4.46 \text { grafo de intervalos do problema. } & 89\end{array}$

Figura 4.47 Possícvel posição relativa de A, B e C no tempo. $\quad 89$

Figura 4.48 Possível ordem. 90

Figura 4.49 Edifício construído utilizando Braced Frameworks. Fonte: https://www.quora.com/What-are-the-advantages-anddisadvantages-of-braced-building. $\quad 91$

Figura 4.50 Acrescentando as Estruturas Diagonais e tornando a estrutura reforçada. $\quad 91$

Figura 4.51 Três projetos apresentados pelos engenheiros. $\quad 92$

Figura 4.52 Grafo do projeto (1). 93

Figura 4.53 Grafo do projeto (2). 93

Figura 4.54 Grafo do projeto (3). 94

Figura 4.55 Árvore geradora do grafo do projeto (1). 95

Figura 4.56 Projeto (1) modificado. Observe que as linhas pontilhadas foram as diagonais retiradas do projeto original. 95

Figura 5.1 Grafos G e G'. 97

Figura 5.2 Sempre somando 2 unidades. $\quad 99$

Figura 5.3 $C_{1}=G$. 100

Figura 5.4 Do grafo $G$ foi "retirado" o ciclo $C_{1}$ formando um novo $\begin{array}{ll}\text { grafo } G^{\prime} . & 100\end{array}$

Figura 5.5 Do grafo $G^{\prime}$ foi "retirado"o ciclo $C_{2}$ formando um novo grafo $G^{\prime \prime} . \quad 101$

Figura 5.6 Todos os vértices passaram a ter grau zero. 101

Figura 5.7 Os ciclos $C_{1}$ e $C_{3}$ possuem em comum o vértice $j . \quad 102$

Figura 5.8 Acrescentando a aresta $a b$ ao grafo $G$ e formando o grafo $G^{\prime}$.

Figura 5.9 Formação de $G^{\prime}$ e $G^{\prime \prime}$ a partir de $G$. Note que já existem ciclos hamiltonianos em $G$ (é absurdamente difícil ilustrar provas por absurdo). 


\section{Lista de tabelas}

Tabela 2.1 Trajetos e custos da viagem do Sr. Tavares. 28

Tabela 4.1 Tabela com os graus dos tipos sanguíneos. 75

Tabela 4.2 Trajetos e distância da companhia aérea. 82 
A Matemática é o alfabeto que Deus usou para escrever o Universo.

Galilei, Galileu. 


\section{1 \\ Introdução}

A dissertação que será apresentada ao leitor tem como objetivo mostrar uma proposta de abordagem de teoria de grafos de forma que desperte o interesse dos alunos da educação secundária.

O interesse pela teoria de grafo teve início com o resultado do problema das sete pontes de Königsberg (que será trabalhado nos próximos capítulos) no artigo de Leonhard Euler, publicado em 1736. (1) Esse resultado é considerado um dos primeiros resultados topológicos em Geometria, ou seja, não dependente de quaisquer medidas. Isso ilustra a profunda conexão entre a Combinatória e a Topologia.

Embora seja um conteúdo que não conste do currículo padrão da educação básica, sendo até mesmo omitido da grade de alguns cursos de licenciatura em Matemática, a abordagem proposta é simples e contextualizada sendo perfeitamente possível trabalhar com os alunos, principalmente do ensino médio, não só em matemática, mas em diversas outras disciplinas, como veremos no decorrer deste trabalho, o que torna o assunto muito mais palpável e viável ao processo de ensino-aprendizagem do estudante.

Além desta breve introdução, o trabalho possui outros quatro capítulos:

No capítulo 2, abordamos quatro problemas clássicos e procuramos resolvê-los sem falar explicitamente sobre grafos. Com isso, pode ser que algum deles não encontre solução imediata. Eles serão revisitados no capítulo 4.

No capítulo 3 , começamos a trabalhar o conceito de grafos, apresentando algumas definições básicas que serão úteis no capítulo seguinte.

No capítulo 4, introduzimos alguns resultados básicos da teoria de grafos para resolver alguns problemas contextualizados que abrangem diversas áreas de conhecimento. Os problemas do capítulo 2 são revisitados usando a terminologia introduzida no capítulo 3 e os teoremas aprendidos neste capítulo 4 .

Por fim, no capítulo 5, apresentamos as demonstrações dos poucos resultados da teoria de grafos que foram usados no trabalho. 


\section{2}

\section{Alguns problemas}

Este capítulo tem como objetivo apresentar quatro probleminhas clássicos, de domínio público, que podem ser abordados usando conceitos básicos de teoria de grafos.

Esses problemas (ou outros com características semelhantes) poderiam ser propostos aos alunos, individualmente ou em pequenos grupos, como desafios, no intuito de que eles empregassem livremente sua criatividade na tentativa de resolvê-los - talvez chegando a soluções satisfatórias de alguns, mas recolhendo ao menos algumas impressões sobre a dificuldade inerente a outros. Assim prevenidos, eles estariam mais bem dispostos a receber rudimentos de teoria de grafos, que seriam prontamente aplicados à solução desses mesmos problemas, facilitada e encaminhada agora pelo professor em sala de aula. Nossa esperança é que o estudante reconheça nos grafos uma maneira muito conveniente e simples de deixar de lado as características acidentais dos problemas propostos, que por vezes distraem do principal, para se concentrar mais eficazmente nas características essenciais, fomentando assim sua capacidade de abstração - uma competência muito valiosa não somente para sua futura vida acadêmica e profissional, como também para outros papéis sociais que ele vier a desempenhar.

Note-se que cada uma das quatro situações apresentadas envolve um algoritmo, que, em princípio, não sabemos sequer se existe; e existindo, podemos nos perguntar se é único; não sendo único, podemos nos perguntar se é o melhor, segundo algum critério conveniente (mais rápido, mais econômico, etc.).

\section{1}

\section{O Problema da raposa, da galinha e do milho.}

Um fazendeiro precisa levar uma galinha, uma raposa e um saco de milho de uma margem de um rio para a outra. Ele dispõe de um pequeno barco, que só o permite levar consigo um item de cada vez. Mas ele deve providenciar, durante todo o processo, que a raposa jamais fique a sós com a galinha, nem tampouco a galinha com o saco de milho (por razões óbvias). É possível fazer isso? Se 


\section{sim, qual a maneira mais eficiente de completar a tarefa?}

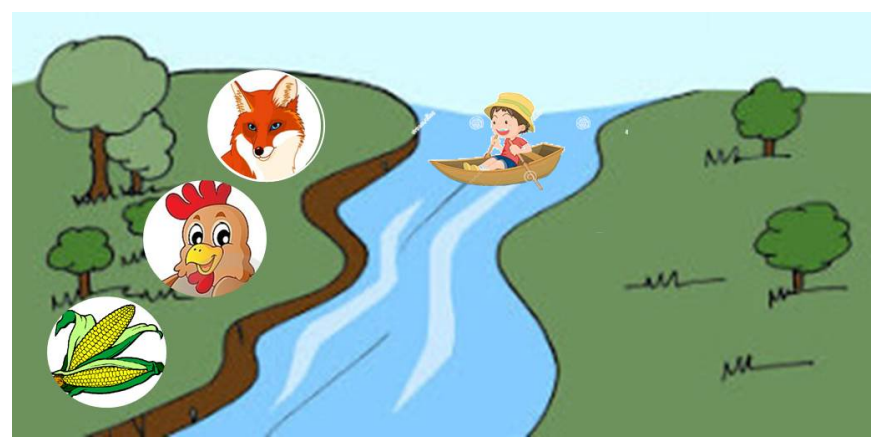

Figura 2.1: Raposa, Galinha e Milho.

É claro que esse problema não tem um grau de dificuldade muito elevado. Após umas poucas tentativas mentais, uma pessoa pode chegar à seguinte solução: ele pode levar a galinha para o outro lado, primeiramente. Depois, leva raposa e deixa lá, voltando para a outra margem com a galinha. Posteriormente, deixa a galinha nessa margem e leva o saco de milho para junto da raposa, na outra margem. Por fim, volta e busca a galinha que ficou do outro lado. Mas será essa a única solução? Existirá uma solução envolvendo um menor número de viagens?

Para tentar responder a essa pergunta, podemos modelar os estágios da nossa tarefa da seguinte maneira: cada "estado" do sistema "galinha, raposa e milho"pode ser representado por ternos ordenados de 0 's e 1 's, onde " 0 " significa que o objeto está na margem de partida do rio e "1" significa que o objeto está na margem final do rio. Além disso, a coordenada $x$ representa a galinha, a coordenada $y$ representa a raposa e a coordenada $z$ o milho.

Portanto, cada estado na qual os objetos (galinha, raposa, milho) se encontram pode ser representado por um vértice do cubo de aresta um. Por exemplo: o vértice $(1,0,1)$ significa que a galinha e o milho estão na margem 1 e a raposa na margem 0 .

Assim, temos que o nosso ponto inicial é o $(0,0,0)$ e queremos chegar no ponto final $(1,1,1)$. Porém para que isso aconteça devemos fazer os deslocamentos necessários de forma que não tornemos a situação perigosa, como por exemplo, deixar a galinha e o milho sozinhos em uma das margens.

Logo, todas as possibilidades de deslocamentos podem ser representadas através de cada segmento que liga dois vértices do cubo da figura 2.2 de aresta 
1. Onde cada um desses segmentos representa uma mudança de margem para cada um dos objetos.

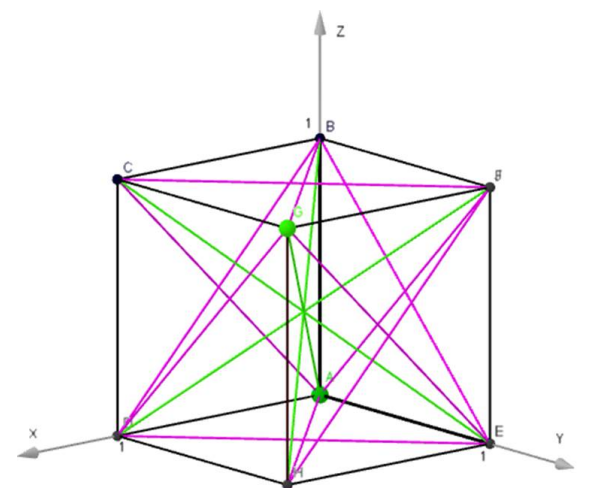

Figura 2.2: Em rosa temos as diagonais das faces do cubo; em verde, as diagonais do cubo; em preto, as arestas.

Como no problema só podemos transportar um objeto por vez, concluímos que as arestas das diagonais não podem ser utilizadas como eventuais deslocamentos, pois isso envolveria uma mudança de duas ou mais coordenadas, o que em nosso problema significaria deslocamentos simultâneos de dois objetos. Portanto, as possibilidades de deslocamentos se reduzem às arestas do cubo, como mostra a figura 2.3 .

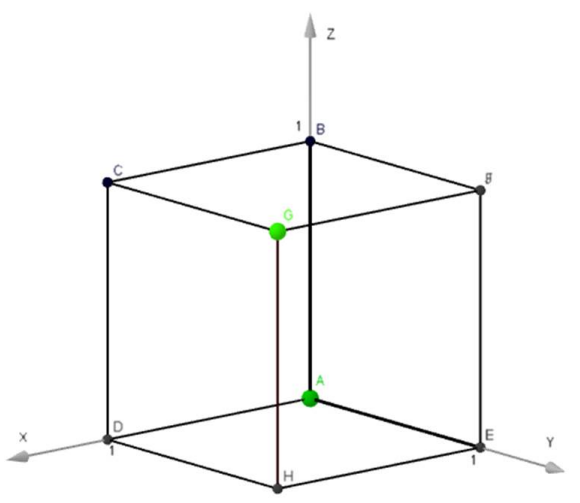

Figura 2.3: Possibilidades de deslocamentos. Ponto de partida $(0,0,0)$ e ponto de chegada $(1,1,1)$.

Com isso, partindo do ponto $(0,0,0)$, temos 3 possibilidades:

- $(0,0,0) \rightarrow(0,0,1)$ : não será possível, pois nesse caso deixaríamos a galinha e a raposa juntas na margem 0 sem supervisão.

- $(0,0,0) \rightarrow(0,1,0)$ : não será possível, pois nesse caso deixaríamos a galinha e o milho juntos na margem 0 sem supervisão.

- $(0,0,0) \rightarrow(1,0,0)$ : é possível, pois levaríamos a galinha para a margem 1 , e deixaríamos a raposa e o milho na margem 0 . 
Logo, o nosso primeiro passo é o $(0,0,0) \rightarrow(1,0,0)$ (1), como mostra a figura 2.4 .

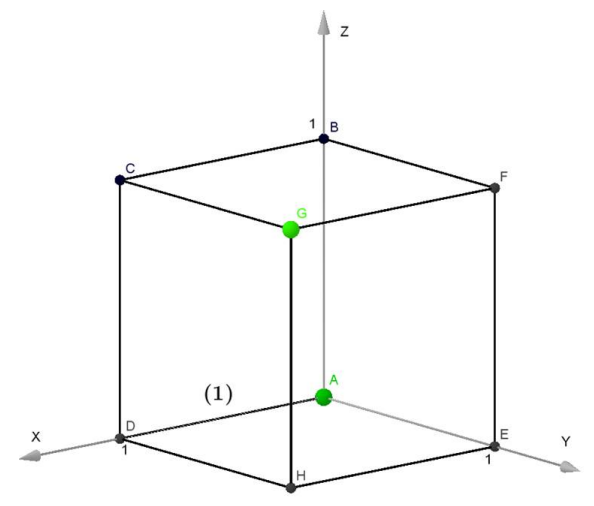

Figura 2.4: As arestas $(0,0,0) \rightarrow(0,0,1)$ e $(0,0,0) \rightarrow(0,1,0)$ foram excluídas das possibilidades.

Agora partindo do ponto $(1,0,0)$, temos 2 possibilidades:

- $(1,0,0) \rightarrow(1,1,0)$ : é possível, basta levar a raposa para a margem 1 e permanecer lá, deixando o milho na margem 0 .

- $(1,0,0) \rightarrow(1,0,1)$ : é possível, basta levar o milho para margem 1 e permanecer lá, deixando a raposa na margem 0 .

Assim, como podemos ver na figura 2.5, temos 2 possibilidades para o segundo passo:

$$
\begin{aligned}
& -(1,0,0) \rightarrow(1,1,0)(2) . \\
& -(1,0,0) \rightarrow(1,0,1)\left(2^{\prime}\right) .
\end{aligned}
$$

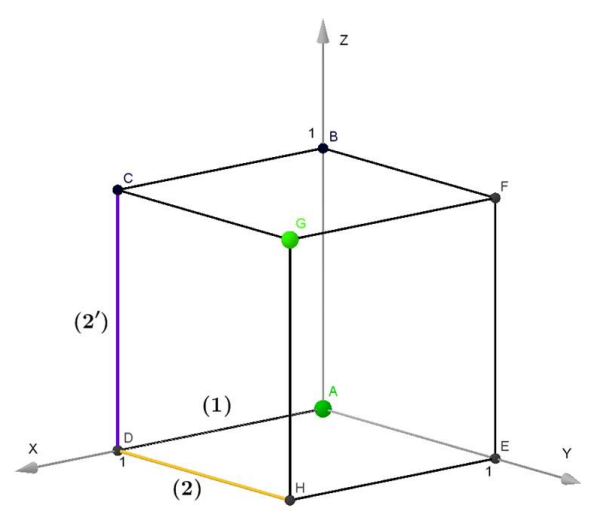

Figura 2.5: O caminho (2), destacado em laranja, e o caminho (2'), destacado em roxo.

Seguindo pelo caminho (2), temos 2 possibilidades:

- $(1,1,0) \rightarrow(1,1,1)$ : não será possível, pois nesse caso seria necessário deixar galinha e raposa sozinhas na margem 1 para voltar e buscar o milho. 
- $(1,1,0) \rightarrow(0,1,0)$ : é possível, basta deixar a raposa na margem 1 , levar a galinha para a margem 0 e permanecer lá.

Assim, o terceiro passo, indo por (2), é $(1,1,0) \rightarrow(0,1,0)$ (3).

Seguindo pelo caminho (2'), temos 2 possibilidades:

- $(1,0,1) \rightarrow(1,1,1)$ : não será possível, pois nesse caso seria necessário deixar a galinha e milho sozinhos na margem 1 para voltar e buscar a raposa.

- $(1,0,1) \rightarrow(0,0,1)$ : é possível, basta deixar o milho na margem 1 , e levar a galinha para a margem 0 e permanecer lá.

Assim, o terceiro passo, indo por $\left(2^{\prime}\right)$, é $(1,0,1) \rightarrow(0,0,1) \quad\left(3^{\prime}\right)$, como podemos observar na figura 2.6.

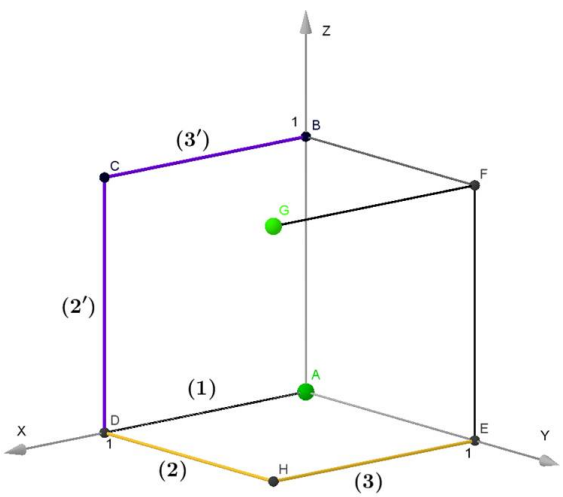

Figura 2.6: As arestas $(1,1,0) \rightarrow(1,1,1)$ e $(1,0,1) \rightarrow(1,1,1)$ foram excluídas das possibilidades.

Seguindo pelo caminho (3), temos 1 possibilidade:

- $(0,1,0) \rightarrow(0,1,1)$ : é possível, basta deixar a galinha na margem 0 e levar o milho para a margem 1 .

Assim, o quarto passo é $(0,1,0) \rightarrow(0,1,1)(4)$.

Seguindo pelo caminho (3'), temos 1 possibilidade:

- $(0,0,1) \rightarrow(0,1,1)$ : é possível, basta deixar a galinha na margem 0 e levar a raposa para a margem 1 .

Assim, o quarto passo é $(0,1,0) \rightarrow(0,1,1) \quad\left(4^{\prime}\right)$, como podemos observar na figura 2.7 .

Agora os caminhos convergem no ponto $(0,1,1)$ e, para alcançar a meta, basta fazer: 


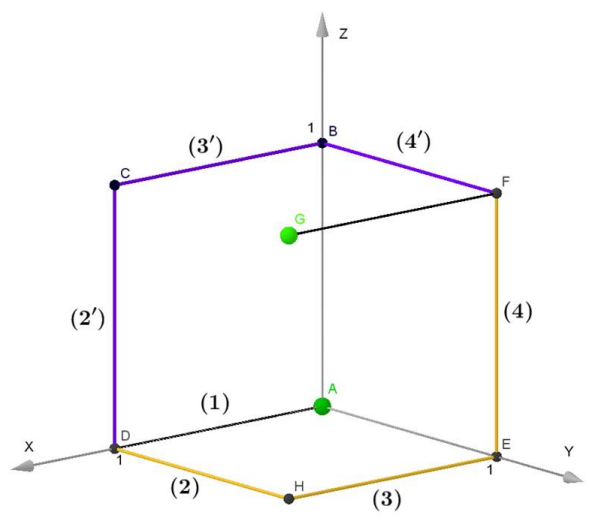

Figura 2.7: O caminho seguindo por (2), destacado em laranja, e o caminho seguindo por $\left(2^{\prime}\right)$, destacado em roxo.

- $(0,1,1) \rightarrow(1,1,1)$ : é possível, basta trazer a galinha para a margem 1 .

$$
\text { Portanto, o passo final é }(0,1,1) \rightarrow(1,1,1)(5)=\left(5^{\prime}\right) \text {. }
$$

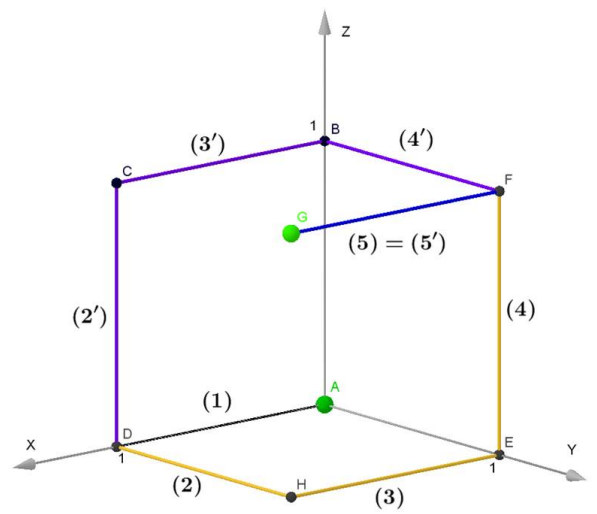

Figura 2.8: Caminhos coincidentes $(5)=\left(5^{\prime}\right):(0,1,1) \rightarrow(1,1,1)$ destacados em azul.

Logo, como mostra a figura 2.8, temos como solução exatamente dois trajetos possíveis, de mesmo comprimento:

$$
(1) \rightarrow(2) \rightarrow(3) \rightarrow(4) \rightarrow(5) \text { e }(1) \rightarrow\left(2^{\prime}\right) \rightarrow\left(3^{\prime}\right) \rightarrow\left(4^{\prime}\right) \rightarrow\left(5^{\prime}\right) .
$$




\section{2}

\section{O Problema das três jarras de água.}

Temos três jarras não-graduadas: uma com capacidade total de 8 litros (A), completamente cheia de água, e outras duas jarras vazias, com capacidades de 5 e 3 litros (B e C, respectivamente). Desejamos separar exatamente 4 litros de água, sem auxílio de outros instrumentos de medida. Isso é possível?

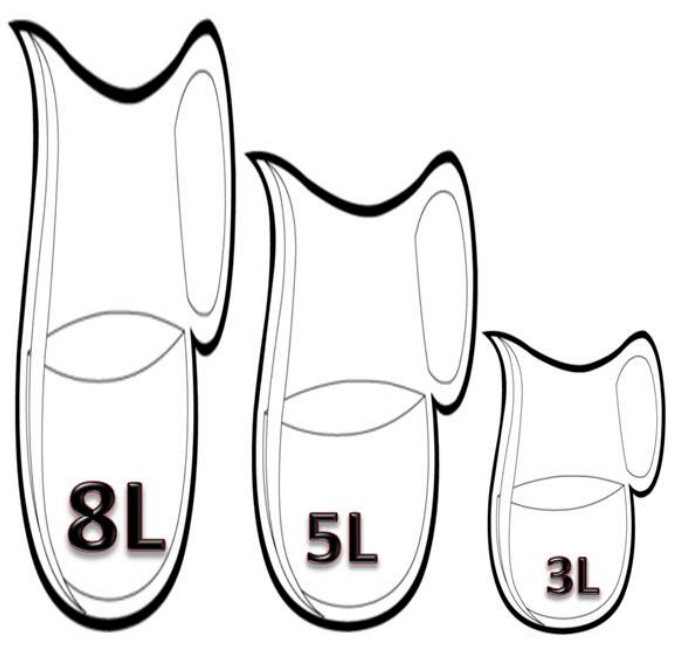

Figura 2.9: Três jarras com capacidade de 8 litros, 5 litros e 3 litros.

Esse problema admite muitas variações e pode ser facilmente implementado em sala de aula (i.e., usando jarras e água mesmo). A regra do jogo é: só nos é permitido, em cada jogada, esvaziar completamente o conteúdo de uma jarra na outra, ou até imediatamente antes do transbordamento, o que ocorrer primeiro.

Para tentar achar uma solução para esse problema, podemos modelar o seu espaço de estados associando a cada configuração um par ordenado de números inteiros, da seguinte forma: a abscissa representa a quantidade de água em litros na jarra (B) e a ordenada representa a quantidade na jarra (C). Evidentemente, o volume faltante em cada par encontra-se na jarra (A). Por exemplo:

- $(0,0)$ significa que toda água esta na jarra $(\mathrm{A})$;

- $(0,3)$ significa que há 5 litros na jarra (A) e 3 litros na jarra (C);

- (2,3) significa que há 3 litros na jarra (A), 2 litros na jarra (B) e 3 litros na jarra $(\mathrm{C})$; 
Assim, estamos partindo do estado $(0,0)$, onde a água está toda na jarra (A) e queremos chegar a um dos seguintes estados: $(4,0),(3,1),(2,2),(1,3),(4,1),(4,2)$ ou $(4,3)$. Dessa forma, teremos separado a quantidade desejada. O problema é saber se existe uma sequência finita de jogadas permitidas levando do estado $(0,0)$ a um dos estados desejados.

Todas as configurações possíveis estão indicadas na figura 2.10.

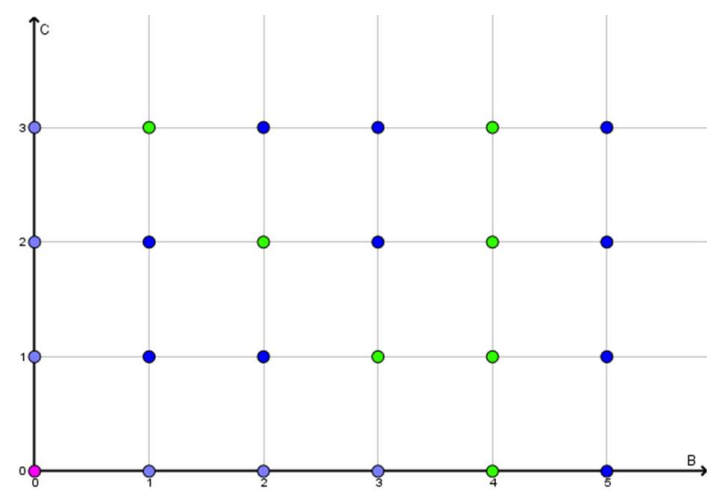

Figura 2.10: O ponto em rosa indica o ponto de partida e os pontos verdes, as configurações finais desejadas.

Para tentar resolver o problema, iremos:

(1) $(0,0) \rightarrow(0,3)$ : encher a jarra $(\mathrm{C})$, como mostra a figura 2.11;

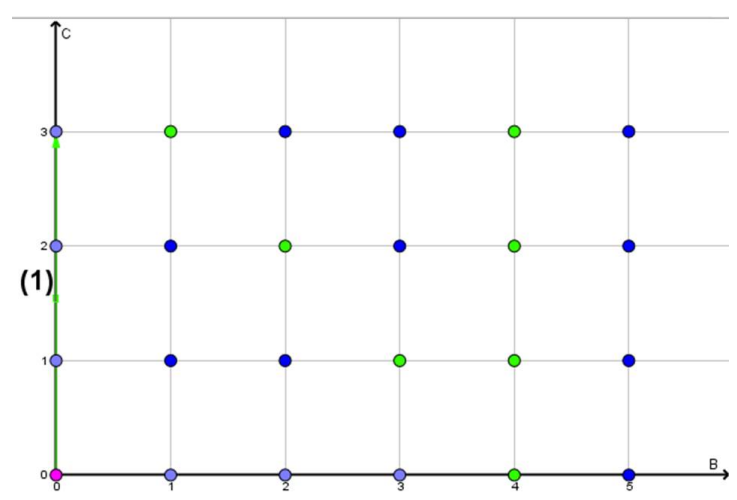

Figura 2.11: Neste momento, temos 5 litros de água na jarra (A), 3 litros na jarra $(\mathrm{C})$ e 0 litros na jarra (B).

(2) $(0,3) \rightarrow(3,0)$ : transportar 3 litros para a jarra (B) utilizando todo o conteúdo da jarra $(\mathrm{C})$, como mostra a figura 2.12; 


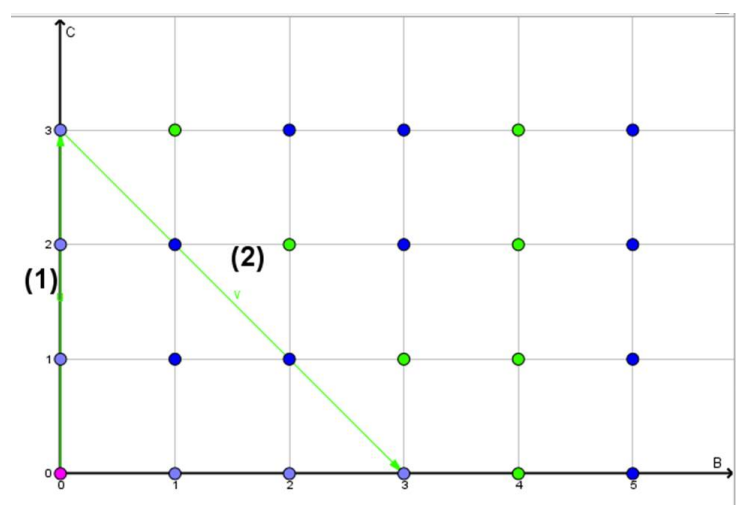

Figura 2.12: Neste momento, temos 5 litros de água na jarra (A), 3 litros na jarra(B) e 0 litros na jarra (C).

(3) $(3,0) \rightarrow(3,3)$ : encher a jarra $(\mathrm{C})$ com a água contida na jarra (A), como mostra a figura 2.13;

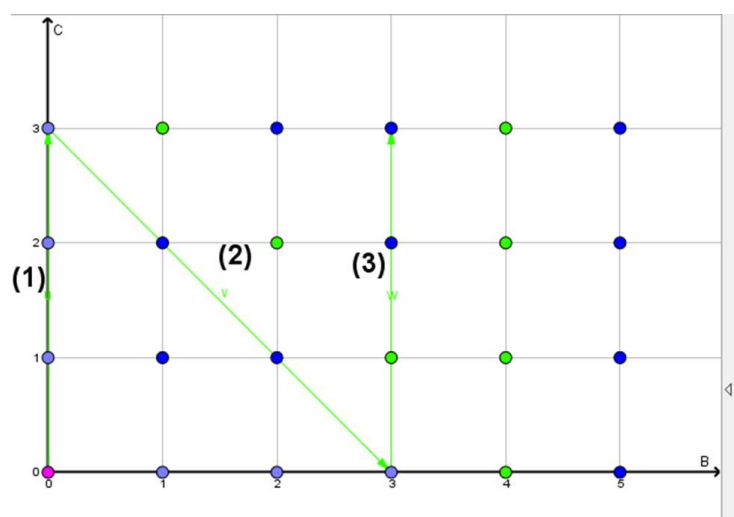

Figura 2.13: Neste momento, temos 2 litros de água na jarra (A), 3 litros na jarra(B) e 3 litros na jarra (C). 
(4) $(3,3) \rightarrow(5,1)$ : encher a jarra (B) com a água contida na jarra (C), como mostra a figura 2.14 ;

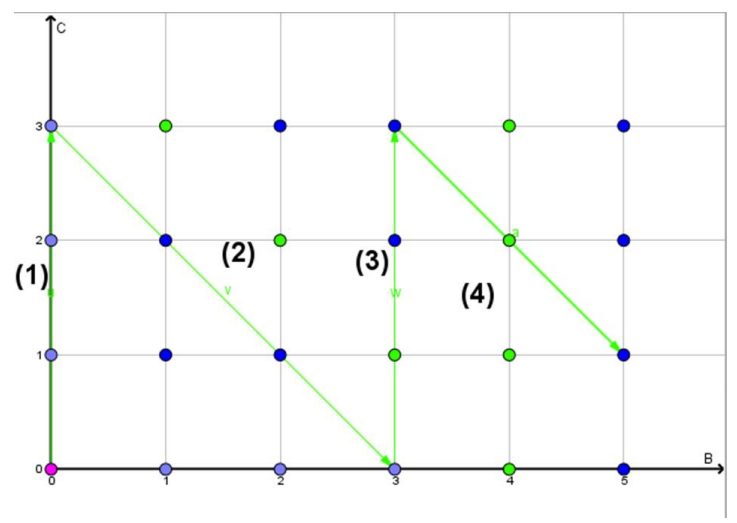

Figura 2.14: Neste momento, temos 2 litros de água na jarra (A), 5 litros na jarra(B) e 1 litros na jarra $(\mathrm{C})$.

(5) $(5,1) \rightarrow(0,1)$ : esvaziar todo o conteúdo da jarra (B) na jarra(A), como mostra a figura 2.15;

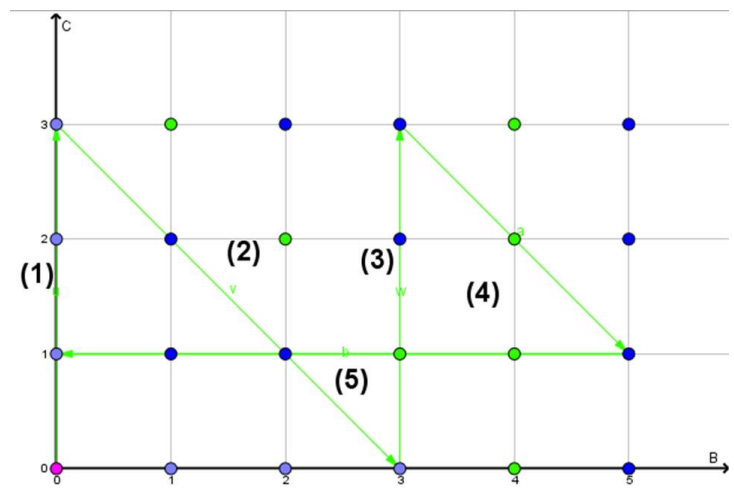

Figura 2.15: Neste momento, temos 7 litros de água na jarra (A), 0 litros na jarra(B) e 1 litros na jarra (C). 
(6) $(0,1) \rightarrow(1,0)$ : esvaziar todo o conteúdo da jarra $(\mathrm{C})$ na jarra(B), como mostra a figura 2.16 ;

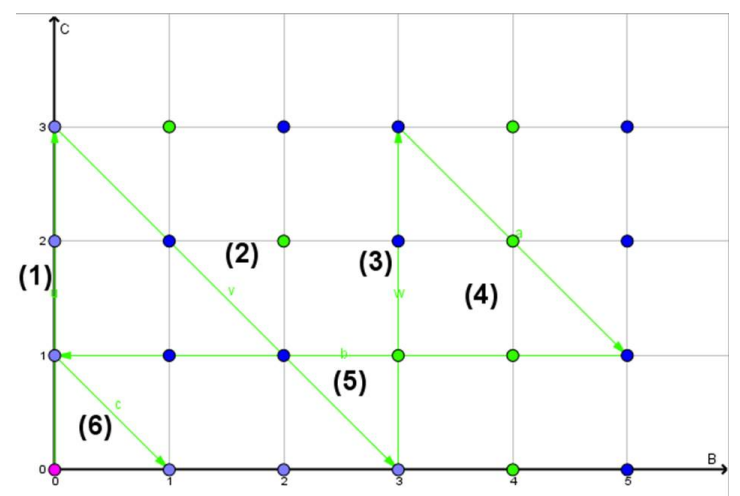

Figura 2.16: Neste momento, temos 7 litros de água na jarra (A), 1 litros na jarra(B) e 0 litros na jarra (C).

(7) $(1,0) \rightarrow(1,3)$ : encher a jarra $(\mathrm{C})$ com a água contida na jarra (A), como mostra a figura 2.17;

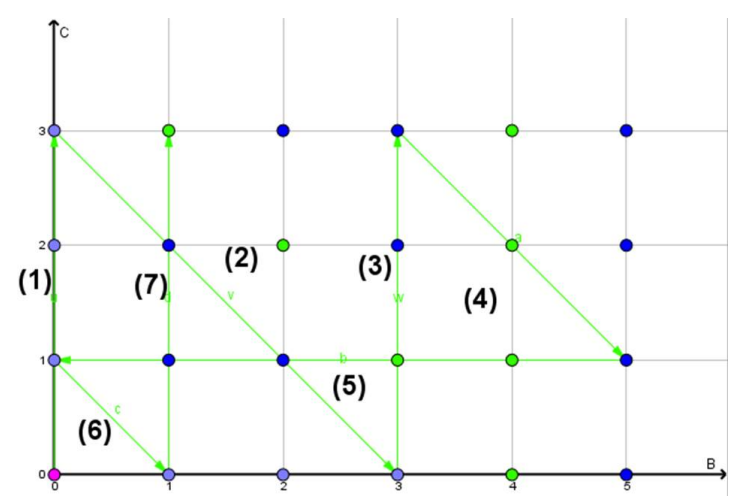

Figura 2.17: Neste momento, temos 4 litros de água na jarra (A), 1 litros na jarra(B) e 3 litros na jarra (C).

Com isso, chegamos ao ponto $(1,3)$, deixando 4 litros de água na jarra (A). Isso mostra que é possível resolver o problema, mas será que essa é a única maneira? Assim como no problema anterior, poderíamos ter outra(s) sequência(s) de jogadas produzindo o resultado desejado, com 4 litros talvez na jarra (B). Outra pergunta natural é: qual(is) a(s) solução(ões) envolvendo o menor número de jogadas? De fato, não é difícil encontrar soluções diferentes envolvendo ainda 7 jogadas. Será esse o número mínimo? Referimos o leitor interessado a (2). 


\section{3}

\section{O Problema do caixeiro viajante.}

O Sr. Tavares é um caixeiro viajante que tem clientes em cinco cidades: cidade 1 , cidade 2 , cidade 3 , cidade 4 e cidade 5 . Foi proposta a ele uma viagem de negócios na qual ele deve começar e terminar na cidade onde reside, que é a cidade 1 , e passar por todas as outras quatro. A fim de que poupar custos, ele precisará passar por cada uma das quatro cidades restantes apenas uma vez. Na figura 2.18, temos um esquema mostrando o custo do trajeto entre cada par de cidades. É possível fazer tal viagem proposta ao Sr. Tavares? Se sim, qual seria o melhor percurso, ou seja, o mais econômico?

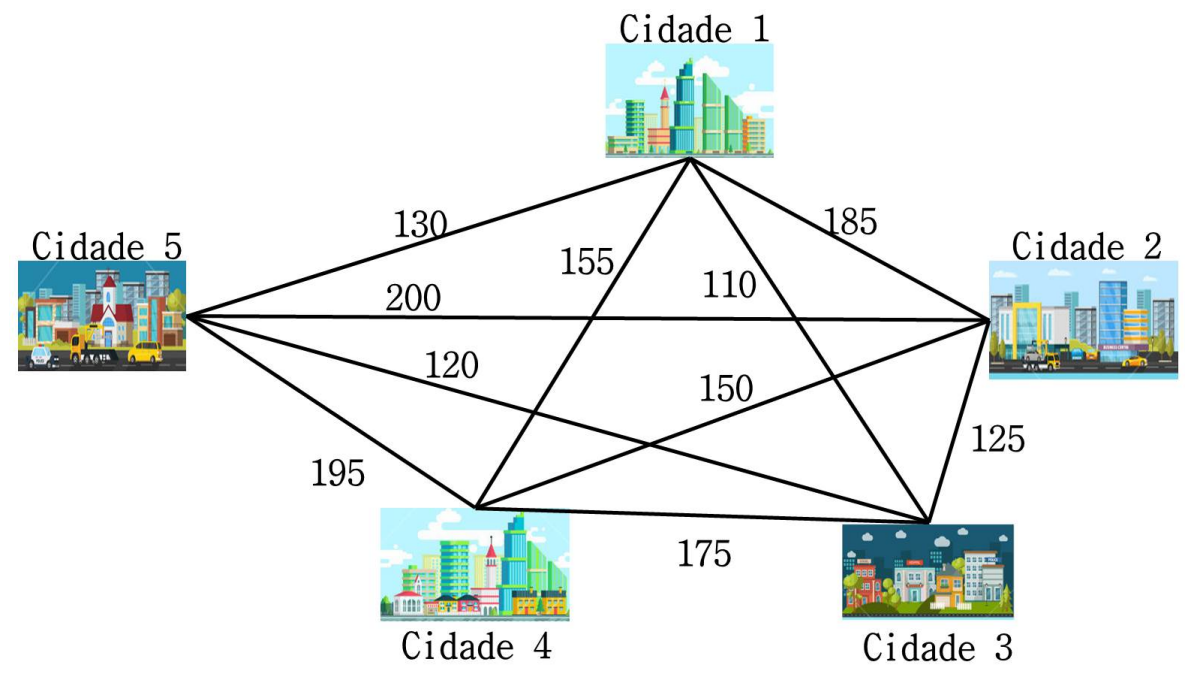

Figura 2.18: Esquema das cidades.

Observe que o problema que envolve o Sr. Tavares contém dois questionamentos:

1. Se a viagem proposta é possível de ser feita.

2. Qual seria o melhor percurso, caso exista uma tal viagem.

Então vamos começar pelo item 1 e tentar descobrir se podemos fazer uma viagem passando pelas cinco cidades, observando que precisamos começar e terminar pela cidade 1 .

Observando a figura 2.18, vemos que se fizermos o trajeto Cidade 1 Cidade 2 - Cidade 3 - Cidade 4 - Cidade 5 - Cidade 1, podemos concluir a viagem que foi proposta ao senhor Tavares.

Logo, para o primeiro questionamento, podemos dizer que sim: viagem proposta é possível. 
Agora, será que esse seria o trajeto mais econômico?

Para resolver isso, faremos uma lista de todos os trajetos possíveis, calculando seus custos e por fim escolhendo o mais econômico.

Para resolver essa parte do problema iremos utilizar abreviaturas para as cidades:

\begin{tabular}{|c|c|}
\hline Cidade & Abreviatura \\
\hline 1 & $C_{1}$ \\
2 & $C_{2}$ \\
3 & $C_{3}$ \\
4 & $C_{4}$ \\
5 & $C_{5}$ \\
\hline
\end{tabular}

Para ter a viagem desejada, todas as cidades devem estar em sequência e a cidade inicial e a cidade final devem ser a mesma, que já foi fixada como sendo a cidade 1 .

Portanto, utilizando um mínimo de Análise Combinatória e lembrando que a primeira e a última cidade do trajeto coincidem com $C_{1}$, teremos:

- 4 possibilidades para escolher a primeira cidade, depois de sair da $C_{1}$.

- 3 possibilidades para escolher a segunda cidade, que precisa ser diferente das anteriores.

- 2 possibilidades para escolher a terceira cidade, que precisa ser diferente das anteriores.

- 1 possibilidades para escolher a quarta cidade, que precisa ser diferente das anteriores e depois retornar para $C_{1}$.

Logo, pelo Princípio Fundamental da Contagem, temos $4 \cdot 3 \cdot 2 \cdot 1=4 !=24$ trajetos distintos. Porém, como estamos falando de custo, um trajeto $C_{1^{-}} C_{2^{-}}$ $C_{3^{-}} C_{4^{-}} C_{5^{-}} C_{1}$ terá o mesmo custo que seu trajeto inverso $C_{1^{-}} C_{5^{-}} C_{4^{-}} C_{3^{-}} C_{2^{-}} C_{1}$.

Portanto, faremos $\frac{24}{2}=12$ trajetos e seus respectivos custos.

A tabela 2.1 mostra os trajetos e seus custos.

Portanto, analisando a segunda coluna da tabela 2.1, podemos concluir que o Trajeto mais econômico é aquele que custa 680 reais.

Logo, o melhor percurso para essa viagem seria $C_{1}-C_{4^{-}} C_{2^{-}} C_{3^{-}} C_{5^{-}} C_{1}$ ou $C_{1}-C_{5}-C_{3}-C_{2}-C_{4}-C_{1}$, como mostra a figura 2.19 . 


\begin{tabular}{|c|c|c|}
\hline Trajeto & Custo & Trajeto \\
\hline$C_{1^{-}} C_{2^{-}} C_{3^{-}} C_{4^{-}} C_{5^{-}} C_{1}$ & $185+125+175+195+130=810$ & $C_{1}-C_{5^{-}} C_{4^{-}} C_{3^{-}} C_{2}-C_{1}$ \\
\hline$C_{1^{-}}-C_{2^{-}} C_{3^{-}}-C_{5^{-}} C_{4^{-}} C_{1}$ & $155+195+120+125+185=780$ & $C_{1}-C_{4}-C_{5}-C_{3}-C_{2}-C_{1}$ \\
\hline$C_{1^{-}}-C_{2^{-}} C_{4^{-}}-C_{3^{-}} C_{5^{-}} C_{1}$ & $130+120+175+150+185=760$ & $C_{1^{-}}-C_{5^{-}} C_{3^{-}}-C_{4^{-}} C_{2^{-}}-C_{1}$ \\
\hline$C_{1}-C_{2}-C_{4}-C_{5}-C_{3}-C_{1}$ & $110+120+195+150+185=760$ & $C_{1}-C_{3^{-}}-C_{5^{-}}-C_{4}-C_{2}-C_{1}$ \\
\hline$C_{1^{-}} C_{2^{-}} C_{5^{-}}-C_{3^{-}} C_{4^{-}} C_{1}$ & $155+175+120+200+185=835$ & $C_{1}-C_{4^{-}}-C_{3^{-}}-C_{5^{-}} C_{2^{-}}-C_{1}$ \\
\hline$C_{1}-C_{2^{-}} C_{5^{-}}-C_{4}-C_{3}-C_{1}$ & $110+175+195+200+185=865$ & $C_{1}-C_{3^{-}}-C_{4^{-}}-C_{5^{-}} C_{2^{-}}-C_{1}$ \\
\hline$C_{1}-C_{3^{-}} C_{2^{-}}-C_{4^{-}}-C_{5^{-}} C_{1}$ & $130+195+150+125+110=710$ & $C_{1}-C_{5^{-}}-C_{4^{-}}-C_{2^{-}} C_{3^{-}}-C_{1}$ \\
\hline$C_{1}-C_{3^{-}} C_{2^{-}}-C_{5^{-}}-C_{4^{-}} C_{1}$ & $155+195+200+125+110=785$ & $C_{1^{-}}-C_{4^{-}}-C_{5^{-}}-C_{2^{-}}-C_{3^{-}}-C_{1}$ \\
\hline$C_{1}-C_{3}-C_{4}-C_{2}-C_{5}-C_{1}$ & $130+220+150+175+110=765$ & $C_{1}-C_{5^{-}}-C_{2}-C_{4}-C_{3}-C_{1}$ \\
\hline$C_{1^{-}}-C_{3^{-}} C_{5^{-}}-C_{2^{-}} C_{4^{-}} C_{1}$ & $155+150+200+120+110=735$ & $C_{1^{-}}-C_{4^{-}} C_{2^{-}} C_{5^{-}} C_{3^{-}}-C_{1}$ \\
\hline$C_{1}-C_{4^{-}} C_{2^{-}}-C_{3^{-}}-C_{5^{-}} C_{1}$ & $130+120+125+150+155=680$ & $C_{1^{-}}-C_{5^{-}} C_{3^{-}}-C_{2^{-}} C_{4^{-}} C_{1}$ \\
\hline$C_{1}-C_{4^{-}} C_{3^{-}}-C_{2^{-}}-C_{5^{-}} C_{1}$ & $130+200+125+175+195=825$ & $C_{1}-C_{5^{-}} C_{2^{-}} C_{3^{-}}-C_{4}-C_{1}$ \\
\hline
\end{tabular}

Tabela 2.1: Trajetos e custos da viagem do Sr. Tavares.

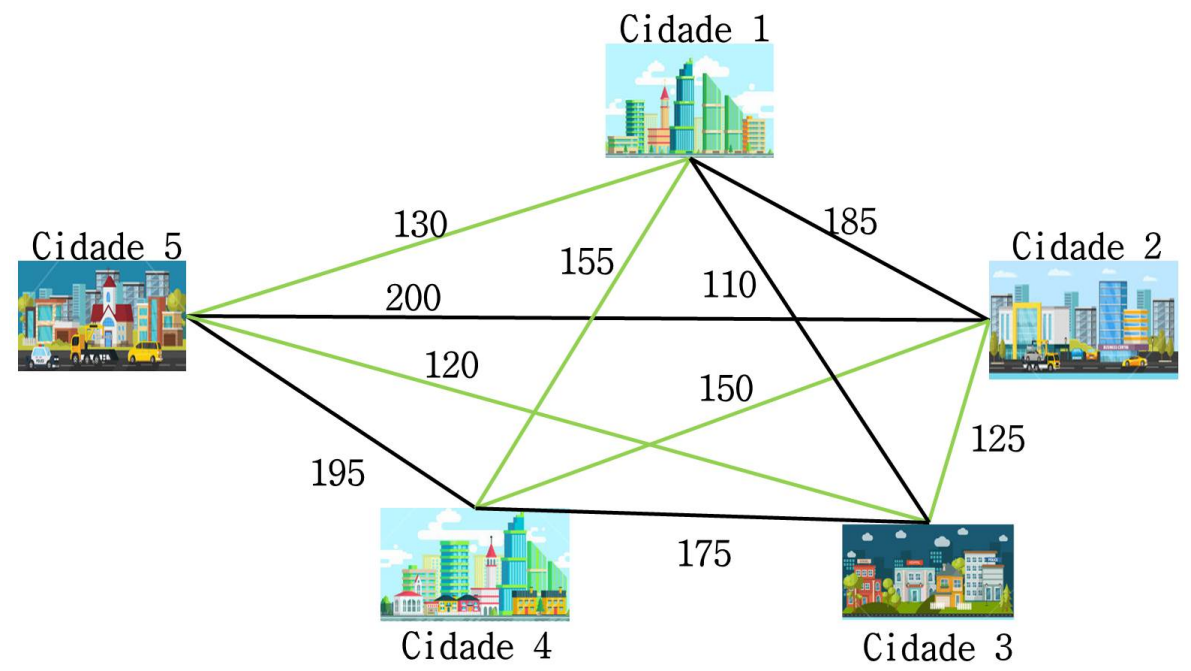

Figura 2.19: Em verde temos o percurso com menor custo.

\section{4}

\section{O Problema das sete pontes de Königsberg}

$\mathrm{Na}$ cidade de Königsberg havia sete pontes que cruzavam o rio Pregel. Elas ligavam duas ilhas do rio entre si e com as margens, como mostra a figura 2.20. Os moradores de Königsberg preocupavam-se com o seguinte problema: é possível passear pelas sete pontes sem repetir nenhuma?

Não parece ser possível chegar a uma conclusão imediatamente. De fato, esse problema mobilizou o gênio de Leonhard Euler (1707-1783), habitante de Königsberg e o mais prolífico matemático da história, e sua solução negativa - marca o nascimento da teoria de grafos. Mas os alunos não precisam ficar sabendo disso imediatamente. Podemos propor a eles que façam algumas 


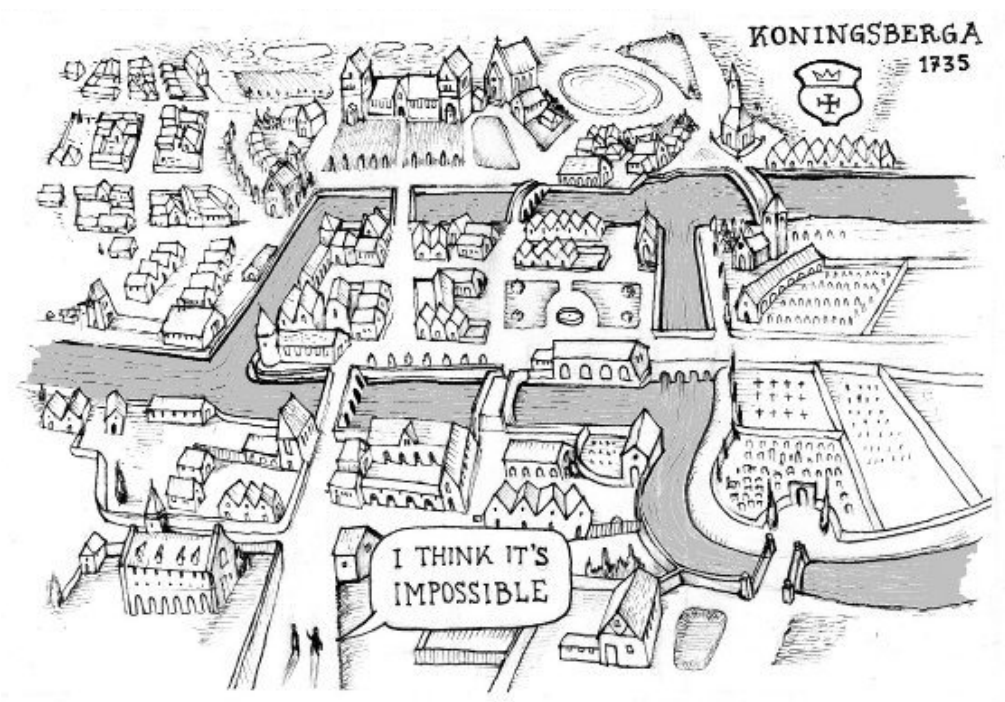

Figura 2.20: Desenho da cidade de Königsberg. Fonte: https://grafos.neocities.org/\#/

tentativas despretensiosas a fim de ganharem familiaridade com o problema. Vamos a seguir simular algumas dessas tentativas. Para facilitar nosso trabalho, iremos associar uma letra entre A,B,C,D a cada pedaço de terra da cidade e numerar as pontes de 1 a 7 como mostra a figura 2.21 .

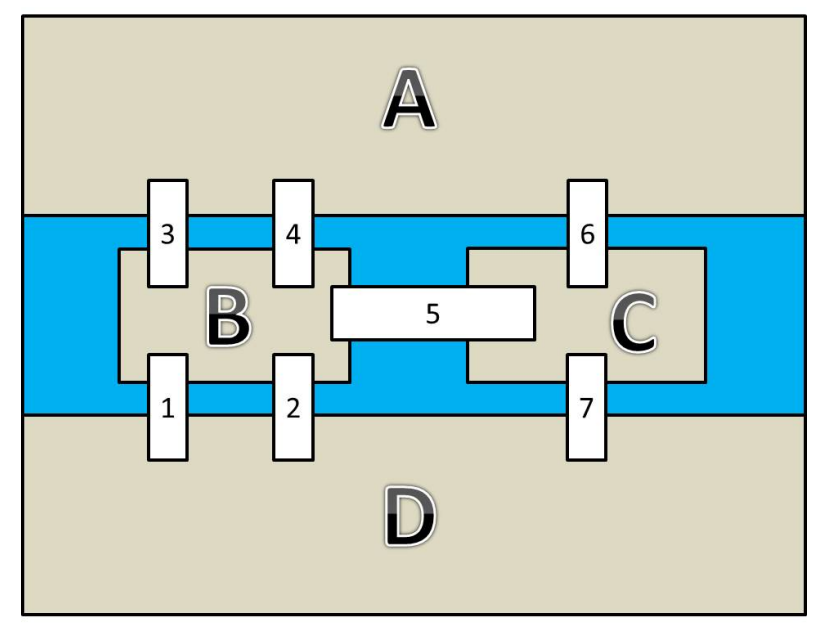

Figura 2.21: Esquema da cidade de Königsberg.

Primeira tentativa. Vamos começar nosso trajeto pela parte $\mathrm{A}: \mathrm{A} \rightarrow 6$ $\rightarrow 7 \rightarrow 2 \rightarrow 4 \rightarrow 3 \rightarrow 1 \rightarrow$ D. Aqui ocorre um problema pois, para passarmos pela ponte 5 , teríamos que repetir a ponte 7 ou 2, como mostra a figura 2.22 . 


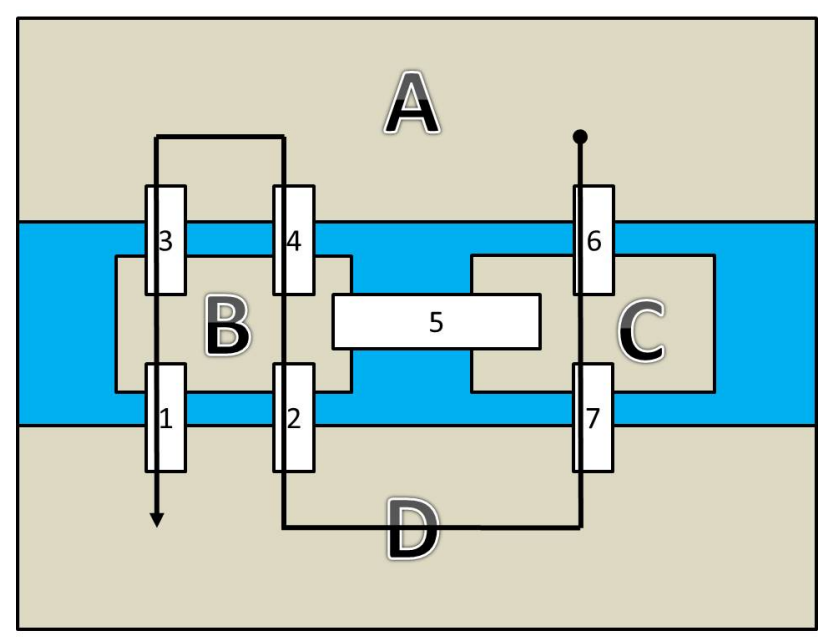

Figura 2.22: Problema para passar pela ponte 5 .

Segunda tentativa. Vamos começar pela parte B: B $\rightarrow 5 \rightarrow 6 \rightarrow 3 \rightarrow$ $1 \rightarrow 2 \rightarrow 4 \rightarrow$ A. Aqui também ocorre um problema pois, para passarmos pela ponte 7 , teríamos antes que repetir a ponte 3,4 ou 6 , como mostra a figura 2.23 .

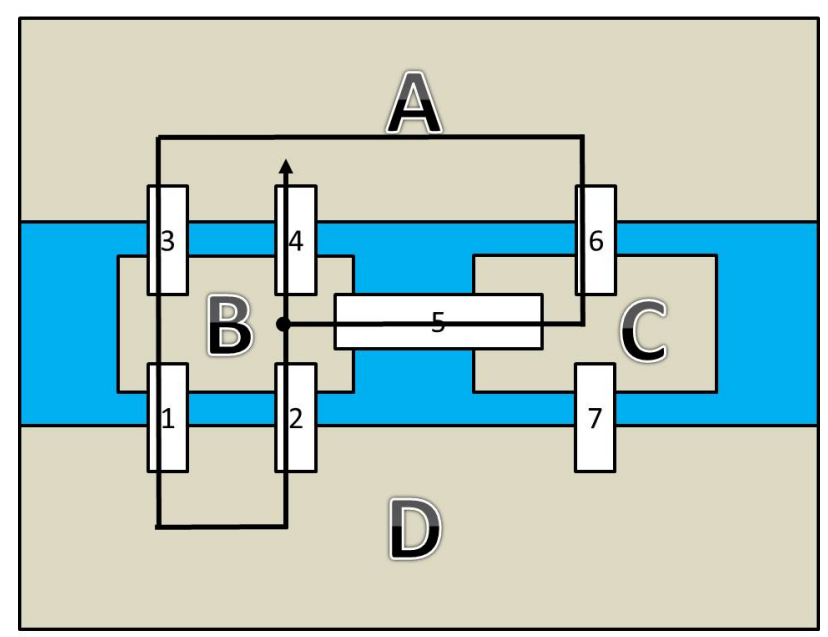

Figura 2.23: Problema para passar pela ponte 7 .

Terceira tentativa. Agora, vamos começar pela parte C: $\mathrm{C} \rightarrow 7 \rightarrow 2$ $\rightarrow 4 \rightarrow 3 \rightarrow 5 \rightarrow 6 \rightarrow$ A. Temos problemas para passar pela ponte 1 , pois teríamos antes que repetir a ponte 3,4 ou 6, como mostra a figura 2.24. 


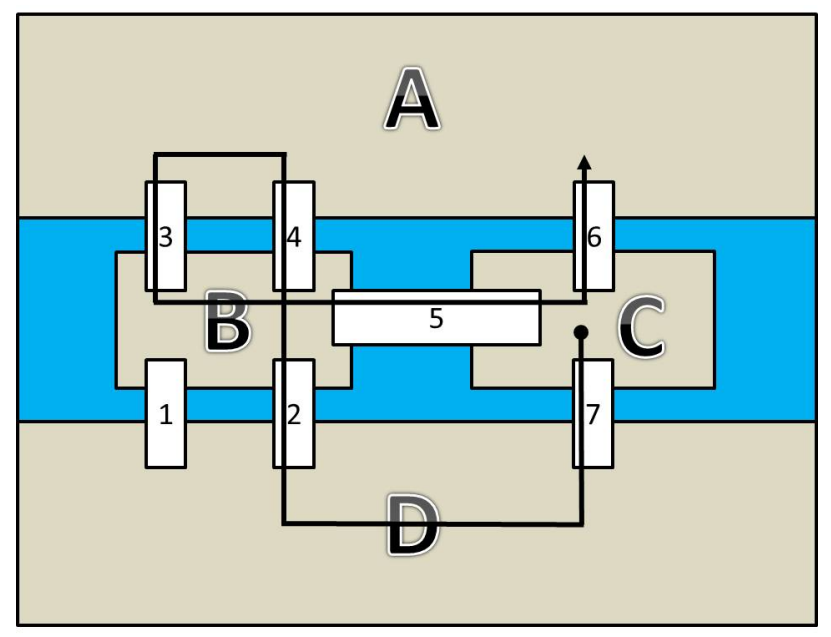

Figura 2.24: Problema para passar pela ponte 1.

Quarta tentativa. Vamos começar pela parte D dessa vez: D $\rightarrow 1 \rightarrow 3$ $\rightarrow 4 \rightarrow 5 \rightarrow 6 \rightarrow$ A. Aqui, não conseguiríamos passar pelas pontes 2 ou 7 sem antes repetir as pontes 3,4 ou 6 , como mostra a figura 2.25 .

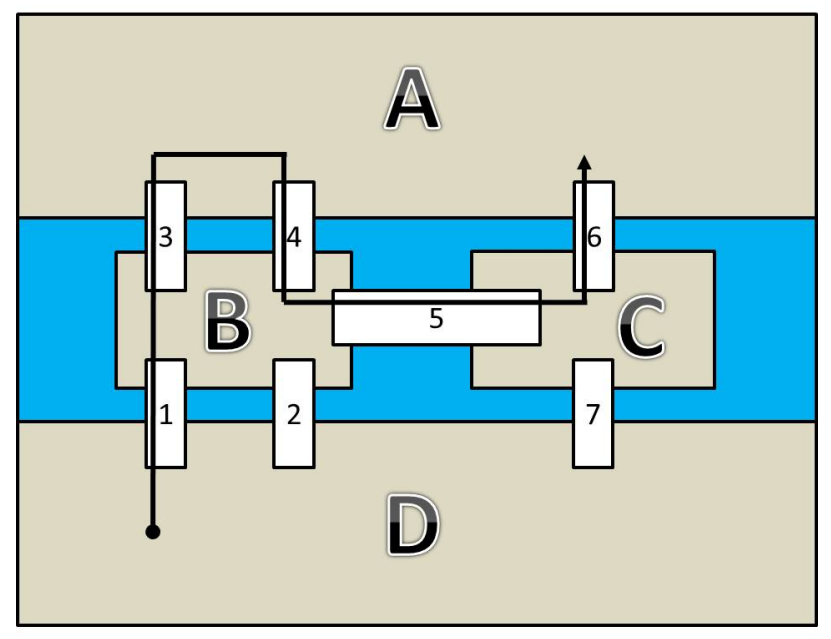

Figura 2.25: Problema para passar pelas pontes 2 e 7 .

Após 4 tentativas, ainda não obtivemos sucesso em alcançar o objetivo da questão. Um aluno, a essa altura, poderia começar a desconfiar de que esse problema não tem solução. Sendo perseverante, ele poderia continuar a fazer mais e mais tentativas. Seria possível testar todas as possibilidades até esgotá-las? Quantas são elas?

Se pararmos para pensar, podemos começar em qualquer pedaço de terra seja ele A, B, C ou D. Como começando por A temos 3 pontes possíveis, por B temos 4 pontes possíveis, por $\mathrm{C}$ temos 3 pontes possíveis e por D temos 3 pontes possíveis, só para iniciarmos os trajetos, temos já de saída 13 possíveis 
trajetos, isso sem considerarmos os demais passos. Tudo indica que a tarefa de esgotar todas as possibilidades seria ingrata.

Nos próximos capítulos, ganharemos as ferramentas necessárias para dar uma resposta definitiva - e rápida - ao problema e a outros similares (mesmo que aparentemente muito distintos). 


\section{3}

\section{Conceitos iniciais de teoria de grafos}

Esse capítulo tem como objetivo introduzir algumas noções básicas da Teoria de Grafos através de definições e exemplos. Essas definições serão dadas para uso nos capítulos seguintes e foram reunidas neste apenas para facilitar a referência do leitor. Em sala de aula, talvez a melhor estratégia seja introduzir os conceitos na medida em que eles se mostrarem úteis para a solução de problemas específicos.

A linguagem subjacente à Teoria de Grafos é estruturalmente muito simples, tendo como objetos apenas vértices e arestas e como única relação a de incidência, como veremos abaixo.

Convém introduzir os estudantes ao assunto da maneira mais natural e intuitiva possível, com uma definição como a que abre a próxima seção.

\section{1 \\ Definições}

Definição 1 (Informal) Grafo é um conjunto de pontos, que chamamos de vértices, que podem ou não estar ligados por um conjunto de linhas que chamamos de arestas, como podemos ver na figura 3.1. (3)

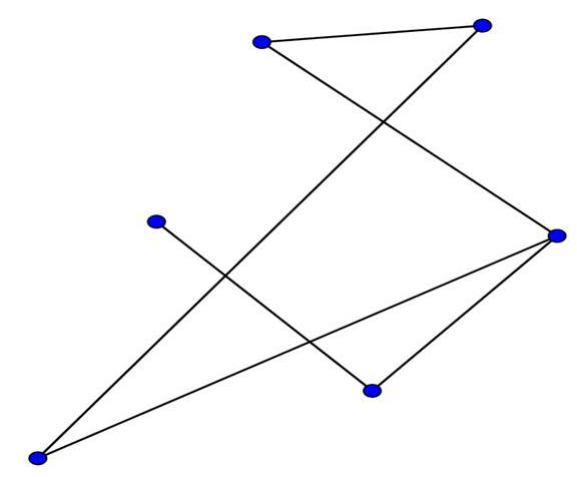

Figura 3.1: Um grafo.

Muitas vezes, quando estamos falando sobre alguma situação específica, podemos fazer uma abstração de suas características acidentais e associar a ela um grafo onde os vértices representam os elementos do contexto e as arestas representam as relações entre estes. 


\section{Exemplo 1}

Cidades da baixada fluminense, no estado do Rio de Janeiro. Nesse caso, os elementos são as cidades e a relação é ser uma cidade vizinha. O grafo correspondente está representado na figura 3.2 .

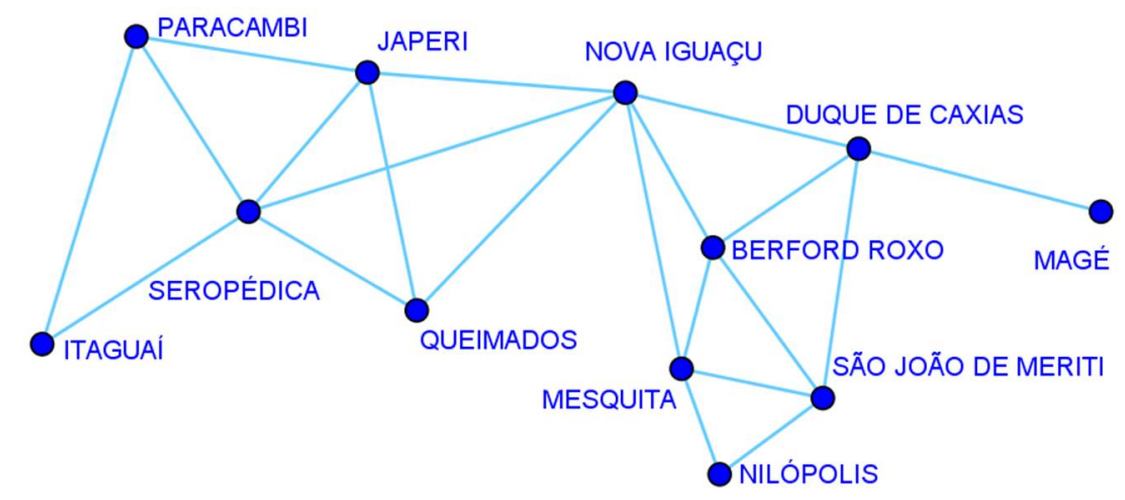

Figura 3.2: Grafo das cidades vizinhas da baixada fluminense.

\section{Exemplo 2}

O grafo das palavras é definido assim: cada elemento é uma palavra da língua portuguesa e dois elementos se relacionam quando diferem em exatamente uma posição. Por exemplo, rato e ralo se relacionam, enquanto ralo e rota não, como podemos observar na figura 3.3. (4)

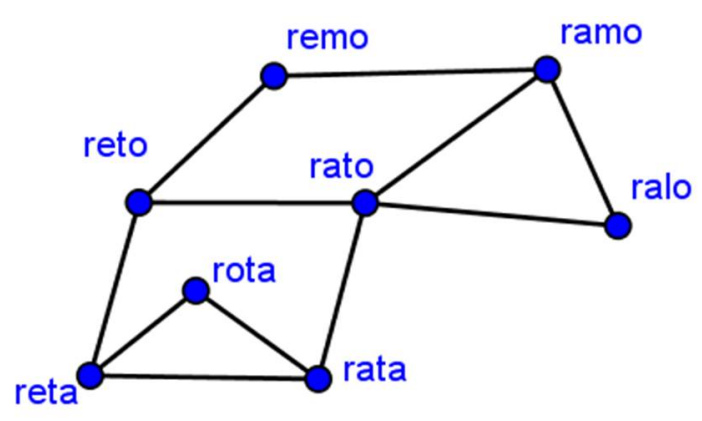

Figura 3.3: Grafo das palavras da língua portuguesa.

\section{Exemplo 3}

O grafo das redes sociais é um dos grafos mais encontrados no nosso cotidiano, pois a maioria da população utiliza de algum tipo de rede social. Nesse tipo de grafo, os vértices podem representar um perfil, um blog, uma página, etc.; e as arestas, um link, um comentário, seguidores e etc. Veja um exemplo na figura 3.4 . 


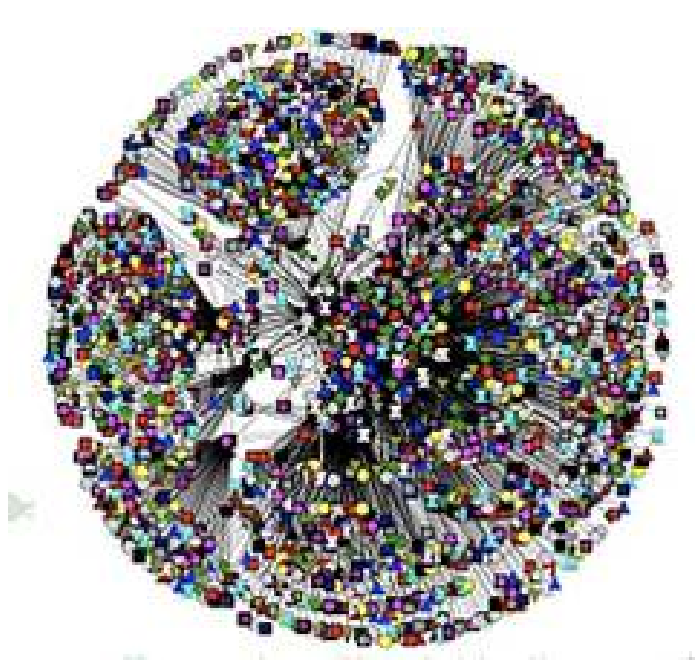

Figura 3.4: Grafo retirado do Estudos de Redes Sociais na Internet feito pela jornalista Raquel Recuero no site: www.raquelrecuero.com.

\section{Exemplo 4}

No Campeonato Brasileiro de Futebol, mais conhecido como "Brasileirão", a cada semana é feita uma nova rodada de partidas entre os times de futebol, como podemos ver na tabela 3.5 , referente à $37^{\circ}$ rodada do campeonato de 2016.

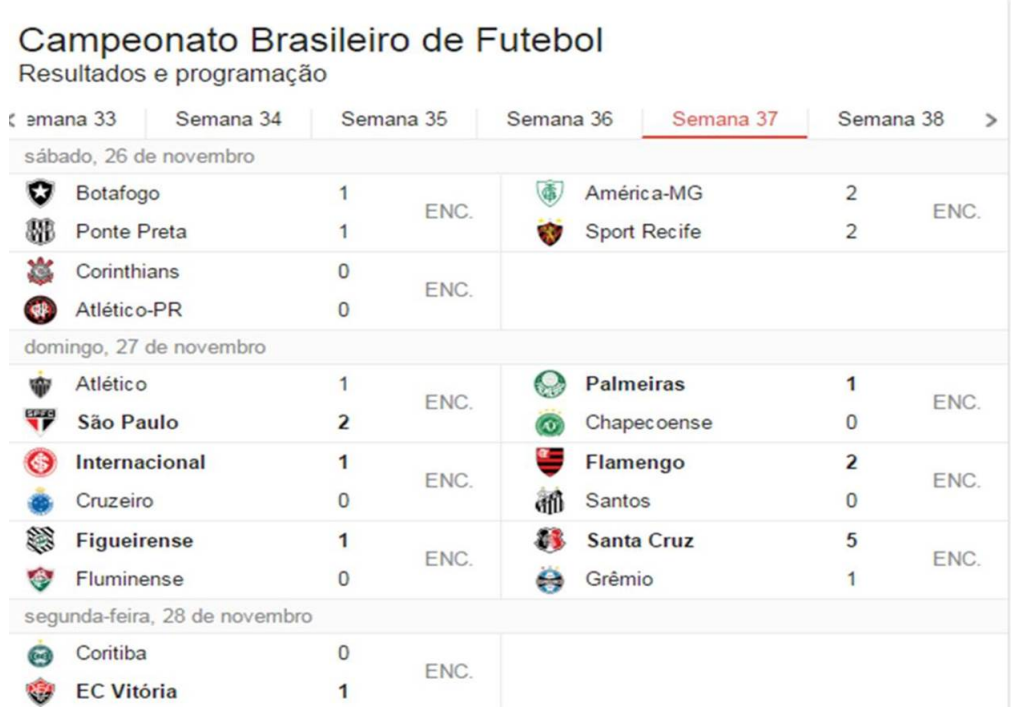

Figura 3.5: Imagem retirada do Google.

Nesse caso, podemos representar graficamente uma edição do Campeonato Brasileiro (Figura 3.6), associando os vértices aos times de futebol e as arestas a uma partida entre os times em que incide, de tal modo que quem venceu a partida recebe a ponta de uma seta, e no caso de empate ambos recebem a seta (ou nenhum dos dois recebe seta). 


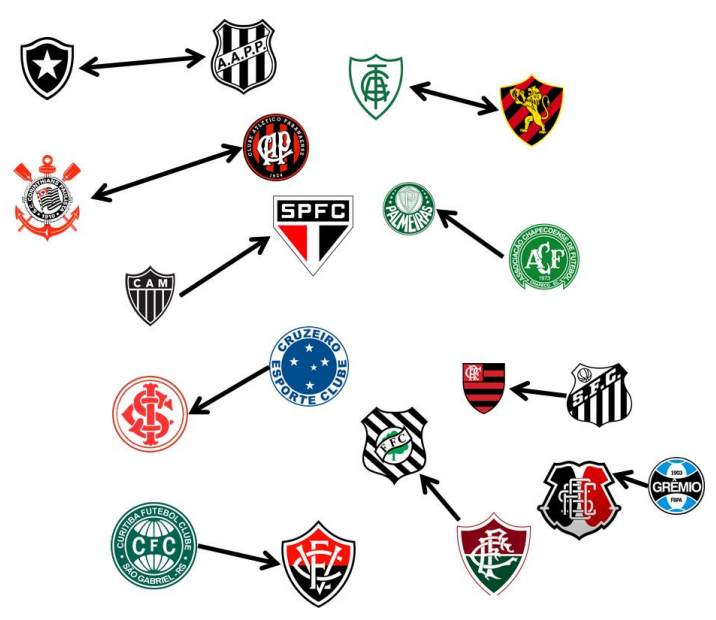

Figura 3.6: Grafo da 37ํㅜㅁodada do campeonato de 2016.

Seria muito interessante propor aos alunos como exercício que desenhassem o grafo correspondente a uma edição completa (i.e., levando em consideração todas as rodadas) de um torneio de pontos corridos em algum esporte de sua preferência (certas edições da Copa do Mundo de Futebol, por exemplo).

Podemos construir modelos da teoria de grafos assumindo como fundamento a Teoria (Ingênua) de Conjuntos. Algumas das definições possíveis excluem casos de interesse como multigrafos. Outras são bem inclusivas, mas pouco naturais. Se o professor considerar indispensável fornecer uma definição de grafo em termos de conjuntos, julgamos que a definição seguinte representa um bom compromisso entre a generalidade e a simplicidade, além de ser acessível a estudantes com um mínimo de familiaridade com o conceito de função.

Definição 2 (Formal) Um grafo (não-ordenado) é uma tripla $G=(V, A, f)$, onde :

- $V$ é um conjunto cujos elementos serão chamados vértices do grafo $G$.

- $A$ é um conjunto cujos elementos serão chamados arestas do grafo $G$.

- $f: A \rightarrow V \cup\left(\begin{array}{l}V \\ 2\end{array}\right)$ é uma função que a cada aresta de $G$ atribui um ou dois vértices, sobre os quais dizemos que tal aresta incide.

Na definição acima, $\left(\begin{array}{c}V \\ 2\end{array}\right)$ representa o conjunto dos subconjuntos de $V$ com cardinalidade 2. Se estivermos interessados em orientar as arestas (como no exemplo do campeonato de futebol acima), basta substituir o contra-domínio de $f$ pelo conjunto $V^{2}=V \times V$ dos pares ordenados de vértices e convencionar que a primeira coordenada de $f(a)$ é o vértice-origem da aresta $a$, enquanto a segunda coordenada é seu vértice-destino (ou vice-versa). 
Geralmente representamos grafos de forma geométrica, com cada vértice correspondendo a um ponto, e cada aresta, a um segmento de reta e/ou arco de curva, cujos extremos representam os vértices nos quais a aresta incide.

\section{Exemplo 5}

Seja $G=(V(G), A(G), f)$, onde $V(G)=\{a, b, c, d\}, A(G)=$ $\{\{a, b\},\{a, c\},\{b, c\},\{c, d\}\}$ e $f=i d_{A(G)}$ (neste exemplo, claramente temos $\left.A(G) \subset\left(\begin{array}{l}V \\ 2\end{array}\right)\right)$.

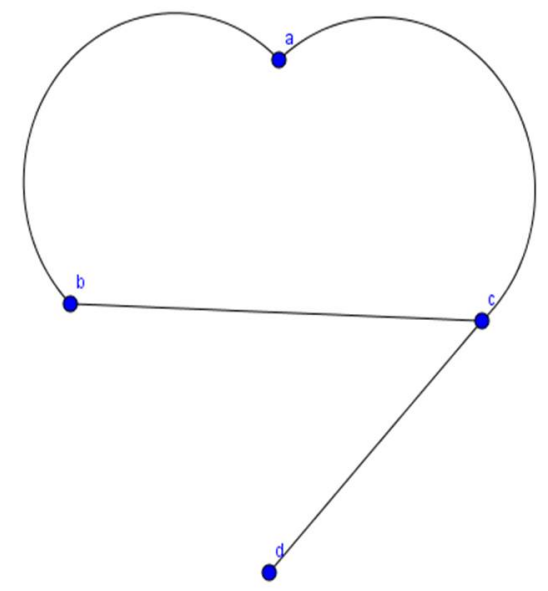

Figura 3.7: Representação gráfica do Grafo $G(V, A, f)$.

Quando não houver risco de confusão, para simplificar um pouco a notação, denotaremos $V(G)$ apenas por $V$ e $A(G)$ apenas por $A$. Além disso, uma aresta $\{a, b\}$ pode ser denotada simplesmente por $\mathbf{a b}$, ou equivalente, por ba. Vejamos outros exemplos:

\section{Exemplo 6}

Seja $G^{\prime}=\left(V^{\prime}, A^{\prime}, f^{\prime}\right)$, onde $V^{\prime}=\{a, b, c, d, e\}, A^{\prime}=\left\{a_{1}, a_{2}, a_{3}, a_{4}, a_{5}, a_{6}\right\}$ $\mathrm{e}$

$$
f^{\prime}=\left\{\begin{array}{l}
f^{\prime}\left(a_{1}\right)=a b \\
f^{\prime}\left(a_{2}\right)=b c \\
f^{\prime}\left(a_{3}\right)=c d \\
f^{\prime}\left(a_{4}\right)=d e \\
f^{\prime}\left(a_{5}\right)=e c \\
f^{\prime}\left(a_{6}\right)=e a
\end{array}\right.
$$

Como mostra a figura 3.8.

Geralmente, ao trabalhar com grafos, é mais conveniente representá-los por meio de desenhos, o que não quer dizer que essa representação seja única. 


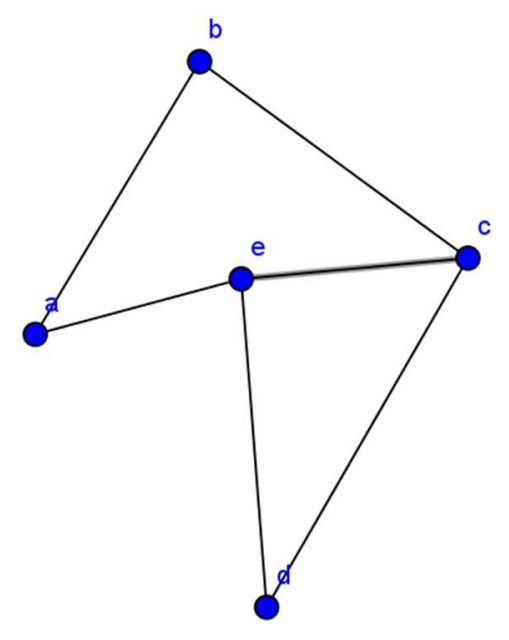

Figura 3.8: Representação gráfica do Grafo G'(V',A').

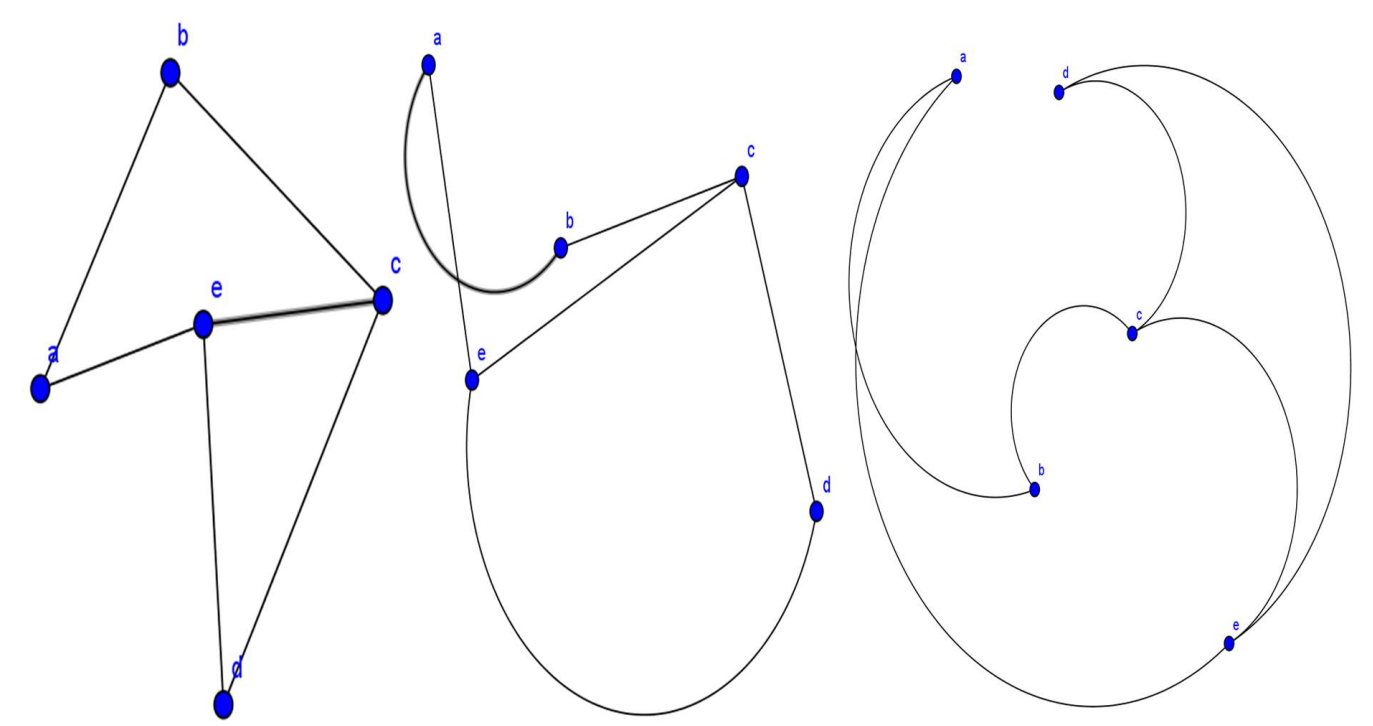

Figura 3.9: Um representação só com segmentos, outra com curvas e segmentos, e a terceira somente com curvas.

Podemos ter um mesmo grafo com duas ou mais representações diferentes. Podemos ver na figura 3.9 três representações do mesmo grafo do exemplo 6 .

\section{Definição 3 (Ordem do Grafo)}

Chamamos de ordem de um grafo $G$ a quantidade de vértices que ele possui, e a denotamos por $|G|$.

Por exemplo, na figura 3.9 temos que $|G|=5$.

\section{Definição 4 (Incidência)}

Seja $\mathbf{u}=\mathbf{a b}$ uma aresta do grafo, então dizemos que a aresta $\mathbf{u}$ liga os vértices $\mathbf{a}$ e b. Nesse caso, dizemos que aresta $\mathbf{u}$ é incidente em $\mathbf{a}$ e b. Quando isso acontece os vértices $\mathbf{a}$ e $\mathbf{b}$ são chamado de vizinhos ou adjacente. 


\section{Exemplo 7}

Observe que no grafo $G$ da figura 3.10 a aresta $f$ incide em $b$ e $d, g$ incide em $c$ e $a, h$ incide em $a$ e $b$ e, $i$ incide em $c$ e $d$. Nesse caso, temos por exemplo que $a$ é vizinho de $c$ e $b$, mas não é vizinho de $d$.

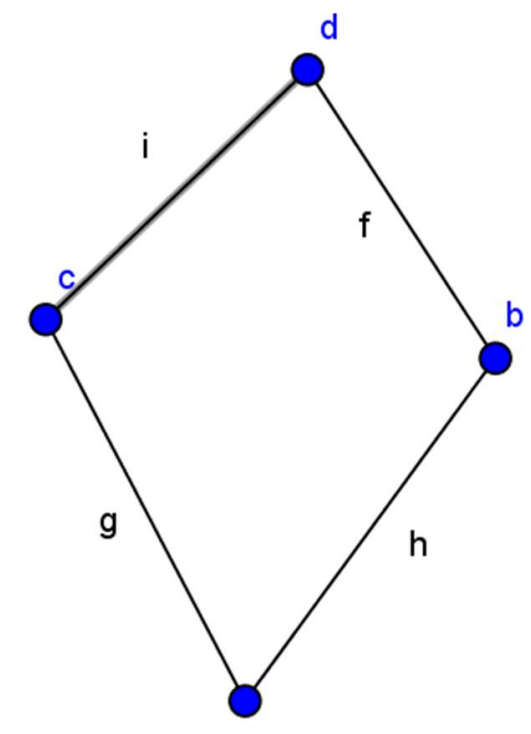

a

Figura 3.10: O vértice c é vizinho de $a$ e $d, d$ é vizinho de $c$ e $b, b$ é vizinho de $a$ e $d$.

\section{Definição 5 (Grau de um vértice)}

Seja a um vértice de um grafo $G$, chamamos de grau do vértice a a quantidade de arestas que incidem nele. Denotamos o grau do vértice a por $g(a)$.

Observe que no exemplo 7 temos que $g(a)=2, g(b)=2, g(c)=2$ e $g(d)=2$ e que no exemplo $6 g(a)=2, g(b)=2, g(c)=3, g(d)=2$ e $g(e)=3$.

\section{Definição 6 (Arestas paralelas)}

Chamamos de aresta paralela aquelas que têm mesma incidência no conjunto das arestas.

Por exemplo, $A=\left\{a_{1}, a_{2}, a_{3}\right\}$ e

$$
f:\left\{\begin{array}{l}
f\left(a_{1}\right)=a b \\
f\left(a_{2}\right)=a b \\
f\left(a_{3}\right)=a c
\end{array}\right.
$$

como mostra a figura 3.11. 


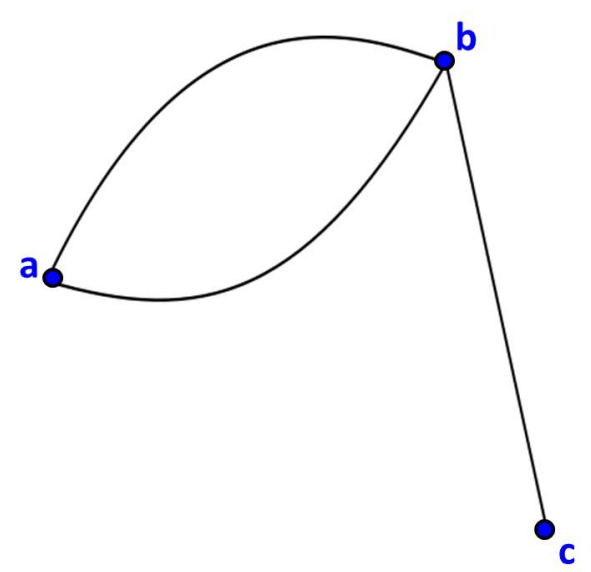

Figura 3.11: Duas arestas paralelas incidindo nos vértices a e b.

\section{Definição 7 (Laço)}

Chamamos de laços aquelas arestas cujos extremos são formados pelo mesmo vértice.

Por exemplo, se $A=\left\{a_{1}, a_{2}, a_{3}\right\}$ e

$$
f:\left\{\begin{array}{l}
f\left(a_{1}\right)=a a \\
f\left(a_{2}\right)=a b \\
f\left(a_{3}\right)=a c
\end{array}\right.
$$

temos que $a_{1}$ é um laço, como mostra a figura 3.12 .

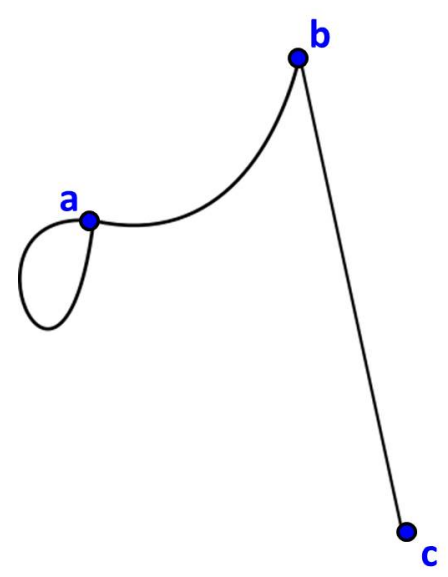

Figura 3.12: Temos o laço aa.

Uma observação: quando falamos sobre o grau de um vértice, um laço é diferente de um aresta simples, pois ele aumenta em duas unidades o grau de cada vértice. Observe que um laço incide duas vezes num mesmo vértice.

Definição 8 (Aresta orientada) 
São aquelas que estão associadas a um par ordenado de vértices $(u, v)$, onde começam em $u$ e terminam em $v$. Quando representamos uma aresta orientada usamos uma seta apontando de $u$ para $v$ para indicarmos o sentido de uma aresta que começa em $u$ e termina em $v$.

Por exemplo, $A=\left\{a_{1}, a_{2}, a_{3}, a_{4}, a_{5}\right\}$ e

$$
f:\left\{\begin{array}{l}
f\left(a_{1}\right)=(a, c) \\
f\left(a_{2}\right)=(a, d) \\
f\left(a_{3}\right)=(b, a) \\
f\left(a_{4}\right)=(b, c) \\
f\left(a_{5}\right)=(d, c)
\end{array}\right.
$$

como podemos ver na figura 3.13 .

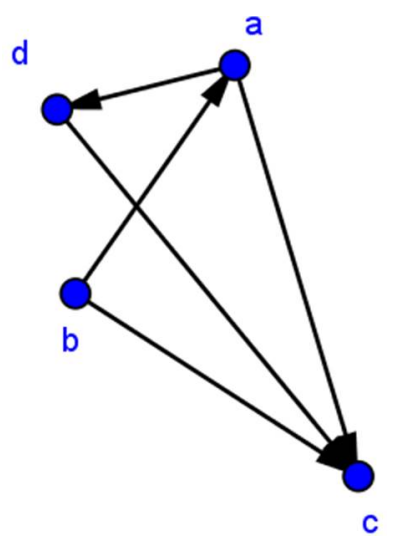

Figura 3.13: Formado somente por arestas orientadas.

Nas arestas orientadas, devemos ter atenção quando falamos de grau de um vértice e de vértices vizinhos, pois esses dois conceitos usam a incidência de arestas nos vértices.

No caso de vértices vizinhos, quando trabalhamos com arestas orientadas, dizemos que $u$ é vizinho de $v$ se existe uma aresta que sai de $u$ e que entra em $v$. Note que, essa relação não é simétrica pois $u$ pode ser adjacente a $v$ sem que $v$ seja adjacente a $u$. Como podemos ver na figura $3.13 a$ é vizinho de $c$, mas $c$ não é vizinho de $a$.

E no caso de grau de vértice, ele é visto de forma diferenciada. Cada vértice $v$ apresenta um grau de entrada, indicado por $g^{-}(v)$, que representa o número de arestas que tem $v$ como vértice final(que terminam em $v$ ). E um grau de saída, indicado por $g^{+}(v)$, que representa o número de arestas que tem $v$ como vértice inicial (que começam em $v$ ).

Por exemplo, no grafo figura 3.13, temos que $g^{-}(a)=1, g^{-}(b)=$ $0, g^{-}(c)=3, g^{-}(d)=1$ e $g^{+}(a)=2, g^{+}(b)=2, g^{+}(c)=0, g^{+}(d)=1$. 


\section{2}

\section{Alguma nomenclatura}

Os exemplos que já apresentamos até aqui podem ser classificados quanto a diversos critérios que têm a ver com o tipo de arestas permitidas ou com certas propriedades globais desejáveis. O que segue é um breve apanhado da terminologia mais usada. (5)

\section{Definição 9 (Grafo simples)}

São aqueles que não possuem laços e nem arestas paralelas.

\section{Definição 10 (Multigrafo)}

São aqueles que possuem laços e/ou arestas paralelas.

\section{Definição 11 (Digrafo ou Grafo orientado)}

São aqueles que possuem arestas orientadas.

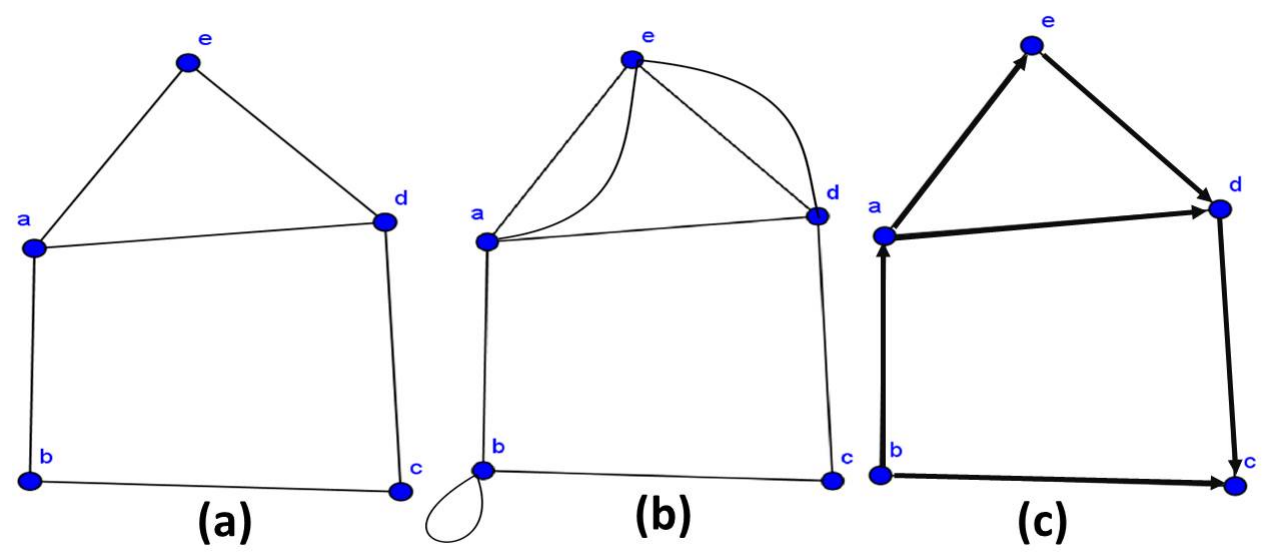

Figura 3.14: O grafo (a) é um grafo simples, o grafo (b) é um multigrafo e o grafo (b) é um digrafo.

\section{Exemplo 8 Grafo do Mapa do Brasil}

Grafo do Mapa do Brasil na figura 3.15 é um grafo simples em que cada estado representa um vértice e cada aresta indica estados vizinhos. 


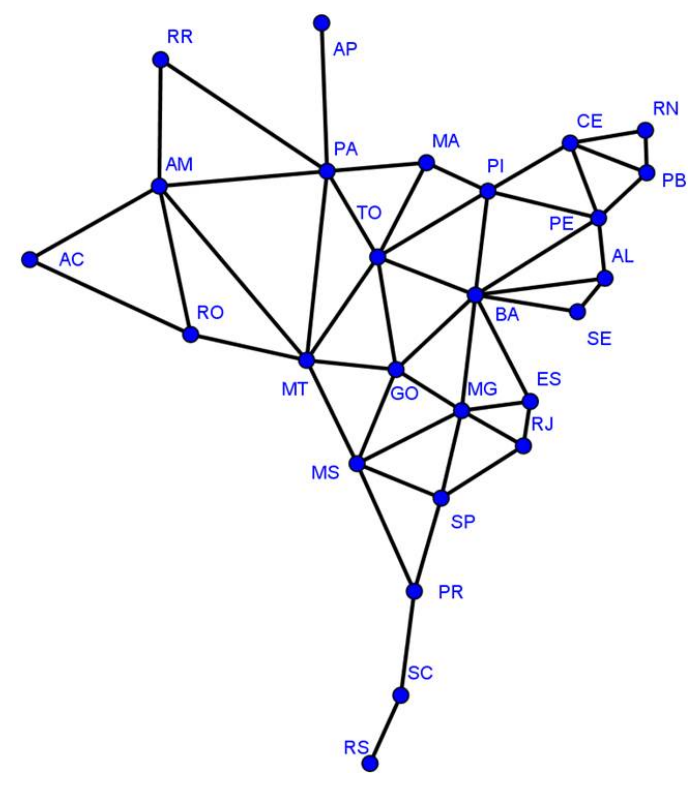

Figura 3.15: Grafo do Mapa do Brasil.

Exemplo 9 Grafo da estrutura da molécula do Benzeno

Grafo do benzeno na figura 3.16 é um multigrafo em que cada vértice é um átomo e as arestas são as ligações químicas entre os átomos correspondentes.

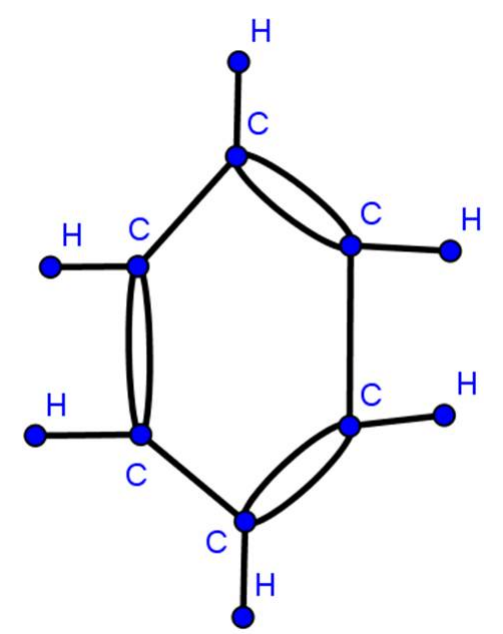

Figura 3.16: Grafo do Benzeno.

Exemplo 10 Grafo de Chamadas

Grafo de chamadas é um digrafo em que cada número de telefone é representado por um vértice e cada chamada telefônica é uma aresta orientada. Na figura 3.17 temos um pequeno grafo com 5 telefones, mas um grafo de chamadas que modele atividades telefônicas reais pode ser imenso. 


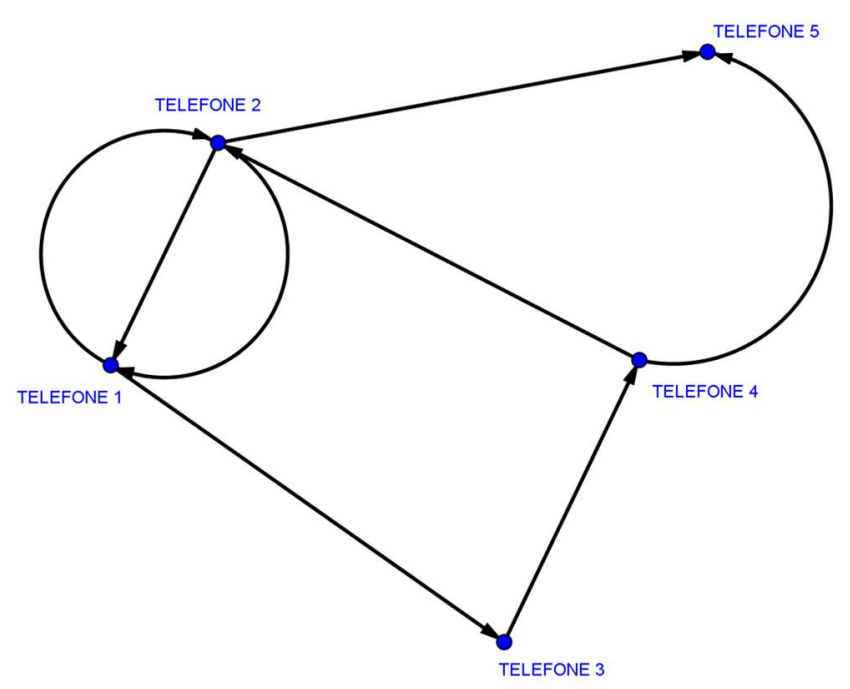

Figura 3.17: Grafo de chamadas telefônicas com 5 telefones.

\section{Definição 12 (Grafo totalmente desconexo)}

É aquele cujo o conjunto das arestas é vazio, ou seja, não possui aresta.

Um grafo totalmente desconexo é representado por um conjunto esparso de pontos, como na figura 3.18.

a

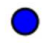

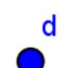

$0^{b}$
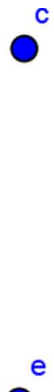

Figura 3.18: Grafo totalmente desconexo.

\section{Definição 13 (Grafo completo)}

É aquele onde quaisquer dois vértices são adjacentes. Esse tipo de grafo é denotado por $K_{n}$, onde $n$ é o número de vértices. Na figura 3.19 temos o $K_{1}, K_{2}, K_{3}, K_{4}$ e $K_{5}$. 

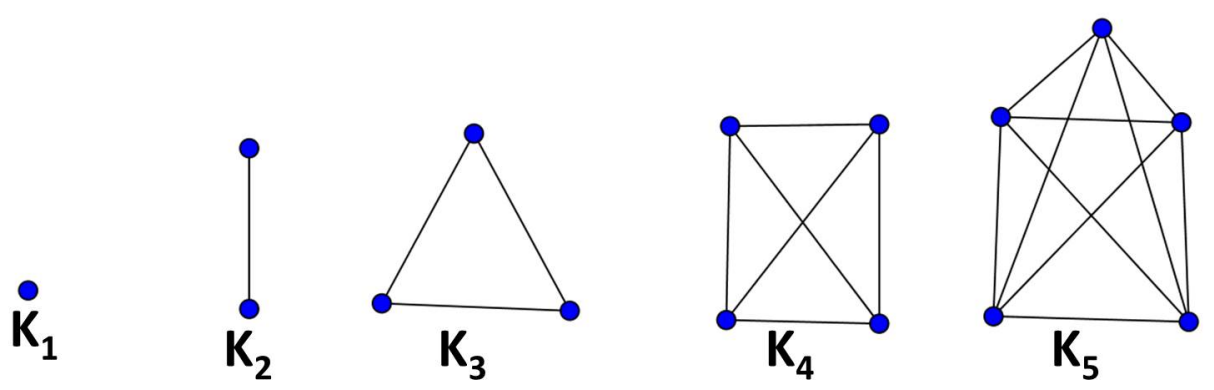

Figura 3.19: Os primeiros cinco grafos completos.

\section{Definição 14 (Subgrafo)}

Seja $G=(V, A)$ um grafo. Dizemos que $H=\left(V^{\prime}, A^{\prime}\right)$ é um subgrafo de $G$ se $V^{\prime} \subseteq V$ e $A^{\prime} \subseteq A$ e $f$ pode ser restrita a $A^{\prime}$ com imagem em $V^{\prime} \cup\left(\begin{array}{c}V^{\prime} \\ 2\end{array}\right)$ (ou $V^{\prime} \times V^{\prime}$, no caso de digrafos). Em outras palavras, todo vértice de $H$ é um vértice de $G$, e toda aresta de $H$ é uma aresta de $G$ unindo vértices de $H$.

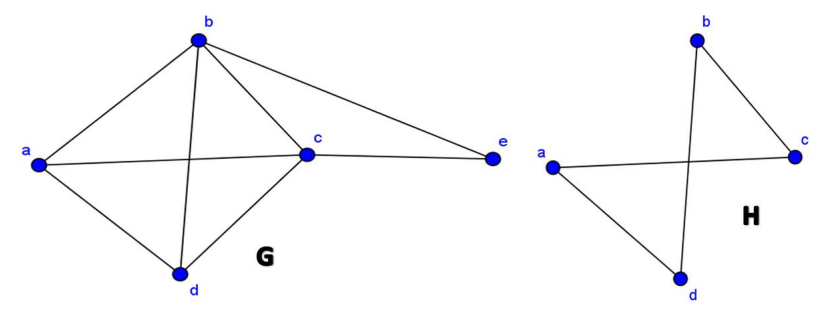

Figura 3.20: H é um subgrafo de G.

\section{Definição 15 (Grafo bipartido)}

Um grafo $G$ é chamada de bipartido no caso em que o conjunto de vértices $V$ pode ser particionado em dois conjuntos $V_{1}$ e $V_{2}$ (ou seja $V_{1} \cup V_{2}=V$ e $V_{1} \cap V_{2}=\emptyset$ ) de tal forma que não exista aresta ligando um elemento de $V_{1}$ a um elemento de $V_{2}$. Na figura 3.21 podemos ver um exemplo de grafo bipartido onde $V_{1}$ tem 3 vértices e $V_{2}$ tem 4 vértices.

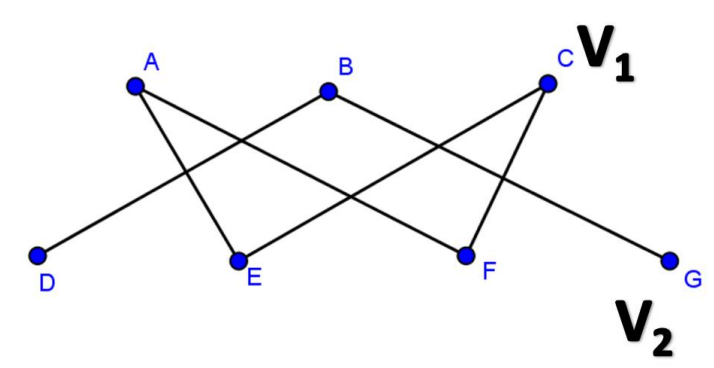

Figura 3.21: Grafo bipartido. 
No caso em que todos os vértices de $V_{1}$ forem adjacentes a todos os vértices de $V_{2}$, temos um grafo bipartido completo. Se $V_{1}$ tem $r$ vértices e $V_{2}$ tem $s$ vértices, então tal grafo bipartido completo é denotado por $K_{r, s}$. (Figura $3.22)$

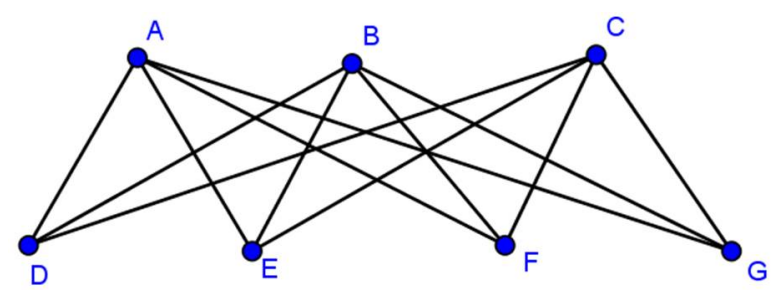

Figura 3.22: Grafo bipartido completo $K_{3,4}$ ou $K_{4,3}$.

\section{Definição 16 (Grafo planar)}

Um grafo $G$ é dito planar se ele puder ser representado graficamente no plano sem que as curvas que representam arestas se cruzem.

Um grafo planar em geral admite representações gráficas com cruzamentos de arestas, pois em geral existem diversas formas de representar um grafo no plano, como mostra a figura 3.23 , que representa o grafo planar $K_{4}$.

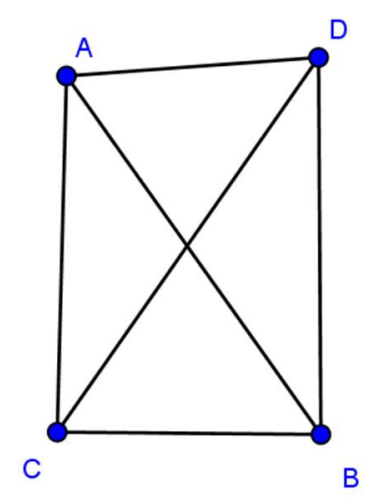

(1)

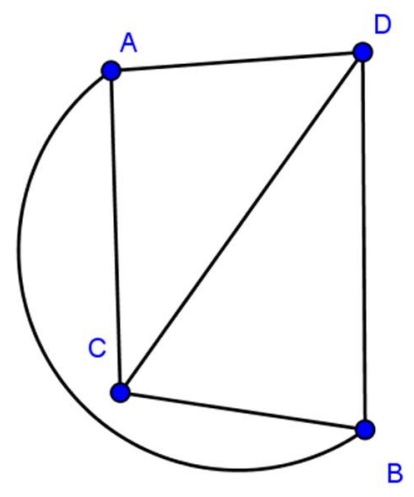

(2)

Figura 3.23: Representações do grafo planar $K_{4}$ : em (1) ocorre cruzamento entre arestas. 
Um circuito elétrico é um arranjo de de dispositivos elétricos, tais como resistores, indutores, capacitores, diodos, linhas de transmissão, fontes de tensão, fontes de corrente e interruptores, ligados por fios condutores, de modo que formem pelo menos um caminho fechado para a corrente elétrica. Em geral, circuitos elétricos não podem ser representados por grafos planares.
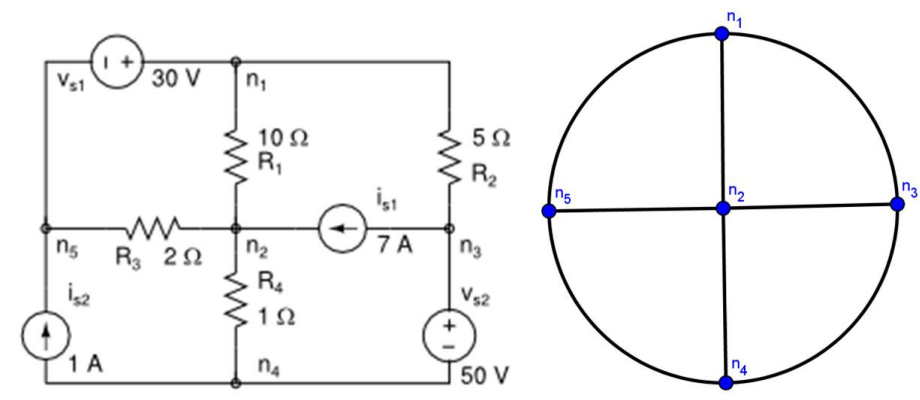

Figura 3.24: Fonte: http://www.mspc.eng.br/elemag/celetr0220.shtml modificada pela autora.

Uma situação em que se encontram grafos planares está em nas placas de circuitos impressos (figura 3.25), nas quais componentes eletrônicos são conectados através de trilhas cobre sobre um material isolante. Uma interseção de arestas (fios de cobre) ocorrendo fora de um componente (vértice) é indesejável porque corresponde a um curto-circuito.
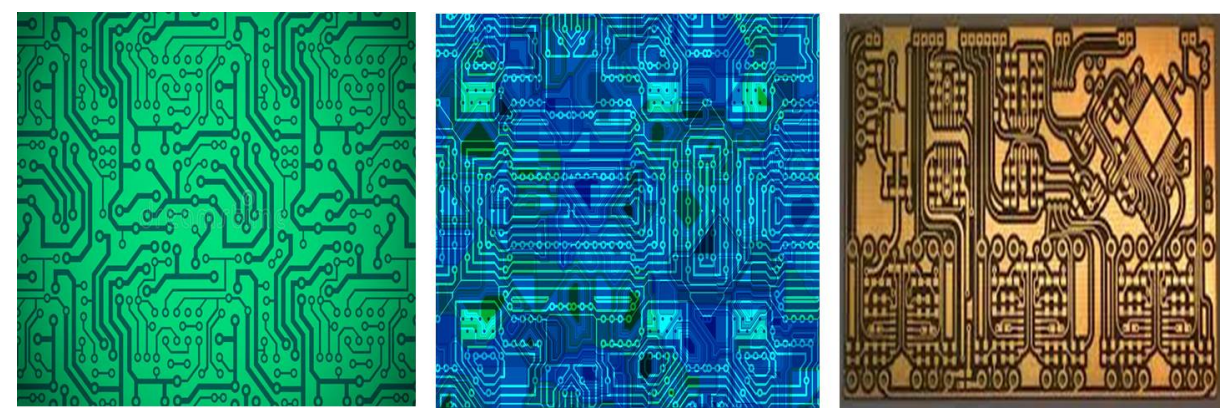

Figura 3.25: Três exemplos de placas de circuito impressos.

Após ver os problemas 13 e 14 apresentados no capítulo seguinte, um estudante secundarista não teria grande dificuldade em verificar que os grafos não-planares de menor ordem são o grafo completo em cinco vértices $K_{5} \mathrm{e}$ o grafo bipartido completo $K_{3,3}$, de seis vértices. É claro que qualquer grafo que contenha um desses dois como subgrafo também não será planar. O mais legal é que essa condição de não ter $K_{5}$ ou $K_{3,3}$ como subgrafo - ligeriamente fortalecida - é não só necessária, mas também suficiente para que um grafo finito seja planar. Esse belo resultado foi provado em 1930 por K. Kuratowski e, assim como o Teorema de Euler (ver problema 3 no capítulo seguinte), 
ilustra a profunda conexão entre Combinatória e Topologia. Infelizmente, sua demonstração encontra-se além do escopo deste trabalho.

\section{3}

\section{Caminhos, Trilhas e Passeios}

Sejam $G$ um grafo e $u$ e $v$ dois vértices de $G$.

\section{Definição 17 (Passeio)}

Um passeio é uma sequência finita de arestas concatenadas de $G$. Denotamos por $u-v$ passeio, um passeio começando com $u$ e terminando em $v$. Caso $u=v$, fala-se em um passeio fechado.

Por exemplo, no grafo $G$ da figura $3.20 a, a b, b c, c d, d b, b e, e c, b c, b$ é um $a-b$ passeio. Observe que a aresta $b c$ aparece duas vezes.

\section{Definição 18 (Grafo conexo)}

Um grafo $G$ é dito conexo quando, dados vértices $x, y \in V(G)$, sempre existe um $x-y$ passeio em $G$. Quando isso não ocorre, dizemos que o grafo $G$ é desconexo como mostra a figura 3.26.

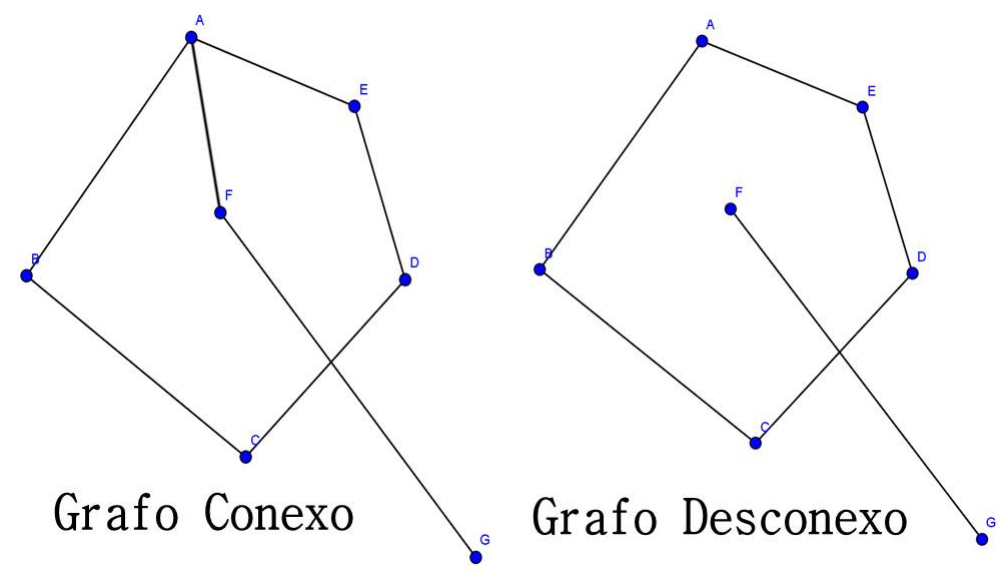

Figura 3.26: No grafo desconexo não existe um A-F passeio.

Um sistema nervoso central (SNC) pode ser interpretado como um grafo conexo, tomando como vértices os corpos celulares dos neurônios e como arestas as sinapses entre essas células nervosas. Interrupções súbitas nessa rede podem acarretar drásticas mudanças no funcionamento do organismo. Houve um tempo em que certas formas de desconectar esse enorme grafo eram prescritas como terapêuticas para certas disfunções neurológicas, provocando danos praticamente irreversíveis nos pacientes. Hoje, intervenções cirúrgicas como a lobotomia ou a calosotomia estão completamente fora de cogitação. 


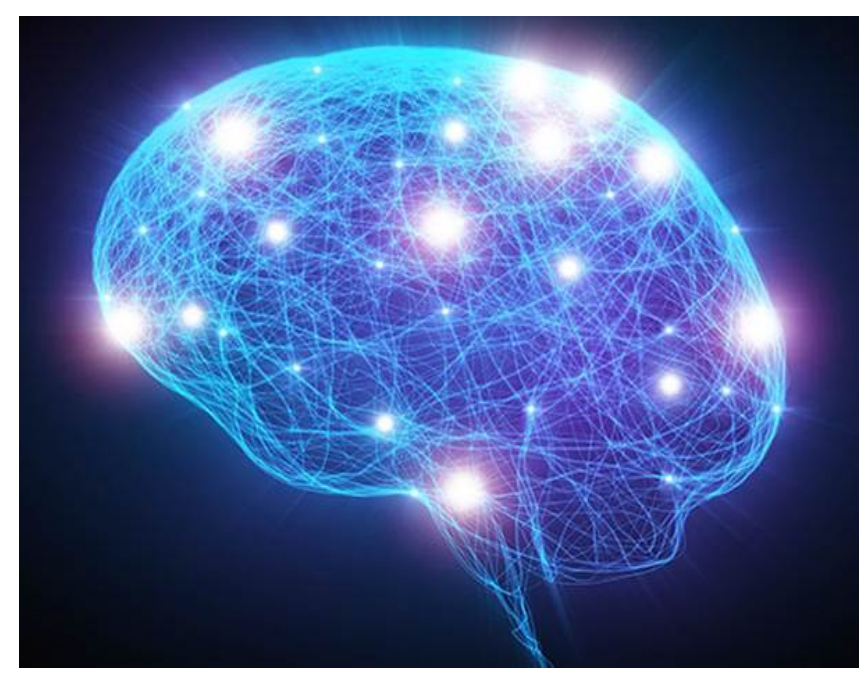

Figura 3.27: Esquema da atividade elétrica num cérebro humano. Fonte: http://news.harvard.edu/gazette/story/2015/09/why-ms-symptoms-mayimprove-as-days-get-shorter/

\section{Definição 19 (Trilha)}

Uma trilha é um passeio que não repete nenhuma aresta.

Quando uma trilha contêm todas as arestas de um grafo, dizemos tratarse de uma trilha euleriana.

\section{Definição 20 (Caminho)}

É um passeio que não repete nenhum vértice. Quando $u=v$, dizemos tratar-se de um ciclo.

Quando um ciclo contêm todos os vértices de um grafo, dizemos tratar-se de um ciclo hamiltoniano.
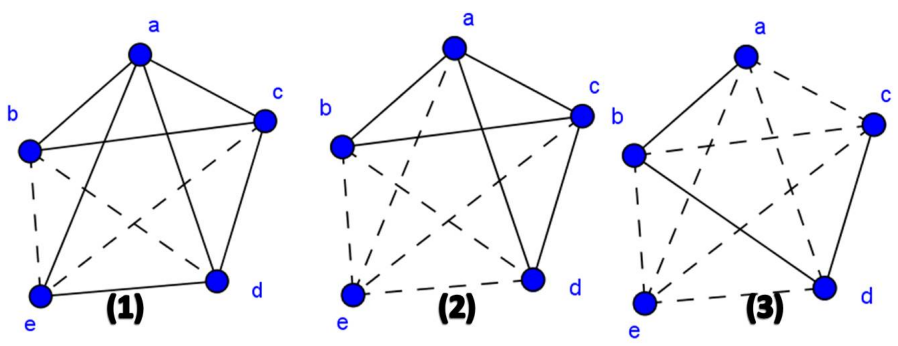

Figura 3.28: (1) aedabcdac é um $a-c$ passeio,(2) abcdac é uma $a-c$ trilha e (3) abdc é um $a-c$ caminho. 


\section{Definição 21 (Grafo euleriano)}

Um grafo é dito euleriano se admite uma trilha euleriana fechada.(Figuras 3.29 e 3.30 ).

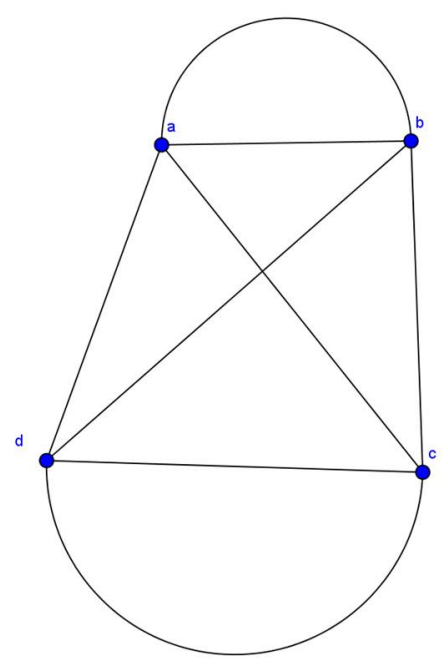

Figura 3.29: Grafo com trilha euleriana fechada abcdcabda.

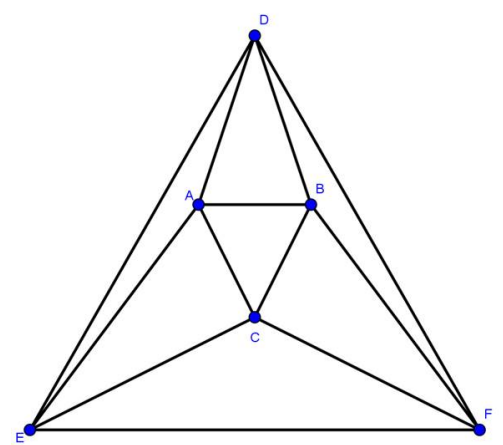

Figura 3.30: O octaedro é um grafo planar com trilha euleriana fechada $A B C F B D F E C A E D A$. 


\section{Definição 22 (Grafo hamiltoniano)}

Um grafo $G$ é dito hamiltoniano se admite um ciclo hamiltoniano.(Figura $3.31)$.

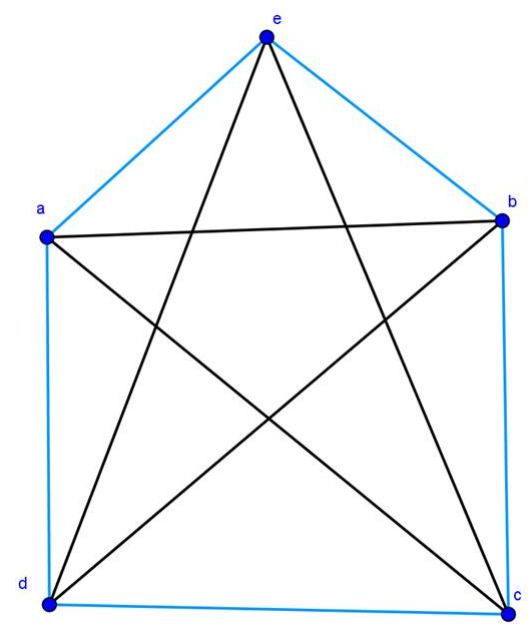

Figura 3.31: Grafo completo $K_{5}$ com o ciclo hamiltoniano mais óbvio destacado em azul.

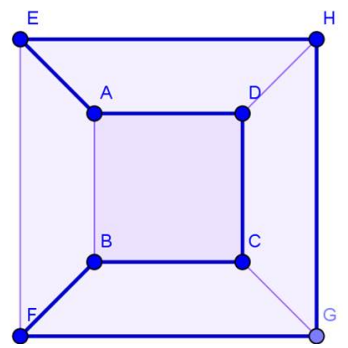

Figura 3.32: O cubo como um grafo planar hamiltoniano. 


\section{Definição 23 (Árvore)}

Um grafo conexo simple é dito uma árvore se não possui nenhum ciclo (ver figura 3.33).

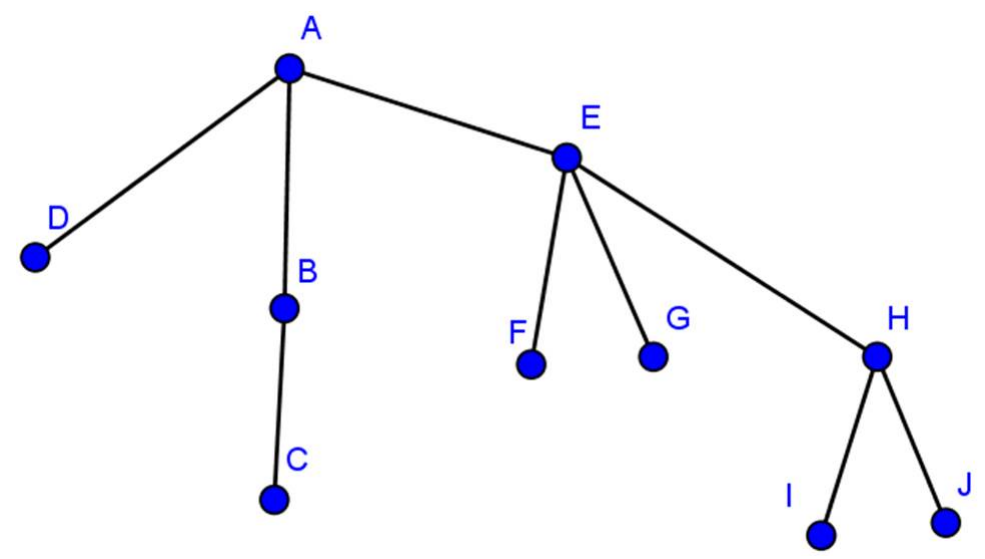

Figura 3.33: Uma árvore.

Exemplo 11 Algumas estruturas das moléculas.

É claro que nem todas as estruturas de moléculas são árvores (a estrutura do benzeno, por exemplo, figura 3.16), mas todas podem sem representados por grafos.

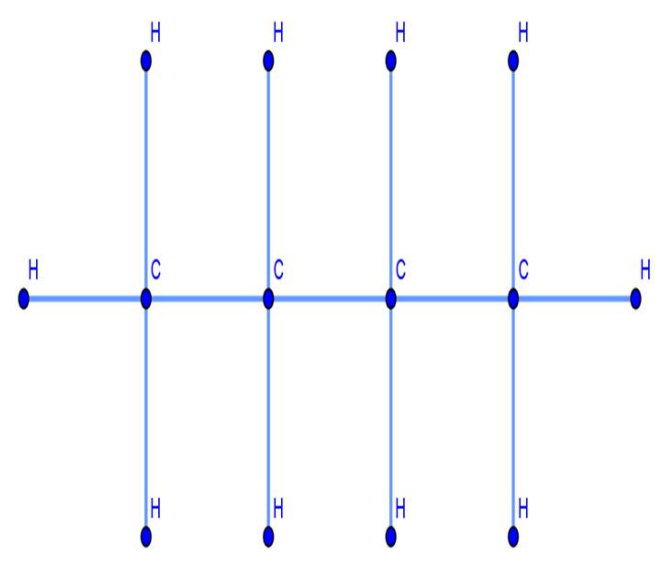

(1)

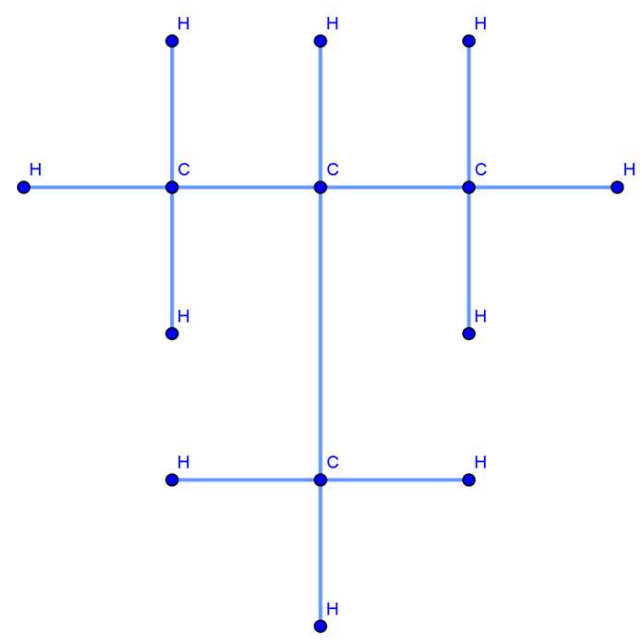

(2)

Figura 3.34: (1):Alcano e (2):Isobutano. 


\section{Exemplo 12 Árvores sintáticas}

Uma árvore sintática é uma estrutura de dados em árvore, que representa a estrutura sintática de uma frase de acordo com alguma gramática formal. Na figura 3.35 temos a árvore sintática de "O Pablo comprou todos os livros.".

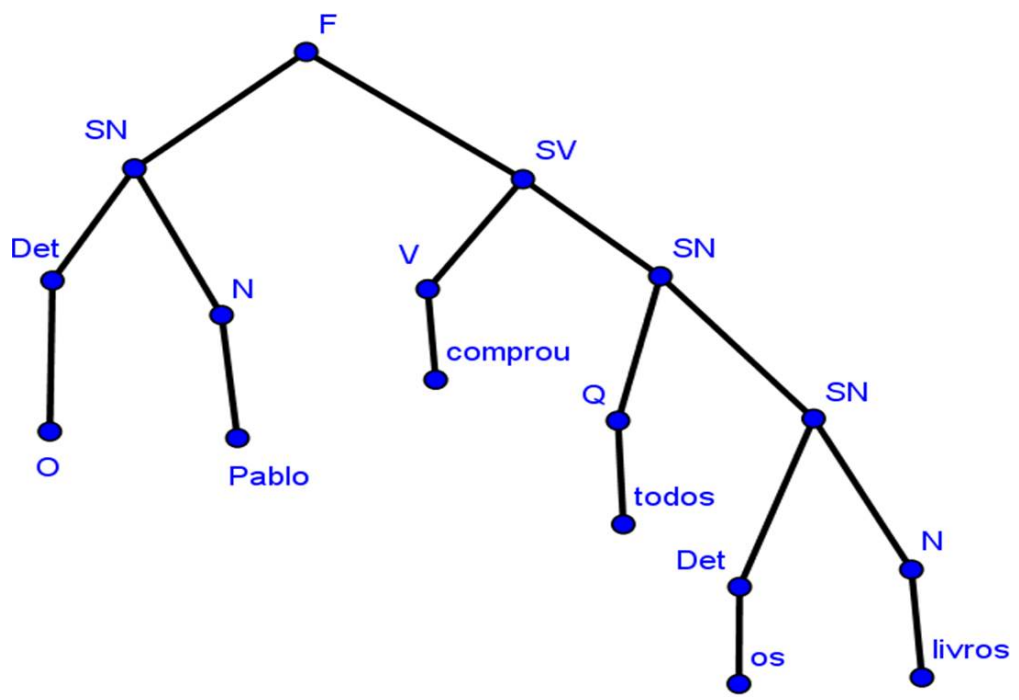

Figura 3.35: $\mathrm{F}=$ frase; $\mathrm{SN}=$ Sintagma Nominal; $\mathrm{SV}=$ Sintagma Verbal; V= Verbo; $\mathrm{Q}=$ Quantificador; DET = Determinante; $\mathrm{N}=$ nome.

Observe que, por não ter ciclos, uma árvore é a forma mais simples de se conectar vértices.

\section{Definição 24 (Árvore geradora)}

Uma árvore geradora(figura 3.36) de um grafo $G$ conexo é um subgrafo conexo que contem todos os vértices de $G$ e que é uma árvore.
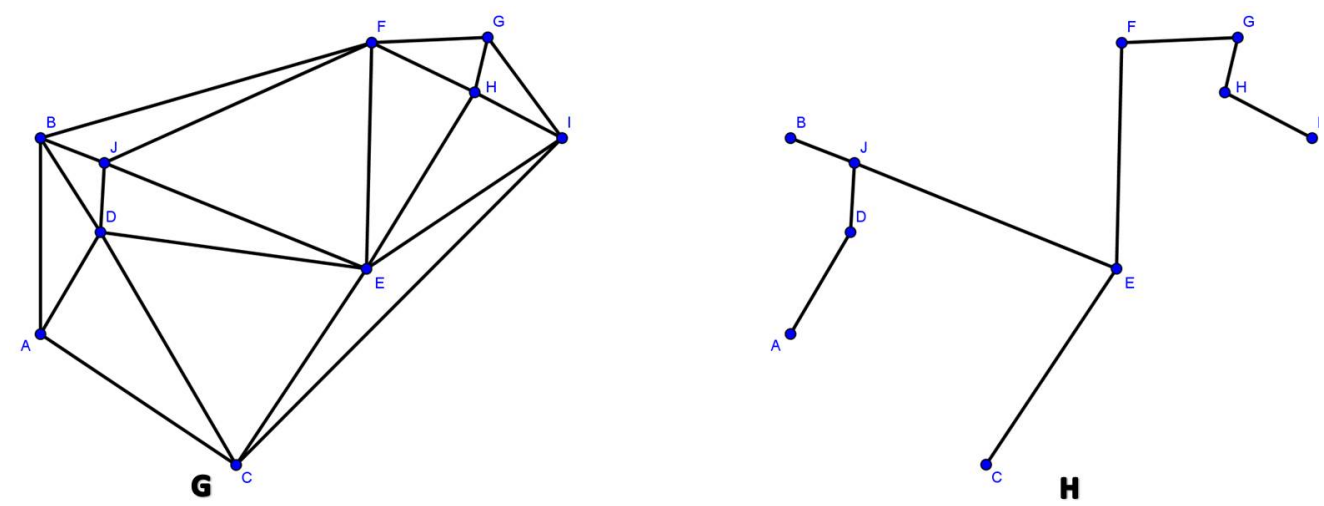

Figura 3.36: H é uma árvore geradora de G. 


\section{4}

\section{Problemas resolvíveis por teoria de grafos}

Esse capítulo tem como objetivo resolver alguns problemas matemáticos através de teoria de grafos.

A ideia é sempre remodelar o problema, fazendo um abstração e associando os vértices do grafo aos objetos do problema e as arestas às relações entre os objetos.

Os objetos podem ser qualquer coisa: lugares, pessoas e etc. E os relacionamentos podem ser divisas, amizades e etc.

Alguns resultados básicos da teoria de grafos serão introduzidos (sem demonstração) à medida em que sejam úteis para a resolução de uma classe particular de problemas. No capítulo seguinte, daremos as provas de todos os resultados utilizados.

Voltemos ao primeiro problema apresentado no início do nosso trabalho.

Problema 1 (Problema: Raposa, Galinha e Milho.) Um fazendeiro precisa levar uma galinha, uma raposa e um saco de milho de uma margem de um rio para a outra. Ele dispõe de um pequeno barco, que só o permite levar consigo um item de cada vez. Mas ele deve providenciar, durante todo o processo, que a raposa jamais fique a sós com a galinha, nem tampouco a galinha com o saco de milho (por razões óbvias). É possível fazer isso? Se sim, qual a maneira mais eficiente de completar a tarefa?

Observe que, indiretamente, já resolvemos o problema utilizando um grafo. Basta fazermos a seguinte associação:

Vértices: São cada "estado" no qual os objetos (galinha,raposa,milho) se encontrando.(Os vértices do cubo)

Arestas: Os deslocamentos entre os "estados".(As arestas do cubo)

Inclusive poderíamos transformar a representação do grafo em 3D do capítulo um para a imagem 4.15 em 2D que representa o digrafo do problema. $\square$ 


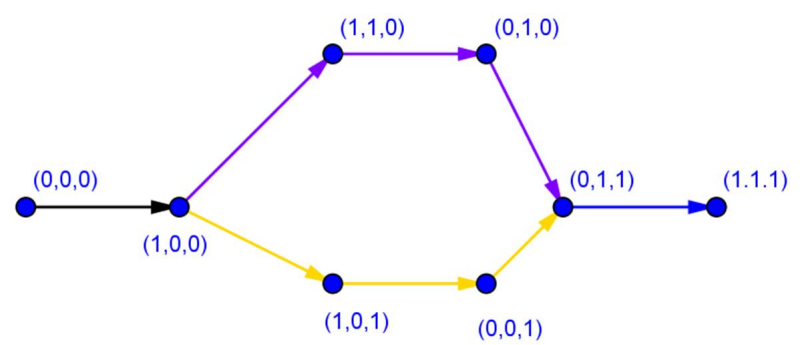

Figura 4.1: Grafo das Movimentações da Galinha,Raposa e Milho.

Problema 2 (Caixeiro Viajante.) O Sr. Tavares é um caixeiro viajante que tem clientes em cinco cidades: cidade 1, cidade 2, cidade 3, cidade 4 e cidade 5. Foi proposta a ele uma viagem de negócios na qual ele deve começar e terminar na cidade onde reside, que é a cidade 1, e passar por todas as outras quatro. A fim de que poupar custos, ele precisará passar por cada uma das quatro cidades restantes apenas uma vez. Na figura 2.18, temos um esquema mostrando o custo do trajeto entre cada par de cidades. É possível fazer tal viagem proposta ao Sr. Tavares? Se sim, qual seria o melhor percurso, ou seja, o mais econômico?

Aqui, retornamos a outro problema do capítulo 2, um dos problemas mais clássicos dentro da teoria de grafos.

Ele pode ser remodelado da seguinte forma:

Vértices: São as cidades.

Arestas: São os caminhos que ligam duas cidades.

Logo podemos fazer a representação gráfica utilizando a imagem 4.2.

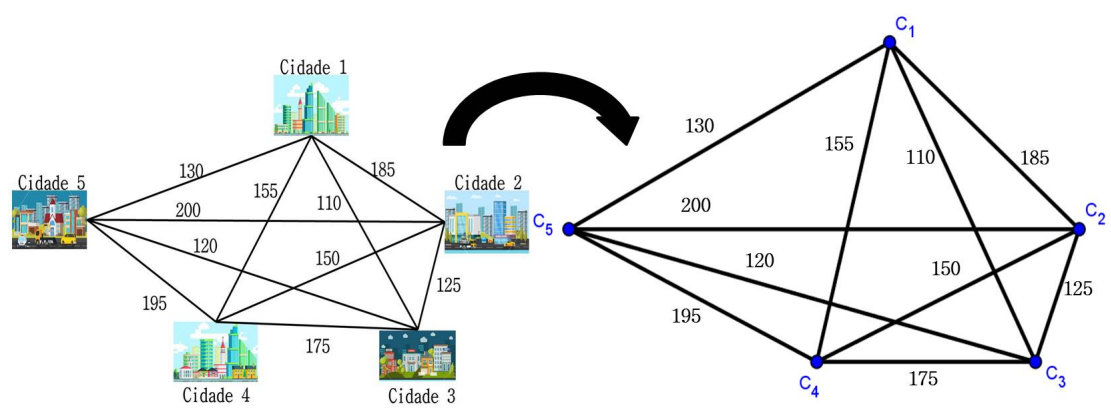

Figura 4.2: Grafo do Esquema das Cidades a serem percorridas pelo Senhor Tavares.

Observe que quando a pergunta diz que o Senhor Tavares irá precisar passar por todas as cidades uma única vez e retornar à cidade inicial, em 
termos de grafos o questionamento seria : "Existe um ciclo hamiltoniano que comece e termine em $C_{1}$ ?".

Critério para Grafos Hamiltonianos- Dirac: Se cada um dos vértices de um grafo conexo finito $G$ é vizinho de pelo menos metade dos vértices de $\mathrm{G}$, então $\mathrm{G}$ possui um ciclo hamiltoniano. Em outras palavras, se $|G|=n$ e $g(v) \geq \frac{n}{2} \quad \forall v \in G$, então $\mathrm{G}$ possui um ciclo hamiltoniano.(6)

Analisando o grafo $G$ da figura 4.2, podemos ver que os graus dos vértices são :

\begin{tabular}{|c|c|}
\hline Vértice & Grau \\
\hline$C_{1}$ & 4 \\
$C_{2}$ & 4 \\
$C_{3}$ & 4 \\
$C_{4}$ & 4 \\
$C_{5}$ & 4 \\
\hline
\end{tabular}

Observe que nesse caso, $|G|=5$ e como $g(v)=4$, que é maior que $\frac{5}{2}=2,5$, para todo $v$ do grafo, então de acordo com o critério de Dirac existe um ciclo hamiltoniano.

E portanto é possível fazer a viagem.

É evidente que como o grafo do problema tem poucos vértices, testar se existe um ciclo hamiltoniano é mais simples do que utilizar o critério, e ainda fornece um ciclo hamiltoniano explicitamente. Mas, quando estamos trabalhando com grafos maiores, esse critério é de grande ajuda.

O Problema do Caixeiro Viajante é a denominação utilizada para uma série de problemas reais que envolvem caminhos hamiltonianos. Infelizmente, a questão do caminho mais vantajoso ainda não dispõe de um método geral eficaz e que nos dê a solução rapidamente.

O método que utilizamos no capítulo 2 é inviável quando temos uma número grande de vértices. Por exemplo, se tivéssemos 30 cidades teríamos que fazer 29! cálculos dos possíveis trajetos.

Problema 3 (7 pontes de Königsberg) Na cidade de Königsberg havia sete pontes que cruzavam o rio Pregel. Elas ligavam duas ilhas do rio entre si e com as margens, como mostra a figura 2.20. Os moradores de Königsberg preocupavam-se com o seguinte problema: é possível passear pelas sete pontes sem repetir nenhuma?

Vamos voltar ao problema das pontes visto no Capítulo 2, e remodelar da seguinte forma: 
Vértices: São cada um dos pedaços de terra da cidade de Königsberg.

Arestas: São as pontes entre esses pedaços de terra.

Assim o grafo formado pode ser representado através da figura 4.3.

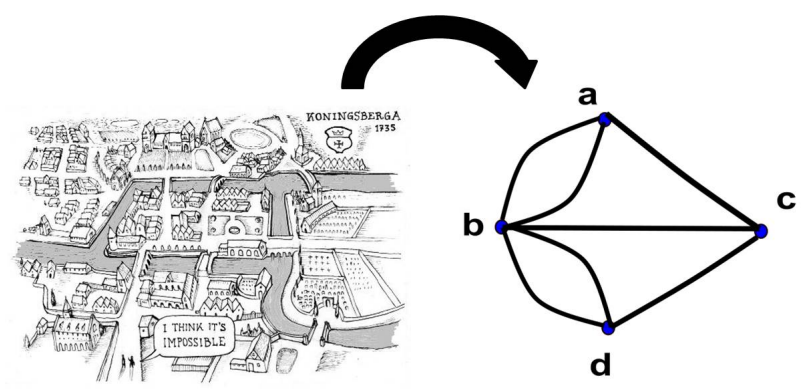

Figura 4.3: Grafo das 7 pontes da cidade de Königsberg.

Agora vamos reformular o problema. Podemos transformar o questionamento em "Existe uma trilha que contenha todas as arestas e vértices do grafo? Em outra palavras, existe uma trilha euleriana?"

Podemos observar que os vértices do grafo da figura 4.3 são tais que:

\begin{tabular}{|c|c|}
\hline Vértice & Grau \\
\hline$a$ & 3 \\
$b$ & 5 \\
$c$ & 3 \\
$d$ & 3 \\
\hline
\end{tabular}

Ou seja, todos os vértices possuem grau ímpar.

Para resolver esse tipo de problema iremos apresentar dois resultados existentes na teoria de grafos.

Teorema de Euler : "Um grafo finito e convexo admite uma trilha euleriana fechada se e somente se todos os seus vértices tem grau par."

Teorema do Grafo traçável: "Um grafo finito e convexo admite uma trilha euleriana aberta $T_{a b}$ se e somente se tem exatamente dois vértices de grau ímpar. Mais precisamente, os vértices $a$ e $b$ são os únicos de grau ímpar."

Com base no Teorema de Euler, para que se tenha uma trilha euleriana fechada todo vértice precisa ter grau par, e nesse caso todos os vértices tem grau ímpar. 
E note que, mesmo o problema não exigindo que comecemos o trajeto e terminemos o trajeto no mesmo lugar, pelo Teorema do Grafo Traçável precisaríamos que o grafo tivesse exatamente 2 vértices de grau ímpar (onde começa e onde termina).

Portanto, não existe solução para esse problema. Em outras palavras, não é possível passear pelas sete pontes sem repetir nenhuma.

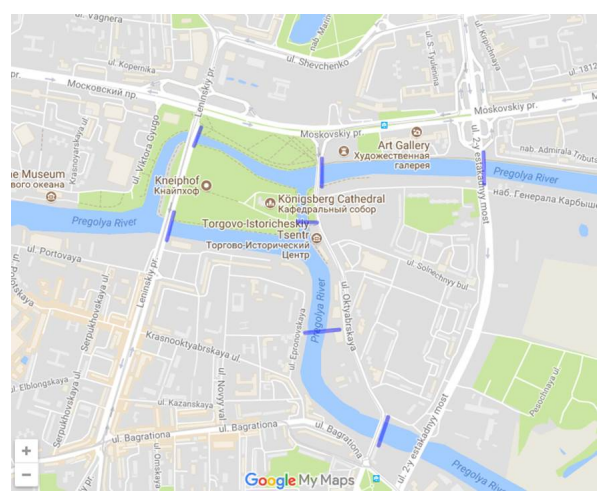

Figura 4.4: Imagem da cidade de Königsberg no dias atuais retirada do "Google Maps" .

Esse problema foi originalmente solucionado por Leonhard Euler(17071783), por isso o teorema recebeu esse nome. O problema das 7 pontes de Königsberg por si só não tinha tanta importância, mas sim o racíocionio que Leonhard Euler utilizou para resolvê-lo. Inclusive esse Teorema recebeu esse nome para homenageá-ló e vem sendo abundantemente utilizado para resolver problemas similares e de grande relevância não somente dentro da matemática, como em outras áreas afins.

Seria importante, após apresentar o Teorema de Euler, mostrar para os alunos que para descobrirmos se um grafo é ou não euleriano, o teorema nos dá uma condição necessária e suficiente, diferente do que acontece com os grafos hamiltonianos, em que demos apenas uma condição suficiente.

Problema 4 (Jogo de Hamilton) "Hamilton inventou um bonito jogo, que chegou a ser comercializado por volta de 1859 e que esteve na moda durante algum tempo. O nome do jogo era Viagem pelo Mundo, figura 4.5. Esse jogo consistia num dodecaedro regular de madeira, onde cada vértice recebia o nome da de uma cidade: Dublin, Roma, Paris; Madrid,... O jogo consistia em encontrar um itinerário contínuo pelas arestas do dodecaedro, saindo de uma determinada cidade, que passasse só uma vez por cada cidade. Este itinerário ia-se marcando com um fio de lã colorido quee dava uma volta no eixo de cada cidade por onde passava." A pergunta é : É possível fazer tal itinerário? Caso, possível, apresente uma solução. 


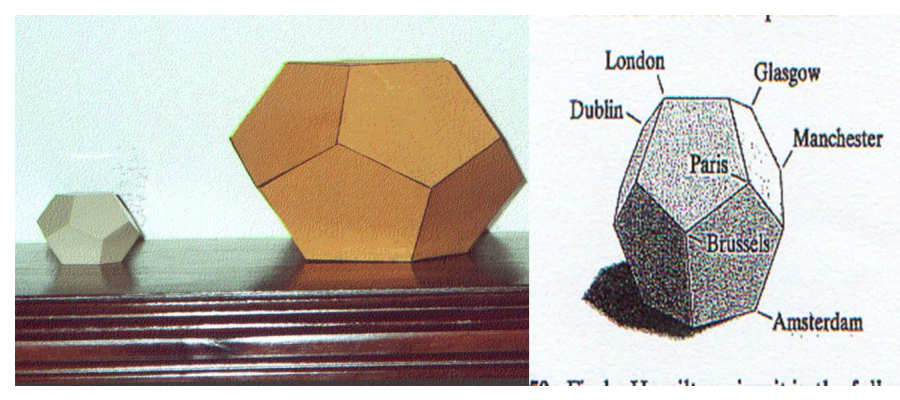

Figura 4.5: Algumas imagens do jogo "Viagem ao mundo". Fonte: http://principo.org/um-pequeno-histrico-da-teoria-dos-grafos-3.html?page $=5$

Primeiro vamos verificar se o desafio proposto é possível. Vamos remodelar o problema, onde:

Vértice: São as cidades(vértices do dodecaedro).

Arestas: São as ligações entre as cidades(arestas do dodecaedro).

Logo o grafo do jogo pode ser visto na figura 4.6.

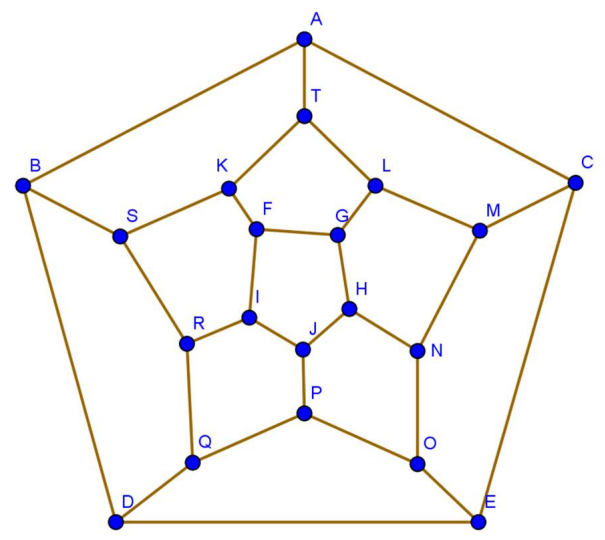

Figura 4.6: Grafo do jogo "Viagem ao mundo".

Então vamos buscar uma possível solução. O desafio não é muito difícil quando passamos a analisar o grafo criado. Podemos fixar um vértice e ir passando pelos demais até encontrar um ciclo hamiltoniano. Na figura 4.7 podemos observar uma solução para o jogo. 


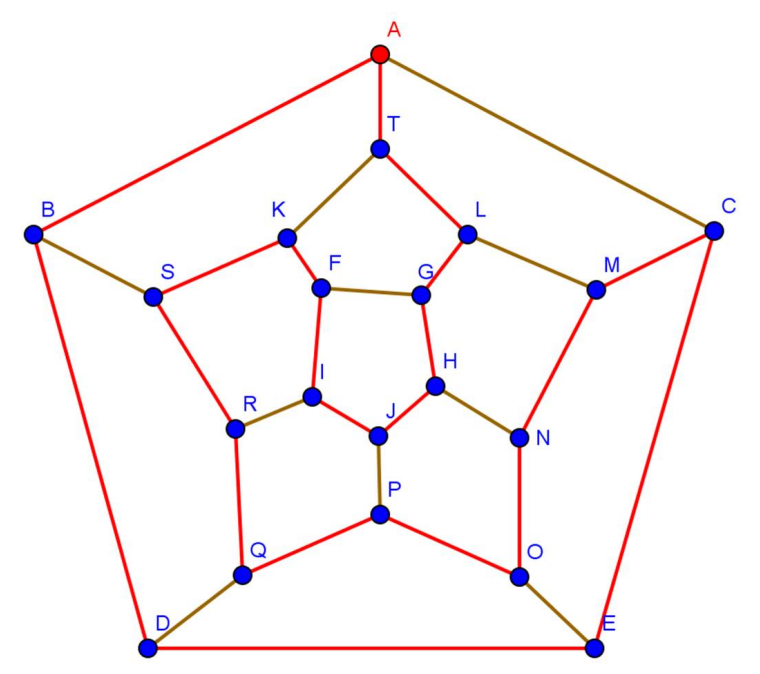

Figura 4.7: Em vermelho temos uma solução do jogo "Viagem ao mundo".

Observe que o grafo da figura 4.6 tem 20 vértices e que $\frac{20}{2}=10$. E analisando os graus dos vértices do problema com o auxílio da figura 4.6, podemos ver que todos os vértices tem grau 3. Logo temos que todos os vértices tem grau menor que 10 (no caso no grau é 3) e não podemos concluir nada utilizando o critério de Dirac visto anteriormente. Isso mostra que, embora o critério nos ajude nos casos em que os graus são maiores, nada podemos concluir caso contrário.

Problema 5 (Dominó) É possível com as pedras de um Jogo de Dominó formar um anel, ou seja, fazer um jogo fechado retornando a peça inicial? (Seguindo as regras do Jogo).

O dominó é um jogo de mesa que possui 28 peças divididas em dois espaços que contem pontos marcados representando os números de zero a seis, como mostra a figura 4.8 .

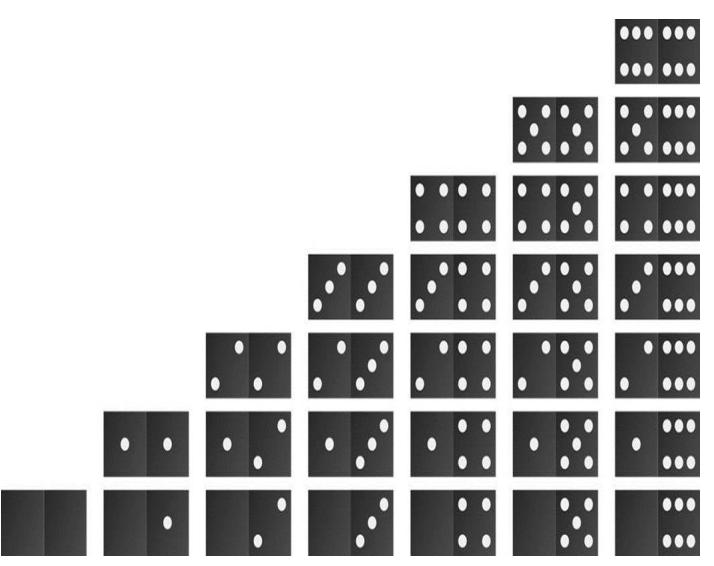

Figura 4.8: Conjunto de dominós duplo-seis. 
Pode ser jogado por 2 ou mais jogadores onde cada jogador recebe 7 pedras quando começa a rodada. No desenvolvimento do jogo cada jogador, em sua vez, deve colocar uma das suas peças em uma das 2 extremidades abertas, de forma que os pontos de um dos lados coincida com os pontos da extremidade onde está sendo colocado. Quando o jogador coloca sua peça sobre a mesa, sua vez de jogar se acaba e passa-se ao seguinte jogador. O objetivo é eliminar todas peças.

O problema em questão quer saber se seria possível colocar todas peças, dentro da regra do jogo, retornando à peça inicial colocada na mesa.

Para tentar resolver o problema vamos utilizar a teoria de grafos e remodelar os elementos, onde:

Vértices: São os números que aparecem nas peças.

Arestas: São as peças do dominó.

Assim formamos o grafo representado na figura 4.9

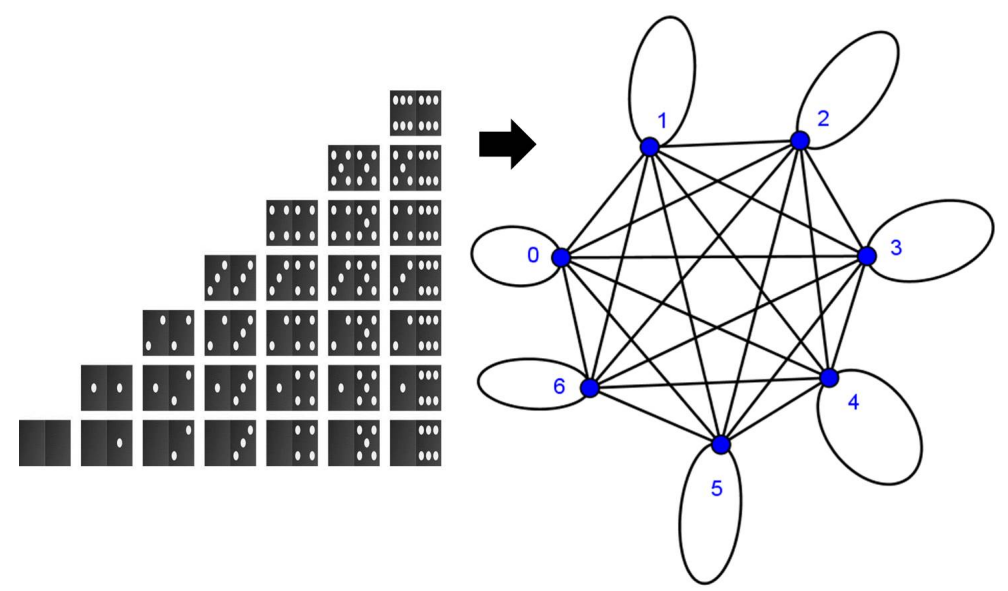

Figura 4.9: Grafo do dominó.

Observe que os laços do grafo representam as peças que têm número iguais marcados $(0-0,1-1, \ldots)$ e as arestas simples, as peças com números diferentes marcados $(1-2,1-3, \ldots)$.

Como as peças do dominó são únicas e não poderemos repeti-lás, podemos reformular o problema, e transformar o questionamento em saber se o grafo gerado é um grafo euleriano.

Para isso, vamos analisar o grau dos vértices. 


\begin{tabular}{|c|c|}
\hline Vértice & Grau \\
\hline 0 & 8 \\
1 & 8 \\
2 & 8 \\
3 & 8 \\
4 & 8 \\
5 & 8 \\
6 & 8 \\
\hline
\end{tabular}

Como todos os vértice tem grau par, temos que pelo Teorema de Euler, o grafo é euleriano.

Portanto, as peças de um dominó formam um anel.

\section{Problema 6 (O assassinato do bilionário Count Van Diamond) $A$}

planta da figura 4.10 é a residência do bilionário Count Van Diamond, que acaba de ser assassinado. Sherlock Gomes(um conhecido detetive que nas horas vagas é um estudioso da teoria dos grafos) foi chamado para investigar o caso. Durante a investigação obteve os seguintes testemunhos:

O mordomo: alega ter visto o jardineiro entrar na sala da piscina (lugar onde ocorreu o assassinato) e logo em seguida deixar aquela sala pela mesma porta que havia entrado.

O jardineiro: afirma que ele não poderia ser a pessoa vista pelo mordomo, pois ele havia entrado na casa, passado por todas as portas uma única vez e, em seguida, deixado a casa.

Depois disso, Sherlock Gomes avaliou a planta da residência (conforme figura 4.10) e em poucos minutos declarou solucionado o caso. Quem poderia ser o suspeito indicado por Sherlock Gomes?

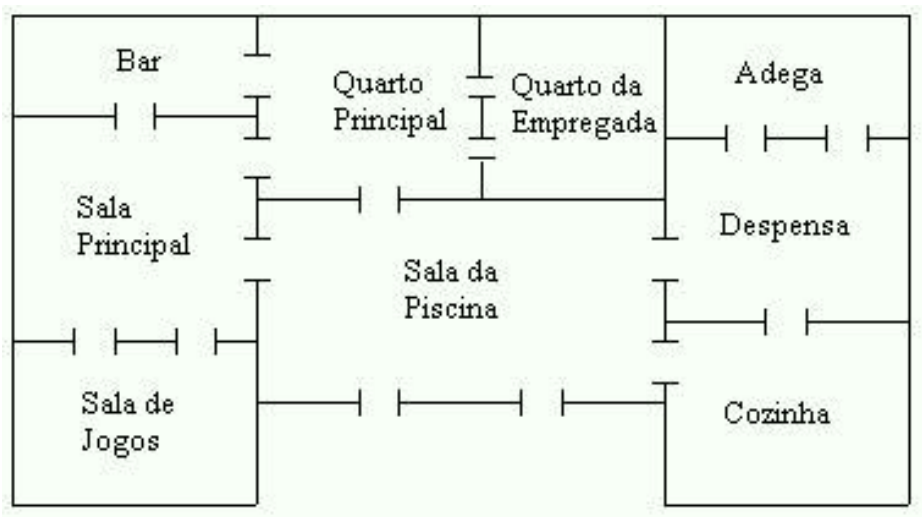

Figura 4.10: Planta da casa. Fonte: http://leandro.md.tripod.com

Como lemos no enunciado do problema que o Sherlock Gomes é um estudioso de teoria de grafos, então vamos tentar reformular o problema nos 
termos dessa teoria e com isso descobrir quem mentiu em seu testemunho fazendo com que Sherlock Gomes chegasse à solução do caso tão rapidamente.

Nesse caso faremos:

Vértices: São os cômodos das casas e parte externa.

Arestas: São as portas ligando os cômodos ou dando acesso à parte externa da casa.

Chegamos ao seguinte grafo da figura 4.11.

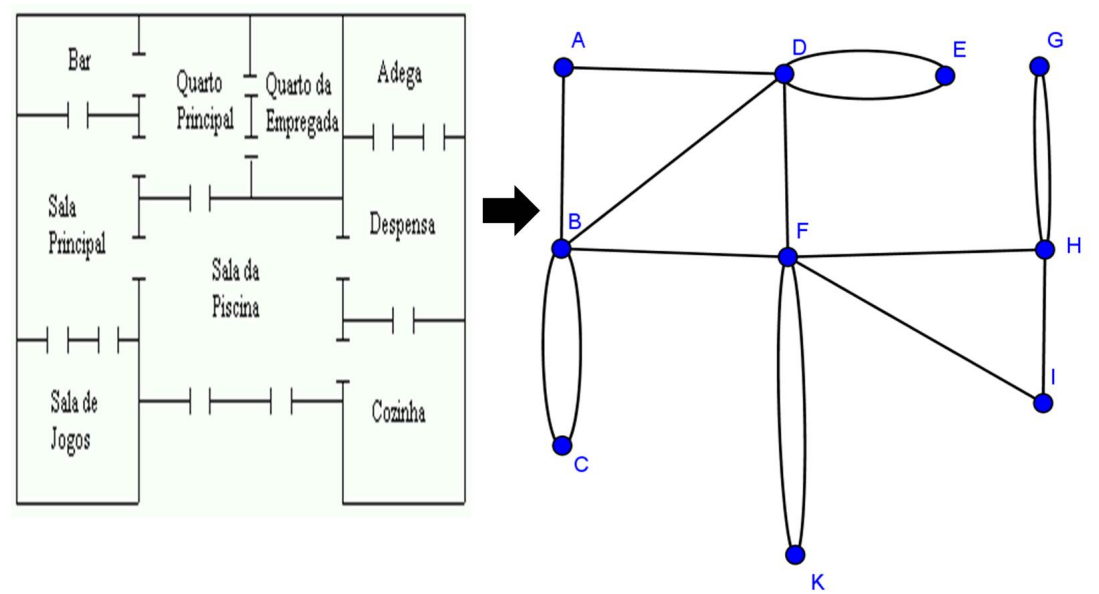

Figura 4.11: Grafo da Planta da casa do bilionário Count Van Diamond.

É claro que o jardineiro pode ter entrado e saído pela mesma porta. Porém isso não conclui o caso.

Agora, a afirmação do jardineiro, que diz em sua defesa ter atravessado cada uma das portas uma única vez, implicaria a existência de uma trilha euleriana fechada.

Para ver se isso seria possível, vamos contar os graus:

\begin{tabular}{|c|c|}
\hline Vértice & Grau \\
\hline$A$ & 2 \\
$B$ & 5 \\
$C$ & 2 \\
$D$ & 5 \\
$E$ & 2 \\
$F$ & 6 \\
$G$ & 2 \\
$H$ & 4 \\
$I$ & 2 \\
$K$ & 2 \\
\hline
\end{tabular}


Como há dois vértices de grau ímpar, pelo Teorema de Euler, não existe uma trilha euleriana fechada. E assim podemos concluir que o jardineiro mentiu.

E por essa razão, o detetive conseguiu solucionar rapidamente o caso, indicando como suspeito o Jardineiro.

Problema 7 (Desenhar sem tirar o lápis do papel) Nos desenhos da figura 4.12, uma criança diz ter posto a ponta do lápis em cima do papel e com movimentos contínuos, sem levantar e sem retroceder o lápis, ter traçado as linhas que formam os desenhos das duas casas, traçando cada casa uma única vez.

A mãe da criança acha que a criança trapaceou em um dos desenhos, pois não foi capaz de achar nenhuma sequência que pudesse produzir tal resultado. A mãe está correta em sua dúvida?

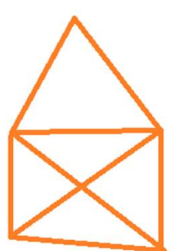

Casa 1

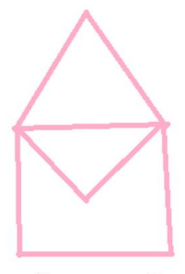

Casa 2

Figura 4.12: "Desenho" das duas casas.

Observe que a dúvida da mãe na verdade pode ser transformada numa questão sobre grafos, associando os desenhos a grafos, e descobrindo se tais grafos são traçáveis ou não, de acordo com o Teorema do Grafo Traçável.

Faremos a seguinte associação:

Vértice: São os "bicos" do desenhos.

Arestas: São as linhas que ligam esses bicos.

Com isso, associamos os desenhos aos grafos representados na figura 4.13 Observe que no grafo $G^{\prime}$ todos os vértices tem grau par, e pelo Teorema de Euler, $G^{\prime}$ é um grafo euleriano e portanto, traçável. 

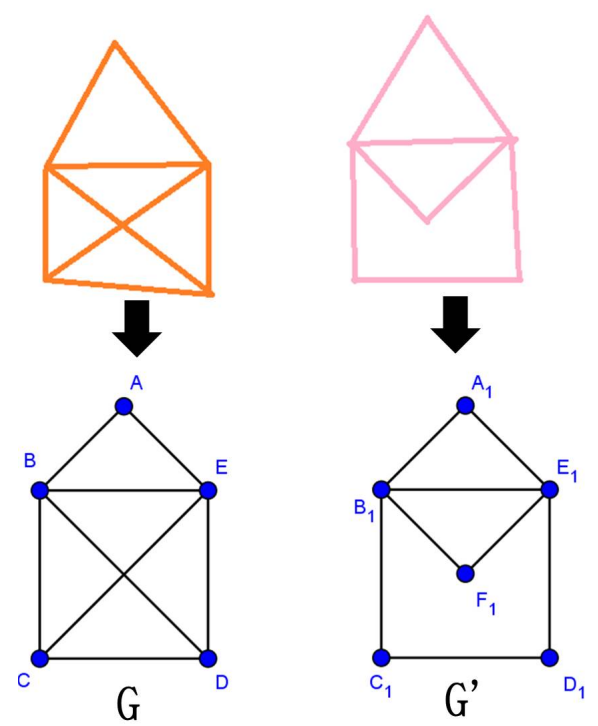

Figura 4.13: Grafo G da casa 1 e grafo $G^{\prime}$ da casa 2.

\begin{tabular}{|c|c|}
\hline \multicolumn{2}{|c|}{ Grafo G' } \\
\hline Vértice & Grau \\
\hline$A_{1}$ & 2 \\
$B_{1}$ & 4 \\
$C_{1}$ & 2 \\
$D_{1}$ & 2 \\
$E_{1}$ & 4 \\
\hline
\end{tabular}

E no caso do grafo $G$, somente os vértices $C$ e $D$ possuem grau ímpar e pelo Teorema do Grafo Traçável, $G$ possui uma trilha euleriana $T_{C D}$, e portanto é traçável.

\begin{tabular}{|c|c|}
\hline \multicolumn{2}{|c|}{ Grafo G } \\
\hline Vértice & Grau \\
\hline$A$ & 2 \\
$B$ & 4 \\
$C$ & 3 \\
$D$ & 3 \\
$E$ & 4 \\
\hline
\end{tabular}

Logo, a desconfiança da mãe é infundada. Mas por qual motivo teria a mãe da criança duvidado e não teria conseguido achar a sequência correta? Possivelmente a dúvida tenha ocorrido no desenho na casa 1, visto que, para conseguir realizá-lo, ela deveria ter começado em $C$ ou $D$, caso contrário não conseguiria fazer o desenho sem tirar o lápis no papel. 
Os próximos problemas poderiam também ser propostos aos alunos para abordar outros conceitos dentro da teoria de grafos,como os subgrafos, grafos planares, árvores geradoras e etc.

Problema 8 Um químico deseja transportar os produtos $A, B, C, D, E, F, H$ usando o menor número de caixas. Alguns produtos não podem ser colocados numa mesma caixa porque reagem. Os produtos $A, B, C, H$ reagem dois-a-dois; $A$ reage com $F$ e com $D$ e vice-versa; $E$ também reage com $F$ e com $D$ e viceversa. Qual seria o menor número de caixas necessárias para transportar os produtos com segurança?

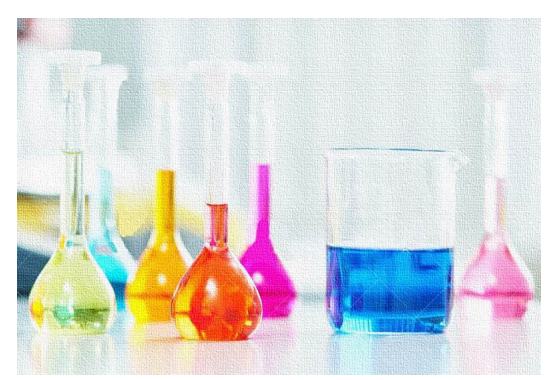

Figura 4.14: Os 7 produtos químicos para serem transportados.

Veja que como alguns produtos reagem entre si não podem ser transportados na mesma caixa e deve-se ter cuidado em relação a isso. Para tentar solucionar esse problema, vamos fazer associações que remodela-lo para a teoria de grafos.

Nesse caso, faremos o grafo $G$ onde:

Vértices: Os produtos.

Arestas: As reações entre dois produtos.

Com isso, teremos a seguinte representação do grafo $G$ na imagem 4.15.

Assim, o problema consiste em criar subgrafos totalmente desconexos do $G$, onde os vértices não sejam adjacentes (os produtos não reagem entre si). Claro que poderíamos fazer isso criando 7 subgrafos de $G$ contendo apenas um vértice, mas não iria resolver a questão de utilizar o mínimo de caixas possível.

Observe que os vértices $A, B, C$ e $H$ são adjacentes entre si, logo não podem estar no mesmo subgrafo. Portanto precisamos de pelo menos 4 subgrafos contendo cada um deles e mais algum outro vértice não adjacente.

Podem formar os subgrafos $S_{1}$ com os vértices $A$ e $E, S_{2}$ com os vértices $B$ e $F, S_{3}$ com os vértices $C$ e $D$, e $S_{4}$ com o vértice $H$, como mostra a figura 4.16 . 


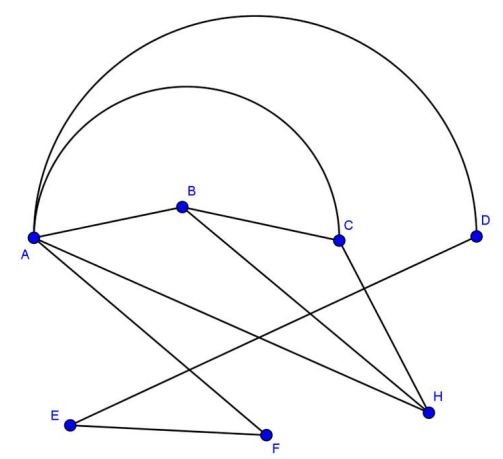

Figura 4.15: Grafo das reações químicas entre os 7 produtos.

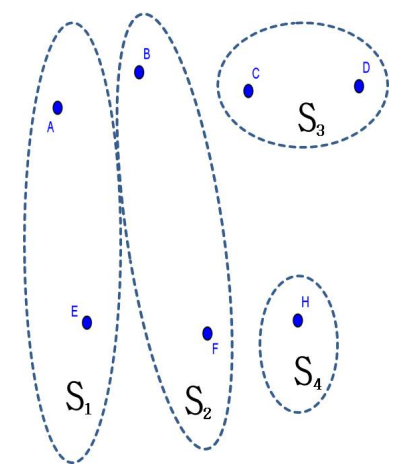

Figura 4.16: O subgrafos formados.

Claro que poderiam ser criados outros subgrafos que resolvessem o problema, mas eles seriam no mínimo quatro, visto que os vértices $A, B, C$ e $H$ são vizinhos.

Logo o menor número de caixas necessárias para transportar os 7 produtos com segurança seria 4 caixas

Problema 9 Era uma vez um reino muito distante. Nesse reino havia exatamente 100 cidades e em cada uma delas ficava o início ou o fim de exatamente quatro estradas do reino. Quantas estradas existiam ao todo no reino, sabendo que não existem estradas que começam e terminam na mesma cidade?

Interpretando os elementos do problema em termos de grafos, teríamos:

Vértices: São cada uma das 100 cidades.

Arestas: São as estradas entre duas cidades.

Assim o questionamento passa a ser "Quantas arestas possui o grafo?"

Desenhar esse grafo e contar o número de arestas desejada seria obviamente cansativo e confuso. 
Então vamos chamar de $v_{1}$ o vértice referente à cidade $1, v_{2}$ o vértice referente à cidade $2, v_{3}$ o vértice referente à cidade 3 , e assim por diante, até chegarmos na cidade 100, que chamaremos de $v_{100}$.

Entretanto nos foi passada pelo problema a informação de que em cada cidade está o começo ou o fim de exatamente 4 estradas. Isso significa que o grau de cada vértice do problema é igual a 4 , ou seja, $g(v)=4$ para todo vértice $v$ do grafo.

Lema do Aperto de Mão: Para todo grafo (não orientado), a soma dos graus de seus vértices é duas vezes o número de suas arestas. Em outras palavras:

$$
\sum_{v \in G} g(v)=2 \cdot n(A)
$$

Com isso temos que $n(A)$ é a quantidade de estradas do reino que queremos descobrir, então vamos associar $n(A)=x$. Logo, pelo lema do aperto de mão:

$$
g\left(v_{1}\right)+g\left(v_{2}\right)+\ldots+g\left(v_{100}\right)=2 \cdot x
$$

Portanto, basta resolver a equação acima e solucionar o problema:

$$
\begin{gathered}
\underbrace{4+4+\ldots 4}_{100 \text { vezes }}=2 \cdot x \\
400=2 x \\
x=\frac{400}{2} \\
x=200
\end{gathered}
$$

Portando $n(A)=200$.

E assim concluímos que no reino existem 200 estradas.

Problema 10 Em uma sala de aula há 30 alunos. Seria possivel que, considerando só as relações de amizade recíprocas na turma, sete tenham 3 amigos cada, nove tenham 4 amigos e quatorze tenham 5 amigos?

Dando uma interpretação gráfica ao problema:

Vértice: São os alunos da sala.

Arestas: São as amizades entre dois alunos 
Portanto, quando o problema diz "...sete tenham 3 amigos cada, nove tenham 4 amigos e quatorze tenham 5 amigos?", interpretamos isso como: 7 vértices tem grau 3 cada, 9 vértice tem grau 4 e 14 tem grau 5.

Reformulando a questão em termos de grafos: "É possível que num grafo de 30 vértices existam: 7 vértices com grau 3 cada; 9 vértices com grau 4; e 14 vértices com grau 5?"

Para nos ajudar a responder essa questão vamos utilizar a seguinte consequência fácil do lema do aperto de mão:

Corolário: Todo grafo G (não orientado) contém um número par de vértice de grau ímpar.'

No problema, temos 21 vértices de grau ímpar (7 vértices de grau 3 e 14 grau 5).

Portanto, teríamos um número ímpar de vértices de grau ímpar. Pelo resultado que acabamos de apresentar, não existe tal grafo.

Logo não é possível que nessa sala de aula exista uma tal distribuição de amizades.

Agora, se em vez de "...sete tenham 3 amigos cada, nove tenham 4 amigos e quatorze tenham 5 amigos?" tivéssemos "... seis tenham 3 amigos cada, doze tenham 4 amigos e doze tenham 5 amigos? " ?, Seriam possíveis essas relações de amizade?

Nesse caso, teríamos 18(6 de grau 3 e 12 de grau 5) vértices de grau ímpar, o que não estaria em desacordo com o corolário acima. Mas isso não prova que tal grafo exista. Entretanto, a figura 4.17 prova.

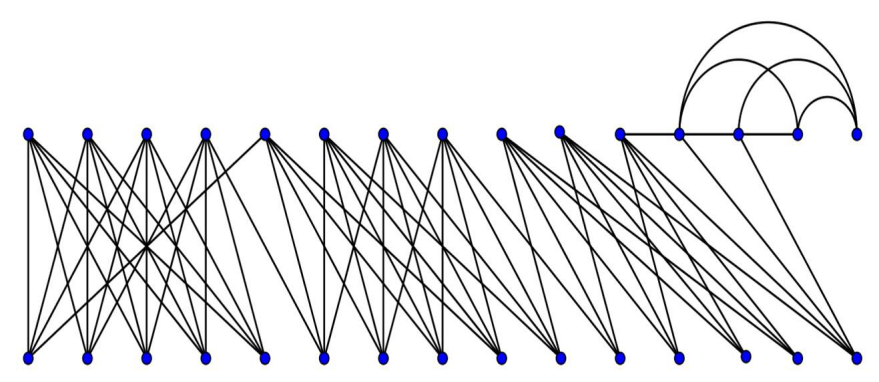

Figura 4.17: Grafo das relações de amizades. 
Problema 11 Chico e sua esposa foram a uma festa com outros três casais. No encontro, houve vários apertos de mão. Ninguém apertou a própria mão (claro!) ou a mão da(o) própria(o) esposa(o), e ninguém apertou a mão da mesma pessoa mais que uma vez.

Após os cumprimentos, Chico perguntou a todos, inclusive à sua esposa, quantas mãos cada um apertou, e recebeu de cada pessoa uma resposta diferente. Com base nessas informações podemos determinar:

(i) Quantas mãos Chico apertou?

(ii) Quantas mãos a esposa de Chico apertou?

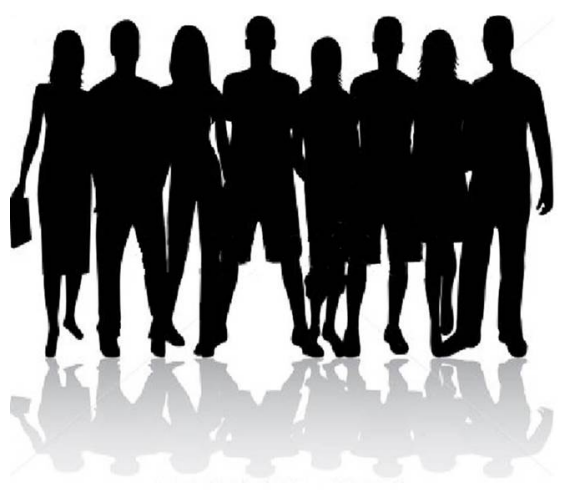

Figura 4.18: Os 4 casais do problema.

A informação de que dispomos pode parecer, à primeira vista, insuficiente para responder às questões colocadas.

Que tal remodelarmos o problema em termos de grafos?

Onde no grafo $G$ :

Vértices: As pessoas na festa.

Arestas: Os "apertos" de mãos entre as pessoas na festa.

Note que, não podemos representar imediatamente o grafo, pois não sabemos quais arestas estão associadas a quais vértices. Até porque, se soubéssemos, já teríamos resolvido o problema.

$\mathrm{Na}$ verdade, o problema se transforma em saber:

(i) Qual grau do vértice que representa Chico?

(ii) Qual o grau do vértice que representa a esposa de Chico?

Podemos tirar do problema algumas informações para resolve-lo: 
1. "Ninguém apertou a própria mão ... e ninguém apertou a mão da mesma pessoa mais que uma vez." : Isso significa que esse grafo não tem laços e nem arestas paralelas, ou seja, trata-se de um grafo simples.

2. "Ninguém apertou a própria mão ou a mão da(o) esposa(o)": Isso significa que o grau do vértice de cada um é máximo 6, excluindo no caso a relação a si próprio e ao seu cônjuge.

3. "Chico perguntou para todos, inclusive para a esposa, quantas mãos cada um apertou e recebeu de cada pessoa uma resposta diferente.": Com isso temos que os graus dos outros vértices (diferentes do vértice de Chico) são: $0,1,2,3,4,5,6$.

Pelo item 3., temos 3 vértices com grau ímpar. Pelo corolário visto anteriormente, devemos ter um número par de vértices de grau ímpar. Com isso, podemos concluir que o grau do vértice que representa Chico é ímpar(1,3 ou 5).

Vamos agora começar a montar a representação do grafo $G$, colocando apenas os vértices como mostra a figura 4.19 e acrescentando as arestas de acordo com as informações do problema.
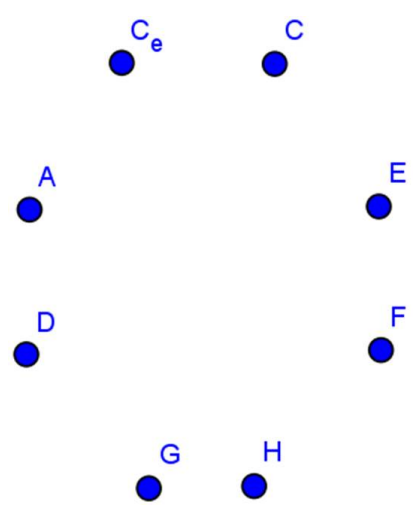

Figura 4.19: Representação parcial no grafo $G$ do problema.

O vértice $C$ representa o Chico, $C_{e}$ representa a esposa do Chico, e $A$ e $D, G$ e $H, E$ e $F$, os demais casais.

Primeiro vamos escolher um vértice aleatório para ter grau 6, e consequentemente, seu cônjuge terá grau 0 (já que cônjuges não realizaram apertos de mãos). Nem $C$ e nem $C_{e}$ poderiam ser tais vértices escolhidos, pois sabemos que o grau de $C$ é ímpar.

Então faremos o vértice $A$ ligado a todos os vértices, e portanto $D$ sem aresta como mostra a imagem 4.20. Assim, eliminamos os graus 0 e 6 .

Agora vamos escolher um outro vértice para grau 5, que irá ligar-se aos demais vértices, menos os vértices $A, D$ e o do seu cônjuge (o vértice $H$ ). 


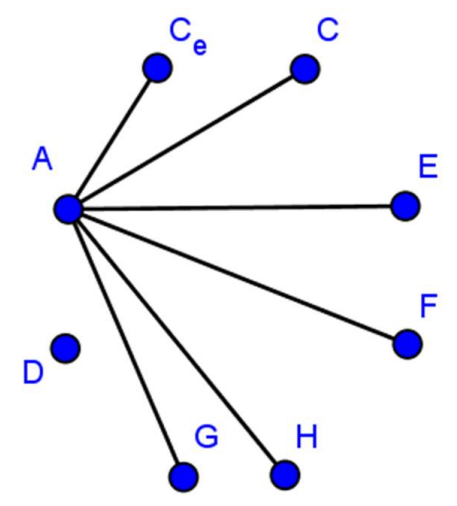

Figura 4.20: Representação parcial no grafo $G$ do problema: Primeiro casal relacionado $\rightarrow A$ e $D$.

Ligaremos então o vértice $G$ a quatro outros vértices, fazendo assim $g(G)=5$. Observe que, consequentemente, $g(H)=1$, pois os demais vértices passaram a ter no mínimo grau 2, como visto na figura 4.21 .

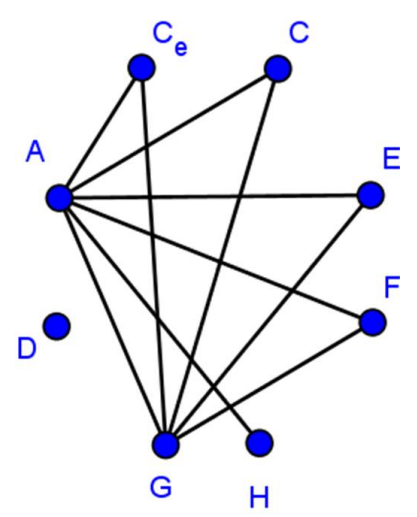

Figura 4.21: Representação parcial no grafo $G$ do problema: Segundo casal relacionado $\rightarrow G$ e $H$.

Por fim, colocaremos $E$ com grau 4, relacionando-se a mais apenas $C$ e $C_{e}$, e portanto $F$ (o cônjuge de $E$ ) terá grau 2. Com isso concluimos a representação do grafo $G$, já que eliminamos todos os possíveis graus dos vértices, como mostra a figura 4.22 . 


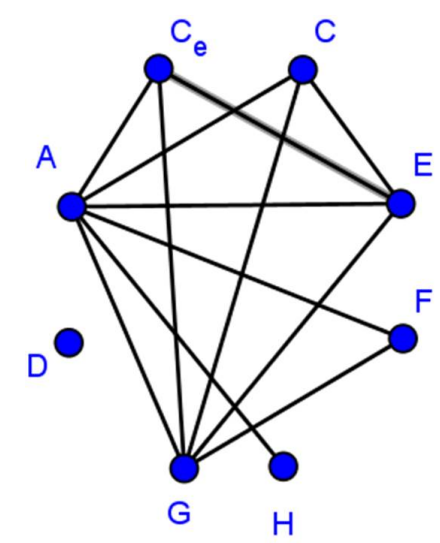

Figura 4.22: Representação final do grafo $G$ do problema.

Agora podemos concluir que $g(C)=3$ e $g\left(C_{e}\right)=3$.

Portanto Chico e sua esposa apertaram 3 mãos cada um.

Será que foi uma coincidência que o Sr. Chico e a esposa tenham apertado a mesma quantidade de mãos? Não, pois existe um famoso resultado que diz que, num momento qualquer de uma festa qualquer, sempre vão existir duas pessoas que apertaram o mesmo número de mãos. A prova deste resultado é simples: seja $n$ o número de pessoas na festa. Uma pessoa pode apertar, no máximo, $n-1$ mãos e, no mínimo, nenhuma. Se num dado momento houver $k$ indivíduos que ainda não cumprimentaram ninguém, o número máximo de apertos de mão que alguém pode ter dado será $n-k-1$. Excetuando esses indivíduos que não cumprimentaram ninguém, sobram $n-k$ pessoas, que terão que ser distribuídas entre os $n-k-1$ números possíveis de apertos de mão $1,2, \cdots, n-k-1$. Pelo Princípio da Casa de Pombos, duas delas terão dado o mesmo número de apertos de mão. Note que podemos tomar $k=0$, obtendo o mesmo resultado.

Problema 12 (Tipos Sanguíneo) $O$ sangue humano é classificado de acordo com o grupo $A B O$ ( $A, B, A B$ e O) e o fator Rh(positivo e negativo). A compatibilidade entre os vários tipos de sangue humano tem a ver com antígenos e anticorpos. As pessoas que são do grupo $A$ têm o Antígeno $A$ e o anticorpo anti- $B$ em suas hemácias; as que são do grupo $B$ têm o antígeno $B$ e o anticorpo anti- $A$; as que são do grupo $A B$ têm antígenos $A$ e $B$ e não possuem anticorpos nem anti- $A$ e nem anti- $B$; e as que são do grupo $O$ não possuem antígeno e apresentam ambos anticorpos anti- $A$ e anti-B. Assim, as pessoas que possuem um determinado anticorpo em seu sangue não podem receber sangue com antígeno de mesmo tipo. Por exemplo, uma pessoa do grupo $A$, não pode receber sangue do tipo $B$ pois ela possui anticorpos anti- $B$, o que poderia causar um grave problema em seu sistema imunológico. 
A mesma ideia está relacionada ao fator $R$ h que determina a presença do antígeno $D$. As pessoas que têm fator Rh positivo possuem o antígeno $D$, e as que tem fator Rh negativo não o possuem. As pessoas com $R h^{+}$só podem doar para quem for $R h^{+}$, enquanto quem for $R h^{-}$pode doar para $R h^{+} e R h^{-}$.

Com base nessas informações, determinar qual o tipo sanguíneo que mais pode doar e o tipo que mais pode receber.

Com base nas informações do texto temos que existem oito tipo sanguíneos, que são : $A^{+}, A^{-}, B^{+}, B^{-}, A B^{+}, A B^{-}, O^{+}$e $O^{-}$. Assim, modelando o problema em termos de grafos temos:

Vértices: São os tipos sanguíneos.

Arestas: É a relação de um tipo sanguíneo poder doar para o outro, ou seja, uma aresta $a b$ siginifica que a pode doar para $b$.

Observe que neste contexto uma aresta $a b$ não necessariamente é igual à aresta $b a$. Portanto, estamos trabalhando com arestas orientadas, e, consequentemente, o grafo do problema será um digrafo. Portanto o nosso questionamento é: "Qual é o vértice com maior grau de saída e qual é o vértice com o maior grau de entrada?"

Vamos começar a montar o digrafo $G$ do problema, colocando todos os vértices e os laços orientados, pois cada tipo sanguíneo pode sempre doar para si próprio como vemos na figura 4.23 .

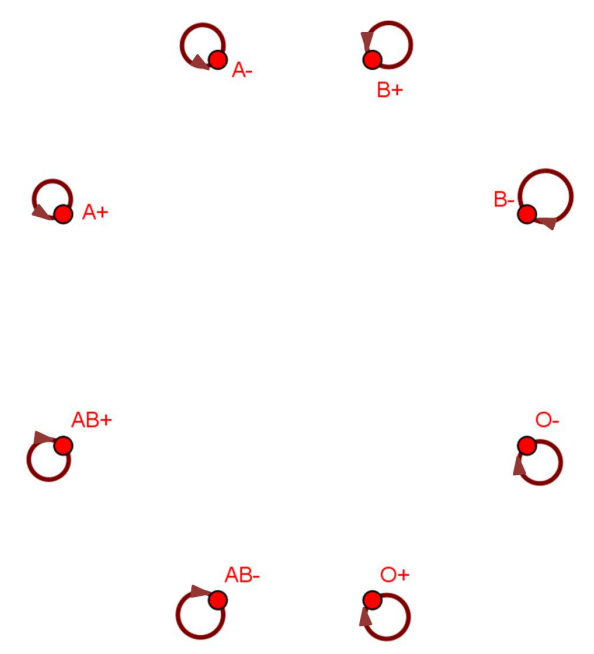

Figura 4.23: Representação inicial do digrafo $G$ do problema.

Acrescentamos as demais arestas tomando os devidos cuidados mencionados no problema, podemos visualizar a representação geométrica final do 


\begin{tabular}{|c||c||c|}
\hline$v$ & $g^{-}(v)$ & $g^{+}(v)$ \\
\hline$A^{+}$ & 4 & 2 \\
$A^{-}$ & 2 & 4 \\
$B^{+}$ & 4 & 2 \\
$B^{-}$ & 2 & 4 \\
$A B^{+}$ & 8 & 1 \\
$A B^{-}$ & 4 & 2 \\
$O^{+}$ & 2 & 4 \\
$O^{-}$ & 1 & 8 \\
\hline
\end{tabular}

Tabela 4.1: Tabela com os graus dos tipos sanguíneos.

digrafo na figura 4.24 .

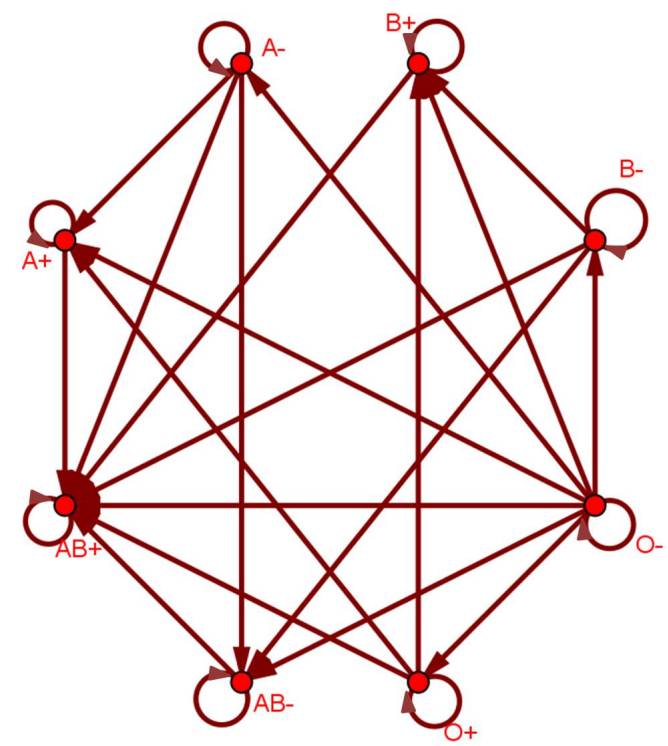

Figura 4.24: Representação final do digrafo $G$ do problema.

Assim, analisando o digrafo podemos construir a tabela 4.1.

Logo, o vértice que possui o maior grau de entrada é $A B^{+}$, pois $g^{-}\left(A B^{+}\right)=8$, e o vértice que possui o maior grau de saída é $O^{-}$, pois $g^{+}\left(\mathrm{O}^{-}\right)=8$.

Portanto, o tipo sanguíneo que mais pode doar é $O^{-}$e o tipo que mais pode receber é $A B^{+}$. Por isso, portadores do sangue $O^{-}$são chamados doadores universais, ao passo que portadores do tipo $A B^{+}$são chamados receptores universais.

Problema 13 (Três vizinhos que se odeiam) Em uma vila tem 3 praças e três vizinhos que se odeiam. Esses vizinhos não podem se cruzar durante o caminho a qualquer uma das praças, pois caso isso aconteça sempre haverá 
uma briga entre eles. É possível criar caminhos para cada uma das três praças a partir de cada casa sem que esses caminhos se cruzem?

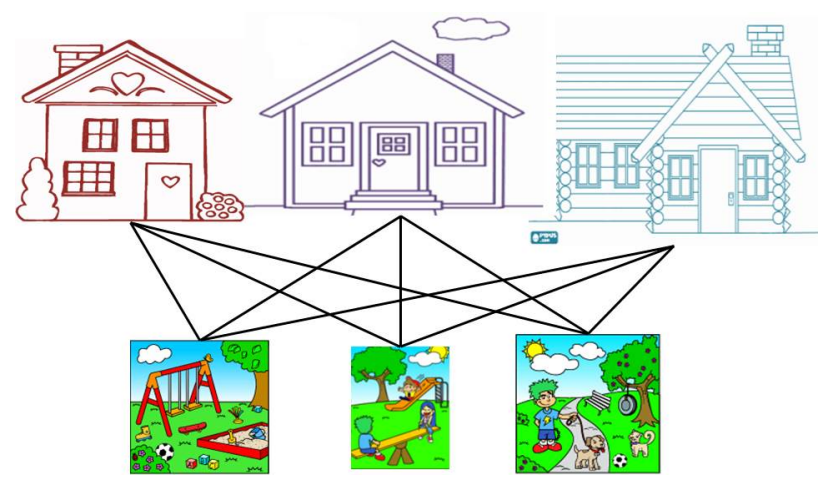

Figura 4.25: Problemas dos 3 vizinhos.

Vamos lá, esse tipo de questionamento pode ser transformado para a teoria de grafo, utilizando a seguinte associação:

Vértices: São as praças e as casas dos vizinhos.

Arestas: São as ligações entre as praças e as casas dos vizinhos.

Logo, podemos representar o grafo do problema através da figura 4.26.

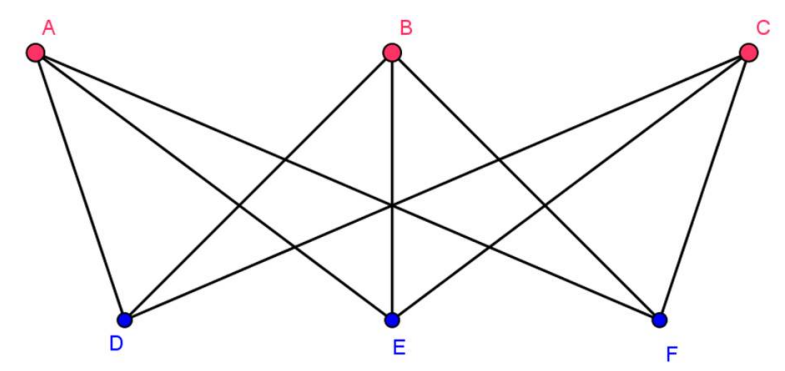

Figura 4.26: Grafo problemas dos 3 vizinhos.

Observe que o grafo formado trata-se do grafo bipartido completo $K_{3,3}$, onde o conjunto $V_{1}=\{A, B, C\}$ de vértices representa a casa dos vizinhos e o conjunto $V_{2}=\{D, E, F\}$ representa as praças.

Na verdade o problema se resume em verificar se existe uma representação planar para o grafo do problema.

A representação inicial que demos claramente não é planar, pois existem vários cruzamentos entre as arestas. Mas podemos tentar outras.

Na figura 4.27 temos uma segunda representação geométrica do grafo do problema em questão, porém ainda aparece um cruzamento entre as arestas $A F$ e $E B$. 


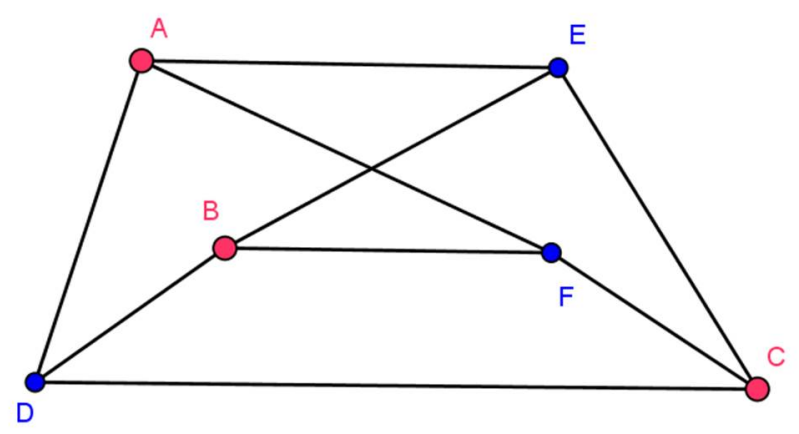

Figura 4.27: Segunda representação geométrica do grafo do problemas dos 3 vizinhos.

Poderíamos continuar fazendo outras tentativas. Entretanto, existe um resultado de Topologia que pode nos ajudar a resolver esse problema de uma forma mais rápida. Vejamos:

Teorema da Curva de Jordan: Uma curva plana fechada conexa e simples (i.e., sem auto-interseções) $C \subset \mathbb{R}^{2}$ divide o plano cartesiano $\mathbb{R}^{2}$ em duas componentes conexas: uma limitada, chamada o interior de $C$; e uma ilimitada, chamada exterior de $C$.

Em outras palavras:

$$
\mathbb{R}^{2}=\operatorname{Int}(C) \sqcup C \sqcup \operatorname{Ext}(C)
$$

É uma consequência imediata do Teorema da Curva de Jordan que, se $x \in \operatorname{Int}(C)$ e $y \in \operatorname{Ext}(C)$, então toda curva contínua ligando $x$ a $y$ deve cortar a curva $C$ em algum ponto (admitindo que esta satisfaça as hipóteses do teorema). (7)

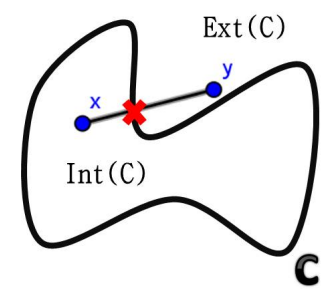

Figura 4.28: Temos a curva $C$ e $x \in \operatorname{Int}(C)$ e $y \in \operatorname{Ext}(C)$.

Fazemos a ressalva de que este é um resultado intuitivo, e não deveria ser apresentado aos estudantes secundaristas como um teorema, mas mencionado como um fato da vida, sem maiores explicações.

De posse dessas informações, os alunos poderiam ser convidados a se debruçar novamente sobre o problema. Ao fim da atividade, o professor poderia apresentar a seguinte solução (negativa). 
Observe na figura 4.29 que 4 arestas formam uma curva fechada $C$ que divide o plano em duas regiões $\operatorname{Int}(C)=R_{1}$ e $\operatorname{Ext}(C)=R_{2}$.

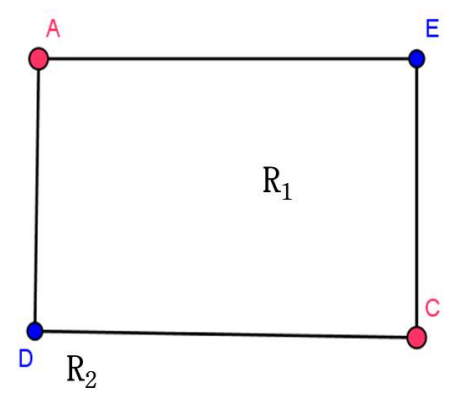

Figura 4.29: A curva $C$ é o Ciclo AECD.

$\mathrm{O}$ vértice $B$ pode ser colocado tanto na região $R_{1}$ quanto na região $R_{2}$ que não ocorreria problema para alcançarmos nosso objetivo.

Então, sem perda de generalidade, vamos desenhá-lo na região $R_{1}$ e acrescentamos suas arestas relacionadas aos demais vértices obrigatórios. Assim as arestas $B D$ e $B E$ dividem a região $R_{1}$ em duas outras regiões $R_{11}$ e $R_{12}$ como podemos ver na figura 4.30 .

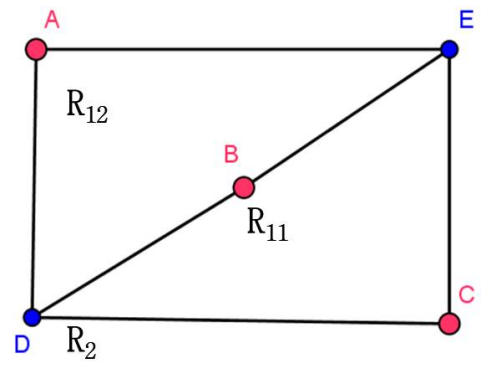

Figura 4.30: Regiões $R_{2}, R_{11}$ e $R_{12}$.

Para finalizar, basta desenhar o vértice $F$ e suas arestas de forma que não corte nenhuma das arestas já desenhadas. Vamos tentar colocar $F$ em cada uma das regiões $R_{11}, R_{12}$ ou $R_{2}$.

Vamos tentar colocar na região $R_{11}$.

Como o vértice $C$ não pertence a região $R_{11}$ (está exterior a curva $A E B D$ ) e $F$ pertence a região $R_{11}$ (está interior a curva $A E B D$ ), então temos que qualquer curva $F C$ corta a curva $A E B D$ em algum ponto, veja na imagem 4.31 .

Analogamente, colocando $F$ na região $R_{12}$ ou $R_{2}$, sempre haverá um cruzamento entre duas arestas do grafo. Portanto, o grafo não é planar.

Logo, não é possível criar caminhos para cada uma das famílias irem a qualquer uma das três praças sem que esses caminhos se cruzem em algum ponto. 


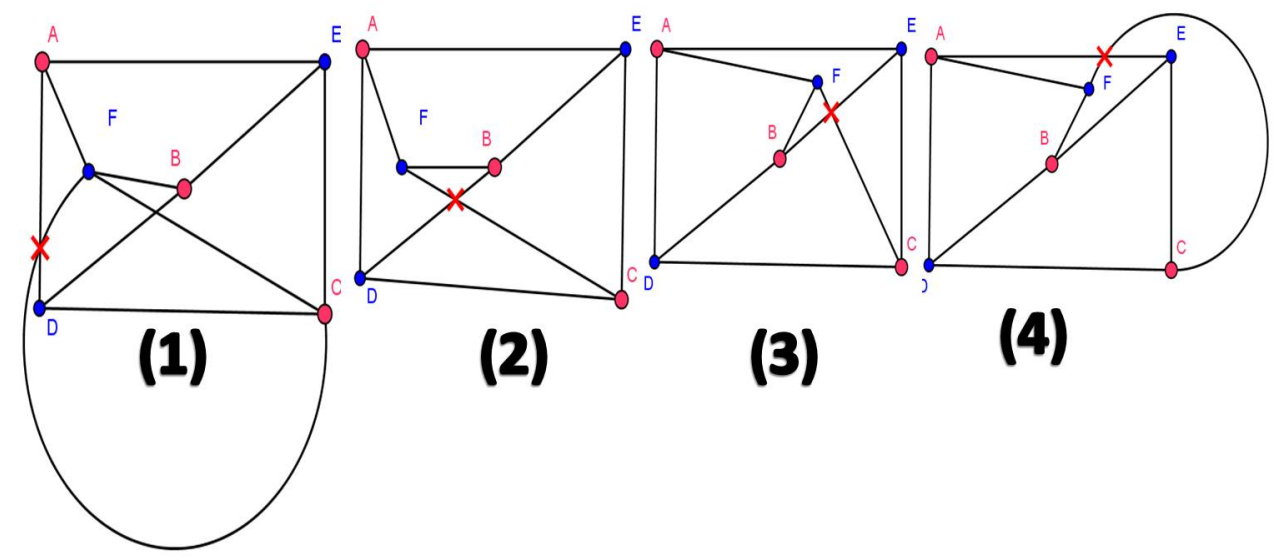

Figura 4.31: Na figura (1) corta a aresta $A D$, em (2) corta $B D$, em (3) corta $B E$ e em (4) corta $A E$.

Note que o problema análogo com duas praças e três casas já foi resolvido (positivamente) (Figura 4.32).

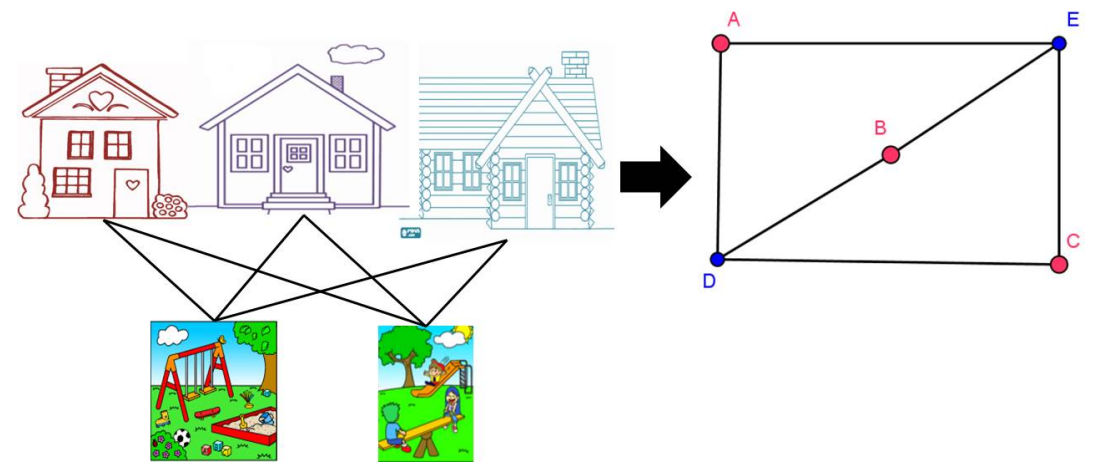

Figura 4.32: Problemas dos 3 vizinhos modificado.

Problema 14 (Condomínio) Em um condomínio fechado, será montado uma rede de internet para uso de wi-fi dos moradores. Para que isso ocorra serão instaladas cinco torres em posições distintas, onde cada uma será conectada com as outras 4 através de cabo resistente. O problema é que esses cabos não podem se encostar pois acaba interrompendo a transmissão da internet. É possivel colocar os cabos sem que haja interrupção?

Uma das aplicações mais utilizados de teoria de grafos é a que está relacionada rede de computadores. Assim remodelando o problema para a grafos podemos considerar:

Vértices: As torres de transmissão.

Arestas: Os cabos. 


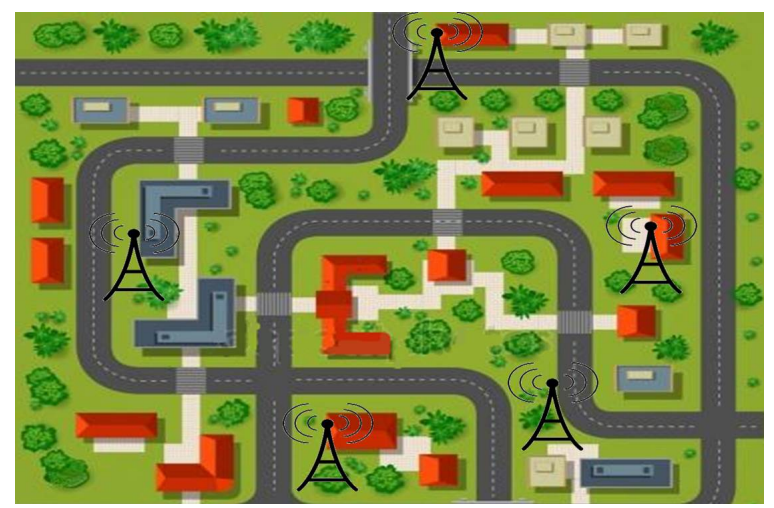

Figura 4.33: Condimínio e as 5 torres.

Assim, uma representação para o grafo do problema pode ser observada através da figura 4.34, que nada mais é que o grafo $K_{5}$.

Observe que o problema está em descobrirmos se o grafo gerado é uma grafo planar.

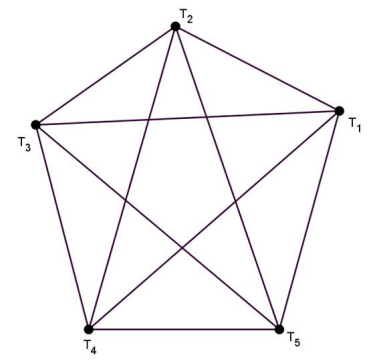

Figura 4.34: Uma representação gráfica do Grafo das cinco Torres.

Agora vamos tentar construir representação planar desse grafo. Inicialmente vamos construir o ciclo $T_{1} T_{2} T_{3} T_{4} T_{5}$, como mostra a figura 4.35.

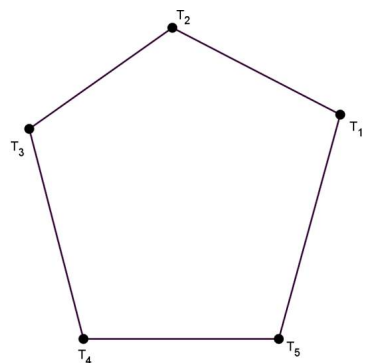

Figura 4.35: Desenhando o ciclo. 
Agora vamos acrescentar as arestas $T_{3} T_{1}$ e $T_{3} T_{5}$. E depois quando vamos acrescentar as arestas $T_{4} T_{1}$ e $T_{4} T_{2}$, podemos observar que é necessário desenhalás externamente ao ciclo $T_{1} T_{2} T_{3} T_{4} T_{5}$, pois caso contrário iria cruzar com as arestas $T_{3} T_{1}$ e $T_{3} T_{5}$ como mostra a figura 4.36 .

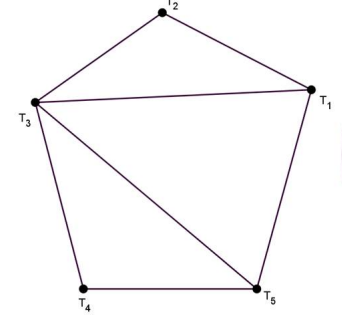

(1)

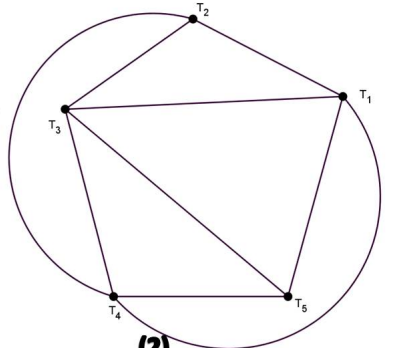

(2)

Figura 4.36: (1):Acrescentando as arestas $T_{3} T_{1}$ e $T_{3} T_{5}$ e (2):Acrescentando as $\operatorname{arestas} T_{4} T_{1}$ e $T_{4} T_{2}$.

Para finalizar a construção do grafo basta acrescentar a aresta $T_{2} T_{5}$. Considerando o ciclo $T_{1} T_{3} T_{4}$, temos que o vértice $T_{5}$ e o vértice $T_{2}$ estão em regiões diferentes. Logo pelo Teorema da Curva de Jordan, temos que qualquer curva que tenha $T_{2}$ e $T_{5}$ como extremos cortará o ciclo $T_{1} T_{3} T_{4}$ em algum ponto, veja a figura 4.37 .

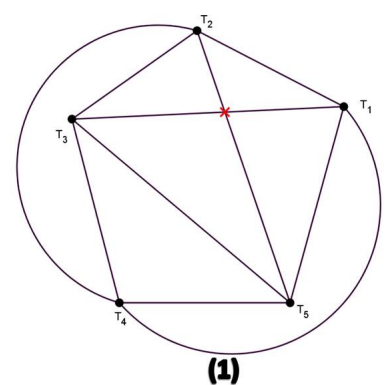

(1)

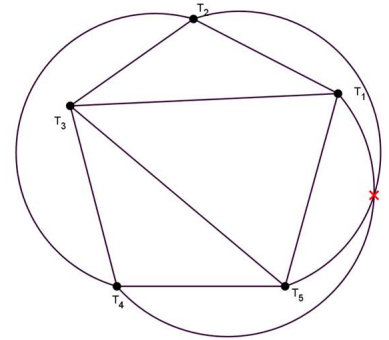

(2)

Figura 4.37: (1):Cortou a arest a $T_{1} T_{3}$ e (2):Cortou a aresta $T_{4} T_{1}$.

Logo o Grafo não é planar. E portanto, não é possível colocar os cabos sem que haja interrupção.

Problema 15 Uma determinada companhia aérea apresentar algumas rotas comerciais entre cidades importantes: Rio de janeiro, São Paulo, Salvador, Belo Horizonte, Brasília, Fortaleza, Curitiba e Manaus. Na tabela 4.2 temos um esquema que mostra distância entre as rotas que a companhia oferece. A companhia deseja voar para todas as cidades, mas usando um conjunto de rotas que minimiza o total de distâncias percorridas. Qual seria um conjunto de rotas desejado? 


\begin{tabular}{|c||c|}
\hline Trajeto & distância \\
\hline Manaus - Brasília & 355 \\
Manaus - Curitiba & 695 \\
Brasília - Belo horizonte & 262 \\
Brasília - Fortaleza & 74 \\
Brasília - São Paulo & 269 \\
São Paulo - Fortaleza & 348 \\
São Paulo - Belo Horizonte & 242 \\
São Paulo - Curitiba & 151 \\
São Paulo - Rio de Janeiro & 83 \\
São Paulo - Salvador & 306 \\
Rio de Janeiro - Salvador & 230 \\
\hline
\end{tabular}

Tabela 4.2: Trajetos e distância da companhia aérea.

Observe que olhando somente pela tabela fica um pouco complicado para conseguir solucionar o problema. Então vamos remodelar para grafo e apresentar uma representação gráfica com o intuito de resolver a questão. Vamos considerar:

Vértices: As cidades.

Arestas: Cada rota entre duas cidades.

Portanto as representação de tal grafo pode ser visualizada através da imagem 4.38.

Observe que o problema em questão dado o grafo 4.38 é apresentar a árvore geradora desse grafo que apresenta as menores distâncias entre as cidades.

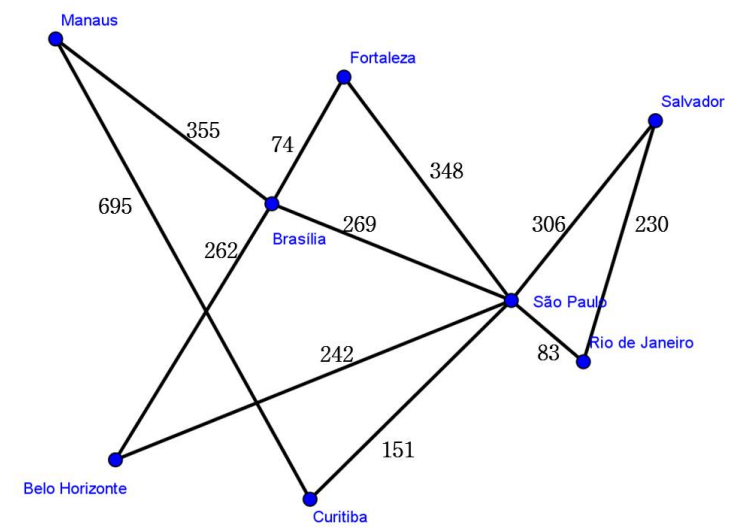

Figura 4.38: Grafo das rotas aéreas. 
Como uma árvore não contém ciclos, iremos eliminar as arestas que formam os ciclos do grafo 4.38 de forma que não torne o grafo desconexo.

Primeiro vamos observar o ciclos Manaus - Brasília - São Paulo - Curitiba e vamos retirar a aresta com a maior distância que seria 695 da aresta Manaus - Curitiba, como mostra a figura 4.39.

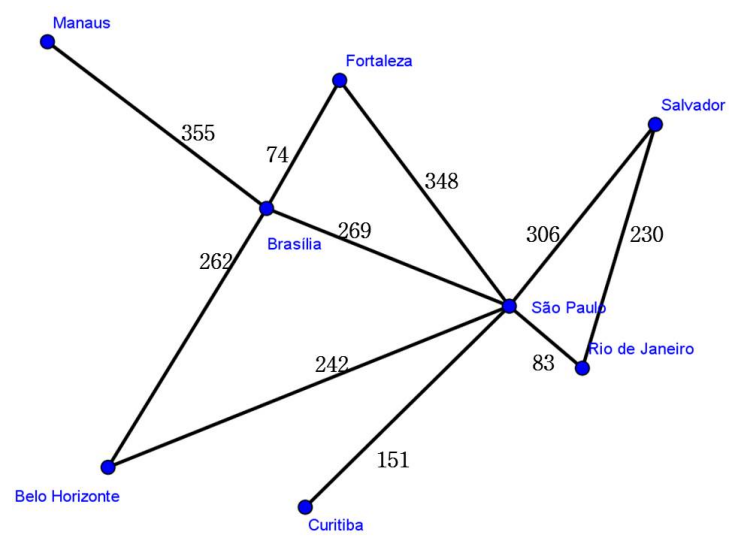

Figura 4.39: Retirando a aresta Manaus - Curitiba.

Utilizando o mesmo raciocínio, iremos eliminar as arestas dos demais ciclos, sempre tomando cuidado para manter o grafo conexo. Faremos isso até chegar na figura 4.40 .

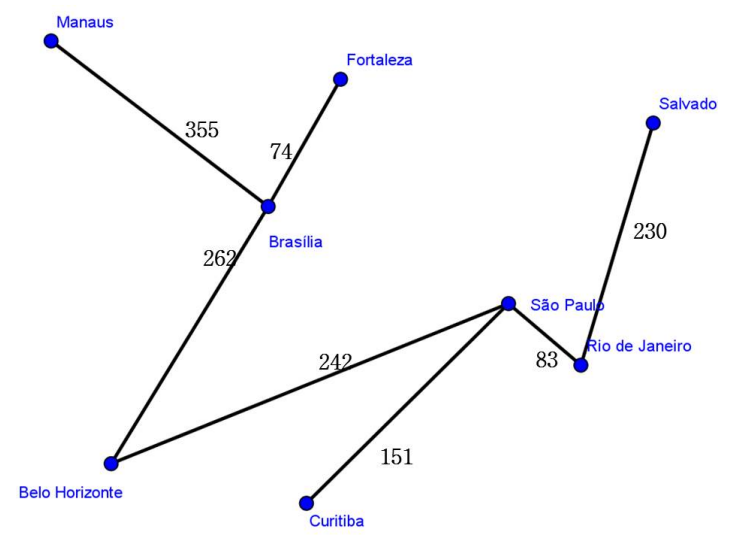

Figura 4.40: Árvore geradora do grafo.

Observe que se retirarmos mais qualquer uma das arestas fará com que o grafo fique desconexo. Logo, encontramos a árvore geradora do grafo.

Portanto o conjunto de rotas conecta todas as cidades pode ser visto na figura 4.40 . 
Uma interessante fonte de aplicações da teoria de grafos a outras áreas das ciências naturais e humanas é o conceito de grafo de intervalos.

\section{Definição 25 (grafo de intervalos)}

Dada uma família indexada $\mathcal{F}=\left\{I_{n}\right\}_{n \in N} \subset \mathcal{P}(\mathbb{R})$ de intervalos abertos da reta dos números reais, com conjunto de índices $N \subset \mathbb{N}$, seu grafo de intervalos $G_{\mathcal{F}}$ associado é formado de acordo com as seguintes regras:

- A cada intervalo $I_{j}$ associa-se um vértice $j$;

- Se $I_{i} \cap I_{j} \neq \emptyset$, então põe-se uma aresta $i j$ entre os vértices $i$ e $j$ correspondentes.

Embora a definição formal acima seja dificilmente compreensível por um estudante secundarista, a noção mesma de grafo intervalo é muito natural e fácil de ser assimilada por meio de exemplos e exercícios, como os que apresentaremos abaixo.

A utilidade dos grafos de intervalos foi descoberta nos anos 1950 pelo físico, bioquímico e geneticista Seymour Benzer (1921-2007), que os empregou para apoiar a hipótese da organização linear da informação genética. Essa organização linear era prevista pelo modelo de hélices para as moléculas de ácidos nucleicos (DNA e RNA), proposto por Francis Crick e James Watson em 1953. Hoje se sabe que a informação genética contida em um cromossomo é totalmente determinada pelas listas ordenadas de bases nitrogenadas nas hélices da mólecula de DNA que ele contém. Os resultados dos experimentos de Benzer vieram ao encontro da proposta de Watson e Crick e ajudaram a consolidá-la.

Na ocasião, Benzer estudava variedades mutantes do vírus bacteriófago T4 obtidas pela deleção de várias partes de seu material genético (cromatina). Ele estava interessado em entender se a informação contida no DNA do vírus em questão encontrava-se organizada linearmente, ou se seriam permitidas ramificações na estrutura fina do material genético.

Os bacteriófagos têm esse nome porque infectam bactérias, inoculando seu material genético nelas e obrigando a maquinaria celular da bactéria hospedeira a replicá-lo. No fim da infecção, a bactéria se rompe liberando milhares de novos bacteriófagos.

Benzer começou a infectar bactérias com exatamente dois vírus mutantes para cada bactéria. Ele observou que em alguns casos a bactéria infectada sobrevivia e conjecturou que isso se devesse ao fato de os trechos de cromatina retirados de ambos os vírus possuírem interseção não-vazia. Nos casos em que 
não havia interseção entre os trechos deletados, o DNA de um vírus fazia o papel da parte faltante no outro, e o processo de infecção seguia seu curso normalmente, levando à morte da bactéria.

Assim, compilando os resultados de um enorme número de experimentos de infecção dupla, ele montou um grafo da seguinte forma:

- a cada variedade de vírus mutante foi atribuído um vértice;

- se a co-infecção por duas variedades não resultava na morte da bactéria, uma aresta entre os vértices correspondentes era incluída. Do contrário, não se colocava aresta.

A partir da análise dos dados obtidos, Benzer reuniu robustas evidências em favor de uma estrutura linear para a informação genética (ao menos no tipo de vírus estudado), em consonância com as descobertas de Watson e Crick.

A enorme quantidade de informação com a qual ele lidou em seus experimentos nos impede de oferecer aqui um exemplo proveniente desse contexto. Entretanto, grafos de intervalos começaram a ser utilizados para outros fins, por exemplo, na arqueologia, como exemplificaremos mais abaixo nesta seção. Vejamos antes dois exemplos ilustrativos da noção de grafo de intervalos.

Exemplo 13 Grafo de contemporaneidade para alguns matemáticos importantes.

Vamos organizar um grafo de intervalos baseado nas datas de nascimento e falecimento da seguinte lista de alguns importantes matemáticos que viveram entre os séculos XVI e XIX.

\begin{tabular}{|c||c||c|}
\hline Matemático & Nascimento & Falecimento \\
\hline Galileu Galilei & 1564 & 1642 \\
René Descartes & 1596 & 1650 \\
Pierre de Fermat & 1607 & 1665 \\
Christiaan Huygens & 1629 & 1695 \\
Isaac Barrow & 1630 & 1677 \\
Isaac Newton & 1643 & 1727 \\
Gottfried Wilhelm Leibniz & 1646 & 1716 \\
Leonhard Euler & 1707 & 1783 \\
Joseph-Louis Lagrange & 1736 & 1813 \\
Carl Friedrich Gauss & 1777 & 1855 \\
William Rowan Hamilton & 1805 & 1865 \\
\hline
\end{tabular}


Assim podemos criar intervalos que representem o curso da vida de cada um deles, como mostra a figura 4.41. A partir desses intervalos, vamos formar o grafo de intervalos 4.42 desejado.

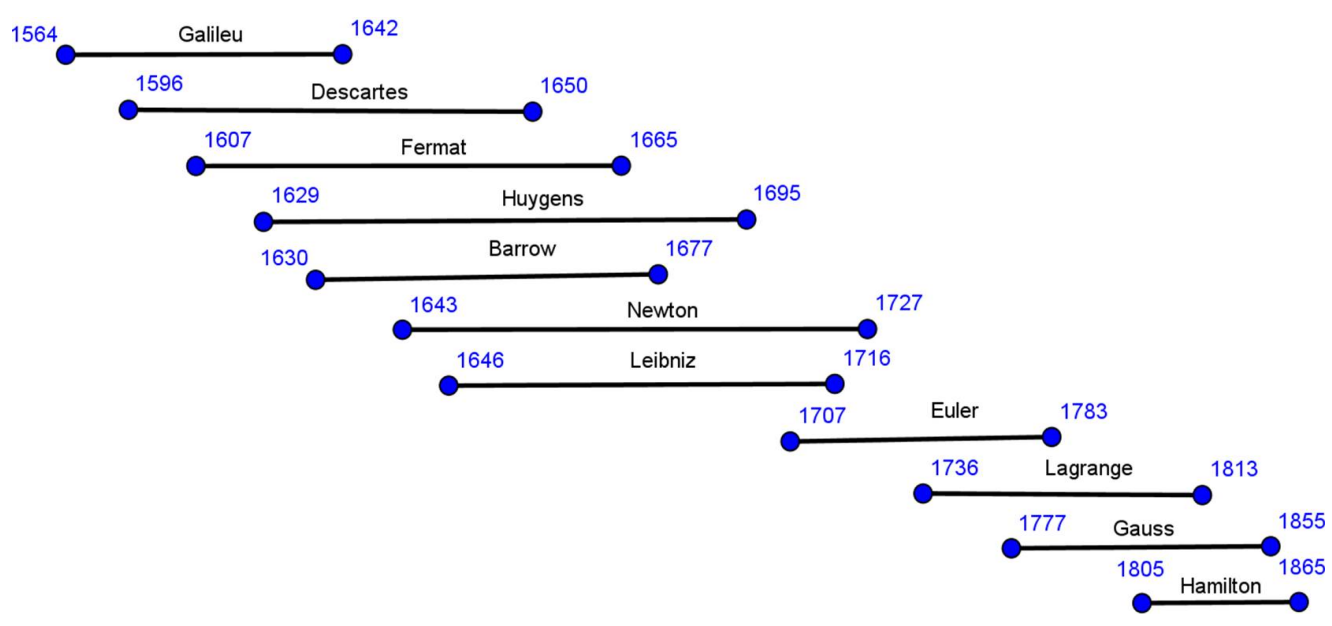

Figura 4.41: Intervalos de vida de alguns matemáticos.

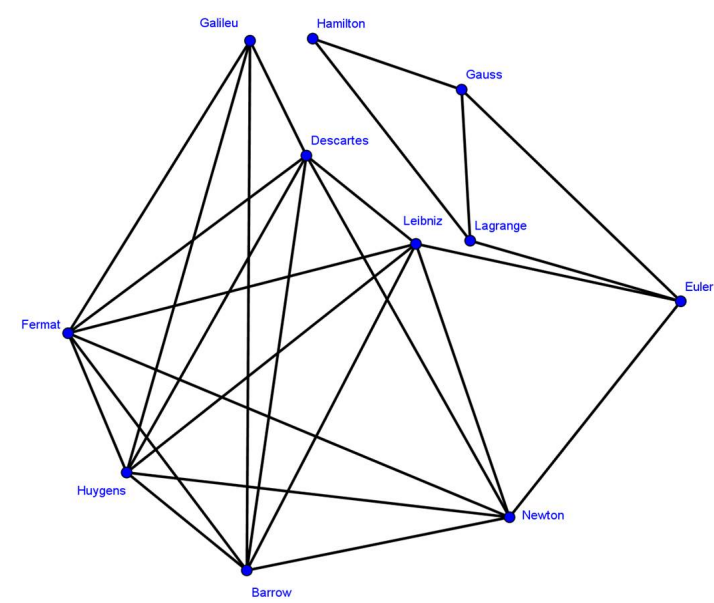

Figura 4.42: grafo de contemporaneidade de alguns matemáticos.

Esse grafo 4.42 representa interações pessoais (meramente) possíveis entre os referidos matemáticos, já que as arestas omitidas representam convivências impossíveis, por se tratarem de pessoas que não viveram na mesma época. Algumas dessas interações possíveis de fato ocorreram. Nem todas foram muito amigáveis.

Será que qualquer grafo pode ser considerado um grafo de intervalos? Ou seja: dado qualquer grafo, existe uma família de intervalos da reta dos números reais que pode ser associado a ele da maneira exposta acima? A resposta é não. Veja o grafo da figura 4.43.

Observe que não seria possível obter os quatro intervalos com as interseções desejadas. O problema seria colocar o intervalo D de forma que tenha 


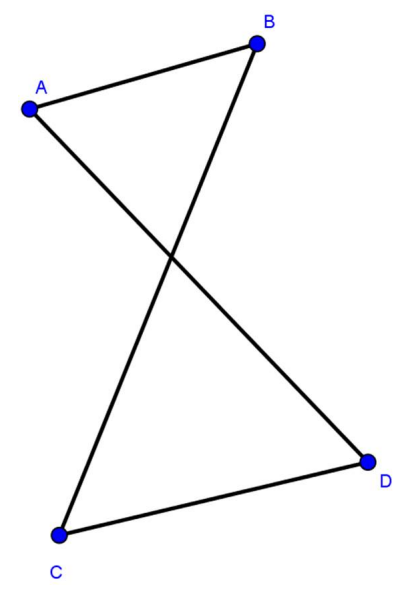

Figura 4.43: Grafo de intervalos?

interseção com A e C e não tenha interseção com B (veja a figura 4.44). Logo, o grafo não é um grafo de intervalos.

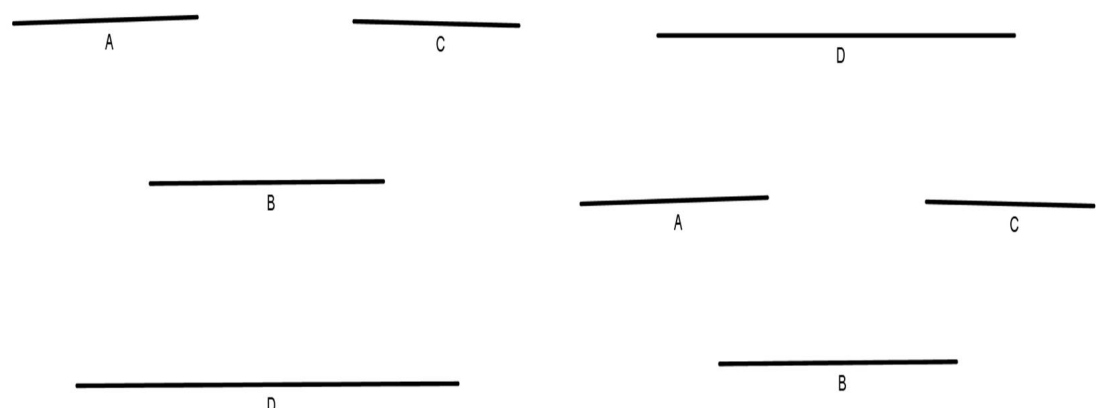

Figura 4.44: Duas tentativas fracassadas de associar quatro intervalos ao grafo 4.43.

Grafos de intervalos têm sido usados extensivamente por arqueólogos tentando organizar cronologicamente certos eventos. No exercício seguinte, vamos imaginar uma situação-brinquedo que poderia ser proposta aos alunos em sala, possivelmente divididos em pequenos grupos.

Problema 16 Um arqueólogo amador investigava os objetos pessoais contidos em seis sarcófagos descobertos em pirâmides egípcias, com o objetivo de colocar essas tumbas em ordem cronológica. Para isso, ele se baseou na hipótese de que dois objetos coexistiram numa mesma época se, se somente se, foram encontrados juntos em algum dos seis sarcófagos considerados. Os objetos encontrados foram: um certo tipo de adaga; um certo tipo de colar; um certo tipo de espelho de bronze; recipientes de kohl (uma pintura para olhos muito utilizada na época). Veja a figura 4.45. Na tabela abaixo, vemos quais objetos foram encontrados em quais sarcófagos. Com base nessas informações, ele concluiu que o objeto mais antigo seria a adaga, seguida do espelho de bronze; depois viria o kohl e o mais recente seria o colar. 


\begin{tabular}{|c||c|}
\hline Sarcófago & Objeto \\
\hline 1 & Adaga \\
2 & Colar e Recipiente de Kohl \\
3 & Espelho de Bronze e Colar \\
4 & Recipiente de Kohl \\
5 & Adaga e Colar \\
6 & Adaga e Espelho de Bronze \\
\hline
\end{tabular}

(a) Encontre a falha no raciocinio dele.

(b) Proponha, baseando-se na hipótese dele, uma ordem cronológica possível para os quatro objetos.

(c) A ordem que você encontrou no item (b) é a única possível?

(d) Discuta com seus colegas e professor(a) qual seria a ordem mais provável, argumentando livremente e, possivelmente, até criticando o método adotado pelo arqueólogo amador.

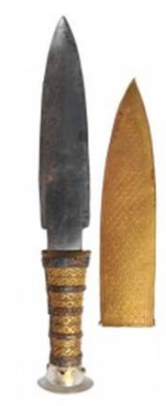

Adaga

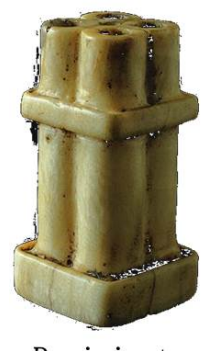

Recipiente de Kohl

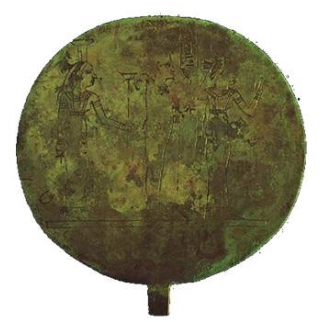

Espelho de bronze

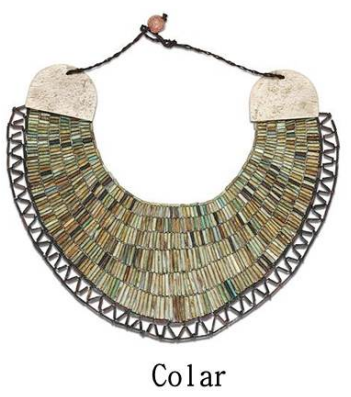

Figura 4.45: Fonte: http://antigoegito.org/visualizando-o-antigo-egito-parte2/. Modificado pela autora.

Evidentemente, o item (d) não será tratado nesta dissertação. Quanto aos itens (a), (b) e (c), podemos responder usando grafos de intervalos.

A ideia é modelar o problema em termos de um grafo, da seguinte forma: 
Vértices: são os objetos.

Arestas: existe uma aresta entre dois vértices se os objetos correspondentes aparecem juntos em um mesmo sarcófago.

Vamos associar a letra $\mathrm{A}$ ao vértice que representa a adaga; $\mathrm{B}$ ao espelho de bronze; C ao colar e D para o recipiente de kohl. Assim, o grafo de intervalos pode ser representado através da figura 4.46 .

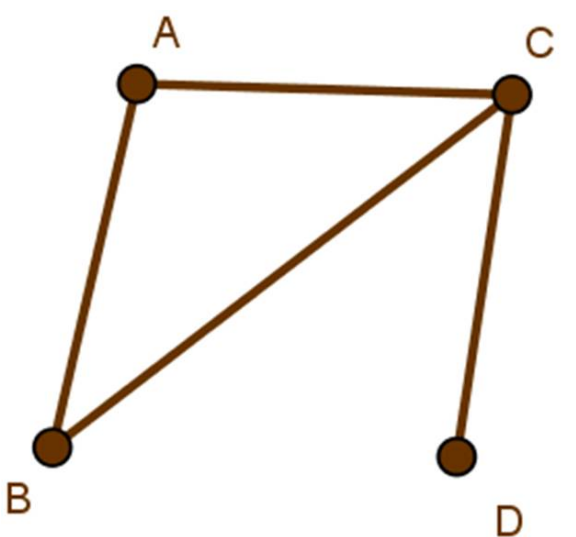

Figura 4.46: grafo de intervalos do problema.

Vamos começar pelo item (b). Para propormos uma ordem cronológica para os objetos, vamos construir os intervalos. Inicialmente (figura 4.47) iremos colocar A, B e C, de forma que, de acordo com o grafo de intervalos, os três se encontrem em algum momento.

A

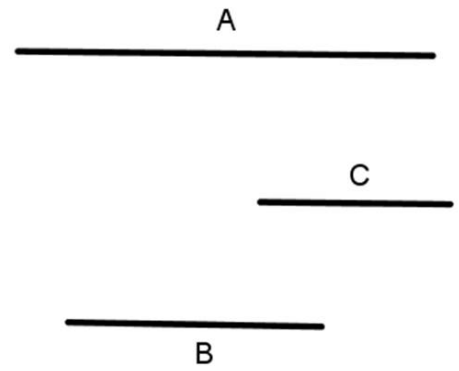

Figura 4.47: Possícvel posição relativa de A, B e C no tempo.

Agora, para acrescentar o $\mathrm{D}$, temos que tomar cuidado para que não encontre nem com A e nem com B, como mostra a figura 4.48. 


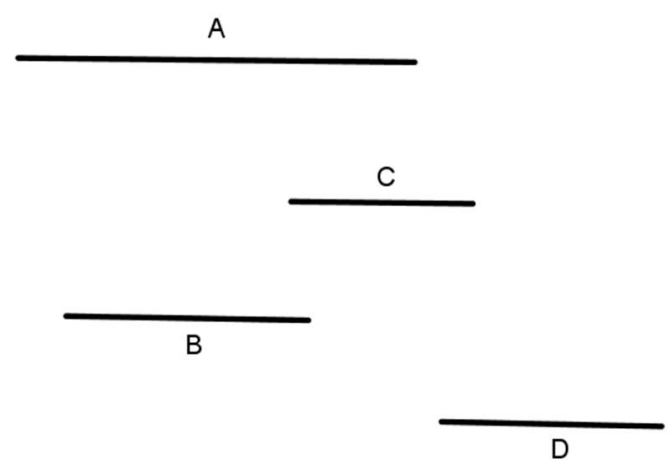

Figura 4.48: Possível ordem.

Logo, uma possível ordem cronológica seria A, B, C e D. Ou, mais precisamente: Adaga, Espelho de bronze, Colar e Recipiente de Kohl.

Agora note que ninguém nos disse onde exatamente deveríamos colocar os extremos dos intervalos. Estendendo os intervalos B ou C para a esquerda, poderíamos ainda gerar a ordem C,A,B,D ou B,A,C,D ou B,C,A,D ou A,C,B, D. Também ninguém nos disse para ler da esquerda para a direita: para cada ordem possível, sua ordem inversa também é possível. Ou seja: D pode ser mais antigo que A! Isso responde ao item (c).

Mas a falha no raciocínio do nosso arqueólogo amador é ainda mais grave: a ordem que ele propôs não é nem sequer possível. As ordens possíveis, como observamos, são obtidas da figura 4.48 por dois processos apenas: extensão para a esquerda dos intervalos B e C; e/ou reversão da ordem. Isso sob pena de criarmos uma interseção $D \cap B$ ou $D \cap A$ inexistente. Isso responde ao item (a). 
Problema 17 (Braced Frameworks) Alguns edifícios, principalmente nos Estados Unidos, são construídos usando estruturas chamadas Braced frameworks como podemos ver na figura 4.49.

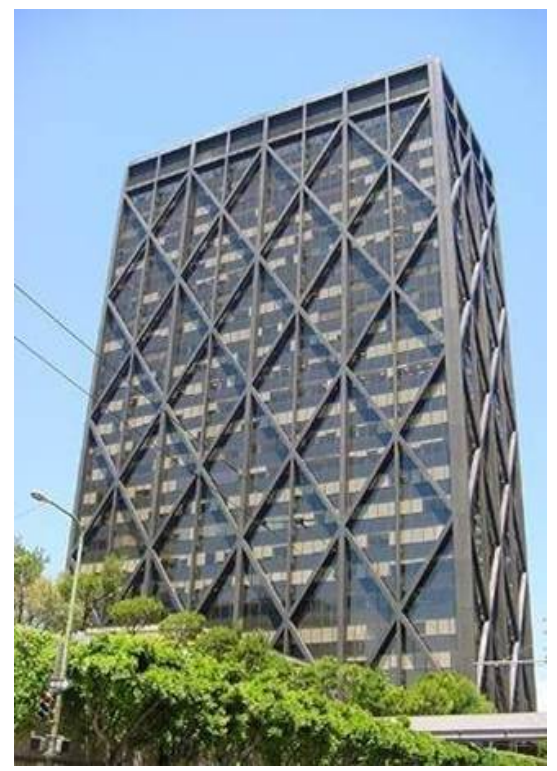

Figura 4.49: Edifício construído utilizando Braced Frameworks. Fonte: https://www.quora.com/What-are-the-advantages-and-disadvantages-ofbraced-building.

Um Braced Frameworks, ou traduzindo estrutura reforçada, é um sistema estrutural que é projetado principalmente para resistir a forças de vento e terremoto. Muitos edifícios são suportados por estruturas de aço retangulares, e é importante que essas estruturas permaneçam rígidas sob cargas pesadas. Para evitar isso, adicionamos aparelhos de proteção diagonais para evitar distorções no plano, como mostrado na figura 4.50(As chaves diagonais podem ir em qualquer direção).

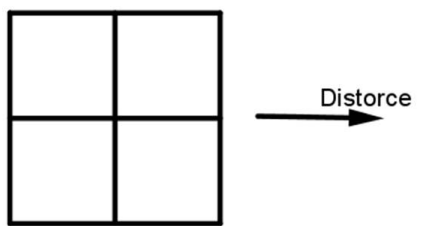

Não Rigido
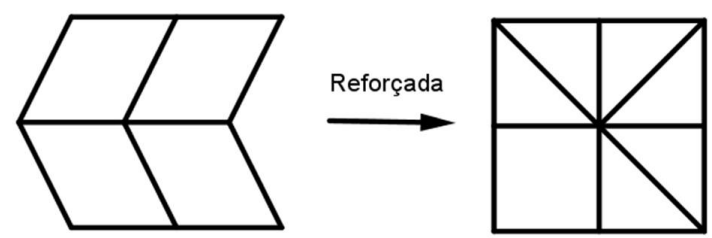

Rigido

Figura 4.50: Acrescentando as Estruturas Diagonais e tornando a estrutura reforçada.

Um grupo de engenheiros foi contratado para elaborar um prédio similar a esses na cidade do Rio de Janeiro. Enquanto estavam elaborando, realizaram três projetos diferentes para a frente do prédio que pode ser visto na figura 4.51. Um engenheiro chefe ficou responsável por fazer uma revisão nesses projetos. 
Após a revisão, ele observou que algum projeto não apresentou estrutura rígida e depois concluiu qual seria o mais vantajoso. Quais dos três projetos apresentam uma estrutura rígida? E qual seria o mais vantajoso?

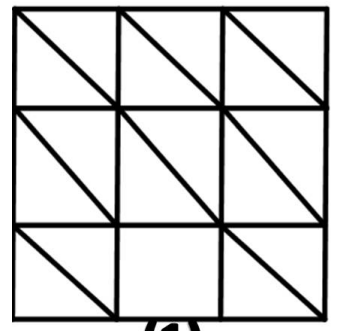

(1)

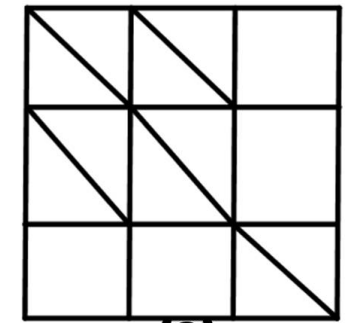

(2)

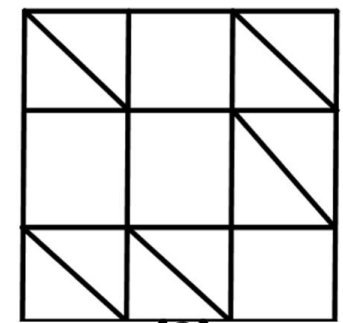

(3)

Figura 4.51: Três projetos apresentados pelos engenheiros.

Para responder esse tipo de questionamento, muitos engenheiros utilizam o estudo de grafo, onde:

Vértices: São as linhas e colunas de cada estrutura.

Arestas: Indicam se existe uma diagonal em uma determinada linha e coluna, ou seja, se juntam a um vértice de linha e um vértice de coluna correspondente.

Para determinar se a estrutura é rígida ou distorcida, utiliza-se o conceito de grafos conexos tomando a modelagem feita acima.Assim:

- Se o grafo for conexo, então a estrutura é rígida.

- Se o gráfico não for conexo, a estrutura pode ser distorcida.

Agora, vamos construir os grafos dos três projetos e tentar responder ao problema.

Observe que todos os grafos formandos pelos três projetos serão grafos bipartidos, pois estamos trabalhando com dois conjuntos de vértices diferentes: o conjunto de $3 \operatorname{linhas}\left(l_{1}, l_{2}\right.$ e $\left.l_{3}\right)$ e o conjuntos de 3 colunas $\left(c_{1}, c_{2}\right.$ e $\left.c_{3}\right)$. E portanto esses grafos só vão se diferenciar pelas arestas representadas pelas diagonais.

No projeto (1) podemos observar que só não existe diagonal na região da linha 3 e coluna 2 . Logo podemos representar o grafo do projeto (1) de acordo com a figura 4.52 . 


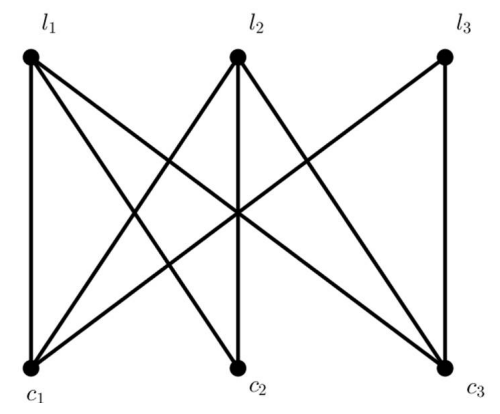

Figura 4.52: Grafo do projeto (1).

Portanto, o grafo 4.52 é conexo e a estrutura do projeto (1) é rígida.

No projeto (2) apresenta diagonais na :

- Linha 1 e Coluna 1 .

- Linha 1 e Coluna 2.

- Linha 2 e Coluna 1 .

- Linha 2 e Coluna 2.

- Linha 3 e Coluna 3.

Portanto, podemos representar o grafo do projeto (2) através da figura 4.53 .

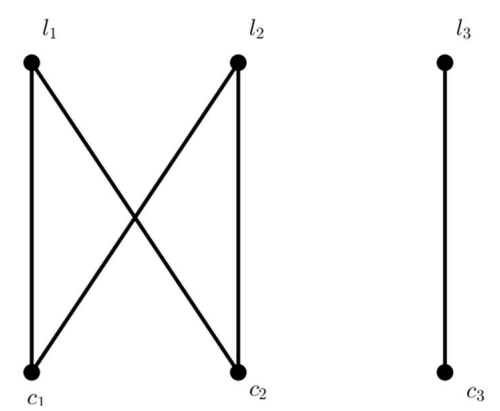

Figura 4.53: Grafo do projeto (2).

Observe que o grafo não é conexo, pois não existe um caminho que ligue $l_{2}$ a $c_{3}$, por exemplo. E assim, a estrutura não é rígida.

No projeto (3) apresenta diagonais na :

- Linha 1 e Coluna 1.

- Linha 1 e Coluna 3.

- Linha 2 e Coluna 3.

- Linha 3 e Coluna 1. 
- Linha 3 e Coluna 2.

Portanto, podemos representar o grafo do projeto (3) através da figura 4.54 .

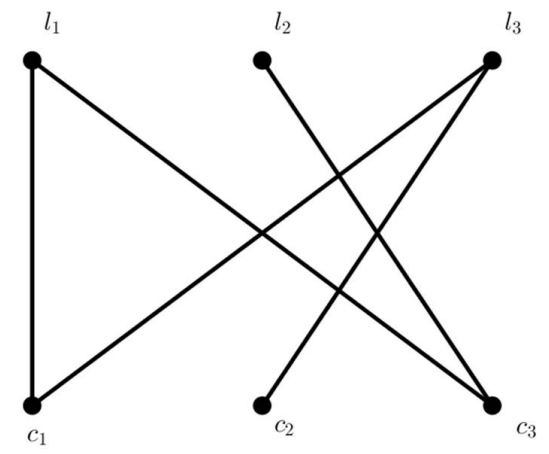

Figura 4.54: Grafo do projeto (3).

Portanto, o grafo é conexo 4.54 e a estrutura do projeto (3) é rígida.

Voltando ao questionamento inicial podemos dizer que os projetos (1) e (3) representam estruturas rígidas, enquanto o projeto (2) apresenta uma estrutura distorcida.

Agora, qual seria o mais vantajoso entre os projetos (1) e (3)?

Bem, o mais vantajoso seria o que apresentasse o menor número de estruturas que nesse caso seria o projeto (3).

Seria possível modificar o projeto (1) para que se torne tão vantajoso quanto o projeto $(\mathbf{3})$ ?

Em outras palavras, podemos retirar arestas do grafo do projeto (1) sem que ele fique desconexo? A resposta para isso é sim, basta buscar a árvore geradora do grafo 4.52 que representa o projeto (1).

Observe também que o grafo 4.52 contém vários ciclos como $l_{1} c_{3} l_{3} c_{1} l_{1}$ por exemplo. Se removermos qualquer aresta desse ciclo, o grafo permanece conexo e, portanto, a estrutura permanece rígida.

Podemos continuar removendo as arestas dos ciclos do grafo 4.52 até que não haja mais ciclos e de forma que o grafo permaneça conexo, como mostra a figura 4.55 . 


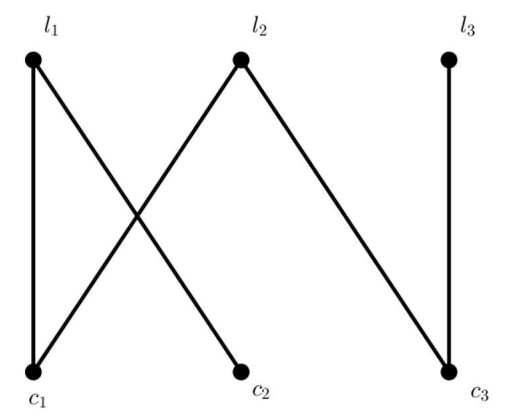

Figura 4.55: Árvore geradora do grafo do projeto (1).

Observe que se retirarmos qualquer outra aresta do grafo 4.55, ele passará a ser desconexo. Logo, o grafo 4.55 resultante é a árvore geradora desejada.

E assim, fizemos com que o projeto (1) tornar-se tão vantajoso como o projeto (3), veja na figura 4.56 .

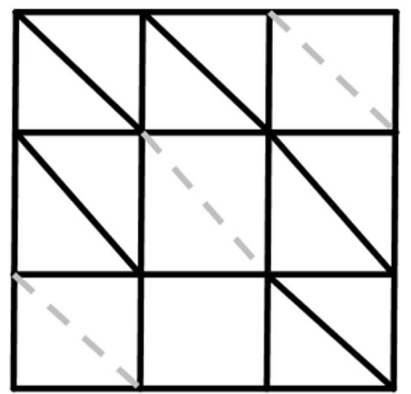

Figura 4.56: Projeto (1) modificado. Observe que as linhas pontilhadas foram as diagonais retiradas do projeto original. 


\section{Demonstrações de alguns teoremas da teoria de grafos}

Esta capítulo apresenta as provas de alguns resultados básicos da teoria de grafos que usamos nesta dissertação. Diferente dos capítulos anteriores, este capítulo é um pouco mais técnico e mais voltado para o professor, sem que necessariamente seja apresentado para o aluno.

Lema 1 (Lema do Aperto de Mão) Para todo grafo (não orientado) G, a soma dos graus de seus vértices é duas vezes o número de suas arestas $(n(A))$. Em outras palavras:

$$
\sum_{v \in G} g(v)=2 \cdot n(A)
$$

Prova. Para a demonstração desse teorema iremos utilizar o método de indução matemática finita no número de $\operatorname{arestas} n(A)$.

(Base): Se $n(A)=0$, temos então que o grafo é totalmente desconexo e portanto $\sum_{v \in G} g(v)=0=2 \cdot 0=2 \cdot n(A)$.

(Hipótese de indução): Se $n(A)=k \quad(k \geq 0)$, então no grafo $\mathrm{G}$ temos que $\sum_{v \in G} g(v)=2 \cdot k$.

(Tese de indução): Se $n(A)=k+1$, então vamos mostrar que no grafo $\mathrm{G}$ o $\sum_{v \in G} g(v)=2 \cdot(k+1)$.

Seja $G$ um grafo tal que $n(A)=k+1$, na qual existe uma aresta $a$ com extremos $x$ e $y$. Agora vamos considerar o outro grafo $G^{\prime}\left(V, A^{\prime}\right)$, onde $A^{\prime}=A \backslash\{a\}$ ( como por exemplo da figura 5.1).

Assim $G^{\prime}$ tem $k$ arestas e pela Hipótese de indução temos : $\sum_{v \in G^{\prime}} g(v)=$ $2 \cdot n\left(A^{\prime}\right)=2 \cdot k$. Além disso, temos que em $G^{\prime}$ :

$$
\left\{\begin{array}{l}
g_{G^{\prime}}(x)=g_{G}(x)-1 \\
g_{G^{\prime}}(y)=g_{G}(y)-1 \\
\sum_{v \in G^{\prime} \backslash\{x, y\}} g_{G^{\prime}}(v)=\sum_{v \in G \backslash\{x, y\}} g_{G}(v)
\end{array}\right.
$$



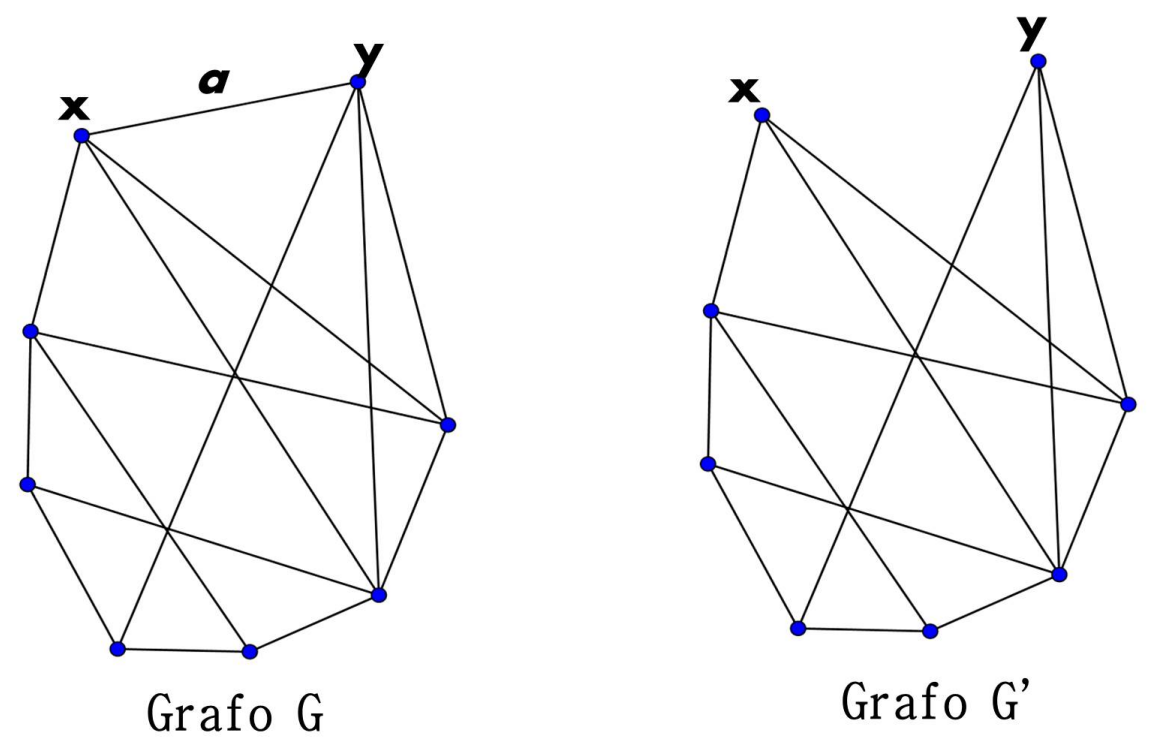

Grafo G'

Figura 5.1: Grafos G e G'.

Portanto,

$$
\begin{gathered}
\sum_{v \in G^{\prime}} g(v)=\sum_{v \in G^{\prime} \backslash\{x, y\}} g(v)+g_{G^{\prime}}(x)+g_{G^{\prime}}(y)=\sum_{v \in G \backslash\{x, y\}} g(v)+g_{G}(x)-1+g_{G}(y)-1 \\
=\sum_{v \in G} g(v)-2
\end{gathered}
$$

E pela Hipótese de indução ,

$$
2 \cdot n\left(A^{\prime}\right)=\sum_{v \in G} g(v)-2
$$

e como $n\left(A^{\prime}\right)=n(A)-1$, temos :

$$
\sum_{v \in G} g(v)=2 \cdot(n(A)-1)+2=2 \cdot n(A)-2+2=2 \cdot n(A)=2 \cdot(k+1)
$$

Lema 2 Todo grafo $G$ (não orientado) contém um número par de vértice de grau impar.

Prova. Seja $G$ um grafo.

Se $G$ não contém vértices de grau ímpar, significa que tem 0 vértices de grau ímpar e portanto um número par de vértices de grau ímpar.

Agora, suponhamos que $G$ tenha $k$ vértices de grau ímpar $(k>0)$, então podemos dizer que os vértices $\left\{v_{1}, v_{2}, \ldots, v_{k}\right\}$ são os vértices dentro de 
$V=\left\{v_{1}, v_{2}, \ldots, v_{k}, v_{k+1}, \ldots, v_{n}\right\}$ que possuem grau ímpar $(k \geq n)$.

Pelo Lema 1 temos que:

$\sum_{v \in G} g(v)=g\left(v_{1}\right)+g\left(v_{2}\right)+\ldots+g\left(v_{k}\right)+g\left(v_{k+1}\right) \ldots+g\left(v_{n}\right)=2 \cdot n(A)$

Como cada um dos números $g\left(v_{k+1}\right), \ldots, g\left(v_{n}\right)$ é par, então :

$$
g\left(v_{1}\right)+g\left(v_{2}\right)+\ldots+g\left(v_{k}\right)=-\underbrace{g\left(v_{k+1}\right)+\ldots+g\left(v_{n}\right)}_{\text {número par }}+\underbrace{2 \cdot n(A)}_{\text {número par }}
$$

Portando $g\left(v_{1}\right)+g\left(v_{2}\right)+\ldots+g\left(v_{k}\right)$ é um número par.

No entanto, cada um dos números $g\left(v_{1}\right), g\left(v_{2}\right), \ldots, g\left(v_{k}\right)$ é um número ímpar e para que a soma desses número seja um número par, precisamos ter $k$ par.

Logo, $G$ tem um número par de vértices.

Teorema 1 Seja G um grafo que possui arestas orientadas, então a soma dos graus de entrada de todos os vértices é igual soma dos graus de saída de todos os vértices e ambos correspondem ao número de arestas. Em outras palavras:

$$
\sum_{v \in G} g^{-}(v)=\sum_{v \in G} g^{+}(v)=n(A)
$$

Prova. Essa demonstração faremos de forma um pouco mais simples e intuitiva do que a demonstração do lema 1.

Observe que cada aresta de uma digrafo obrigatoriamente precisa começar e terminar em um vértice, podendo ele ser diferente ou não (no caso de um laço orientado).

Logo cada aresta de um digrafo acrescenta uma unidade para a somatório dos graus de entrada e uma unidade para a somatório dos graus de saída. E com isso, cada vez que contamos uma aresta é a mesma coisa que verificar o valor da soma dos graus de todos os vértices de entrada ( ou de saída) do grafo $G$

Portanto:

$$
\sum_{v \in G} g^{-}(v)=\sum_{v \in G} g^{+}(v)=n(A)
$$


Teorema 2 (Teorema de Euler) Um grafo simples finito e conexo admite uma trilha euleriana fechada se e somente se todos os seus vértices tem grau par.

Prova. ( $\Longrightarrow)$ "Se um grafo simples finito e conexo que admite uma trilha euleriana fechada então todos os seus vértices tem grau par."

Seja $G$ um grafo simples finito e conexo.

Seja T uma trilha euleriana fechada em $\mathrm{G}$.

Como $\mathrm{G}$ é conexo, sempre vai existe um $u-v$ caminho para todo par $(u, v)$ de vértices. Suponhamos que T comece e termine no vértice $u$. Agora tomemos um outro vértice qualquer, $v$, desse grafo. Como $v$ não é o único, e nem o primeiro, vértice do grafo, cada vez que uma aresta de $\mathrm{T}$ incide em $v$, aumenta em 2 unidades o grau do vértice $v$. Uma aresta "entrando" em $v$ e outra "saindo" de $v$ em, como mostra a figura 5.2. Logo $v$ tem grau par.

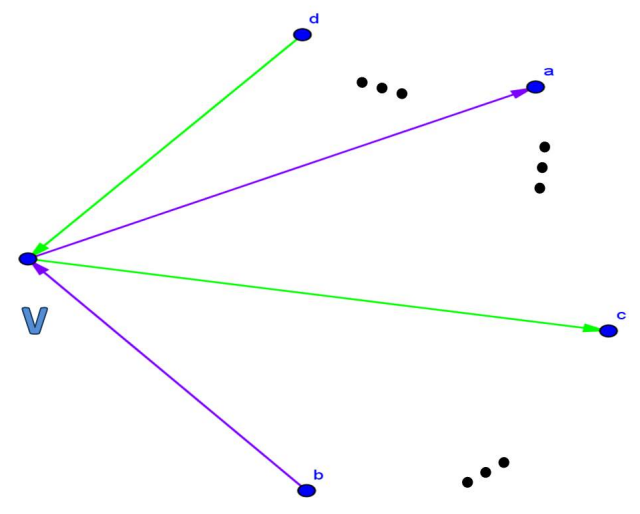

Figura 5.2: Sempre somando 2 unidades.

Além disso, esse mesmo raciocínio acontece com o vértice $u$ e inclusive a aresta inicial e a aresta final contribuem com mais uma unidade cada. Logo, podemos concluir que todo vértice de $\mathrm{G}$ tem grau par.

$(\Longleftarrow)$ " Se um grafo simples finito e conexo que possui todos os vértices de grau par, então G admite uma trilha euleriana fechada"

Seja $G$ um grafo simples finito e conexo, onde todos os vértices tem grau par.

Para mostrar que $G$ admite uma trilha euleriana, iremos particionar $G$ em um conjunto de ciclos $C$ da seguinte forma.

Cada vértice de $G$ possui no mínimo grau maior ou igual a 2 , visto que $G$ é conexo(logo não tem vértice de grau zero) e possui somente vértice de grau 
par, portanto $G$ contém um ciclo $C_{1}$. Se esse ciclo $C_{1}$ contiver todas as arestas do grafo $G$, o particionamento $C$ está concluído, como mostra a figura 5.3 .

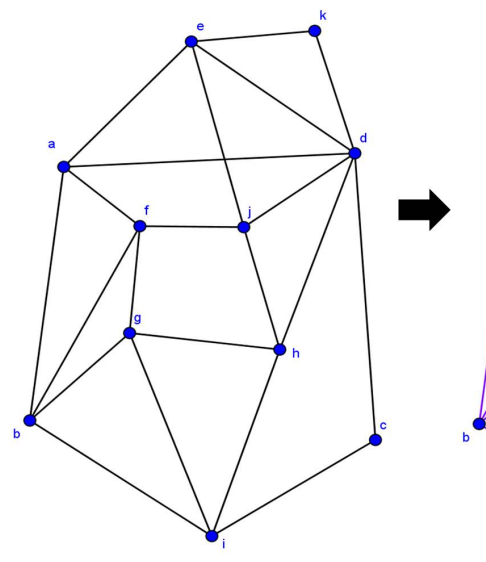

G

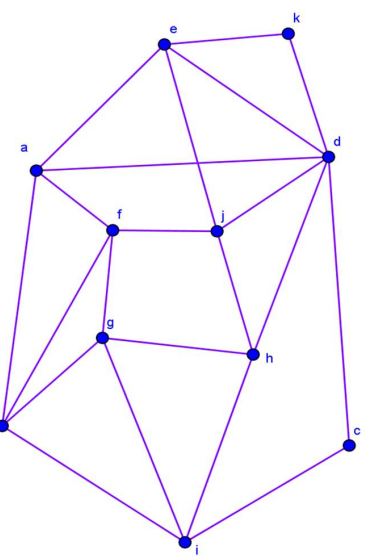

$\mathrm{C}_{1}$

Figura 5.3: $C_{1}=G$.

Caso contrário, iremos retirar as arestas de $G$ presente no ciclo $C_{1}$, formando um novo vértice $G^{\prime}$ que continuará tendo grau par como mostra a figura 5.4 .

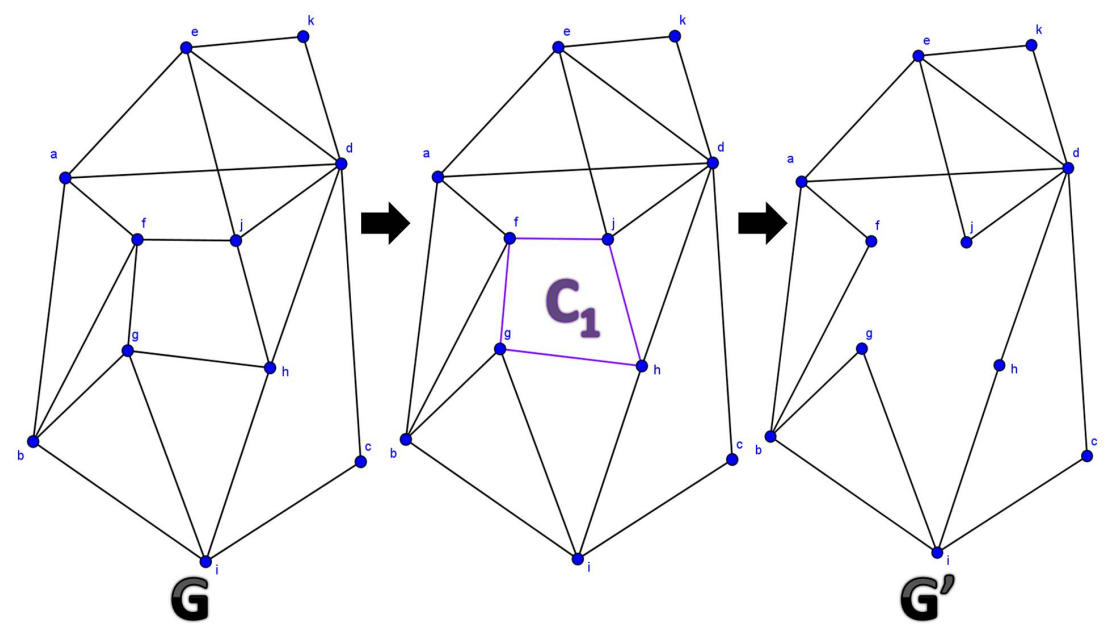

Figura 5.4: Do grafo $G$ foi "retirado" o ciclo $C_{1}$ formando um novo grafo $G^{\prime}$.

No novo grafo formado cada vértice ainda continua tendo grau par, pois como foi tirado um ciclo no grafo original temos que ou os vértices ficaram sem arestas( grau zero que é par) ou foram tiradas quantidades pares de arestas ( para cada entrada e saída do vértice ). Assim no novo grafo $G^{\prime}$ iremos determinar um novo ciclo $C_{2}$, e retiras as arestas de $C_{2}$ de $G^{\prime}$, como mostra a figura 5.5. 


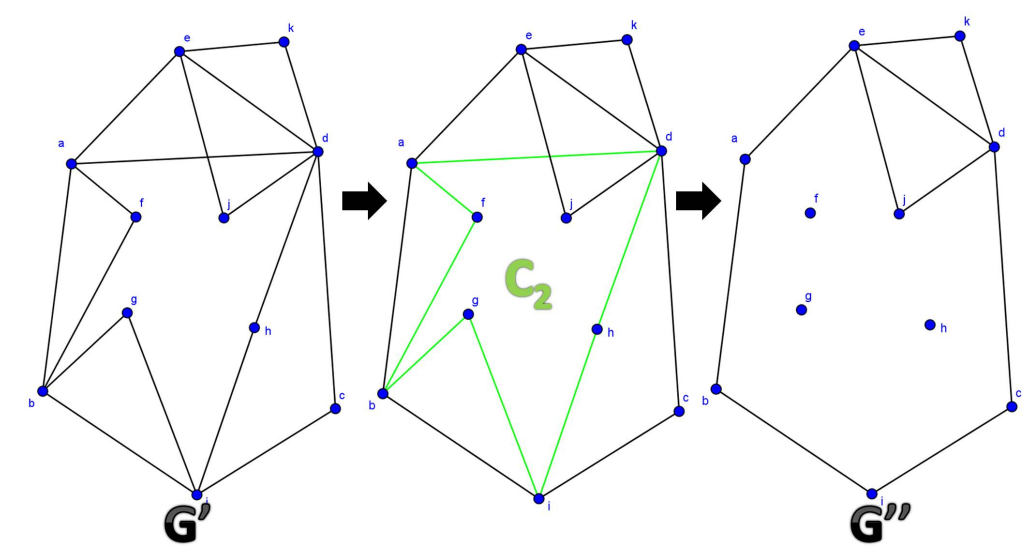

Figura 5.5: Do grafo $G^{\prime}$ foi "retirado"o ciclo $C_{2}$ formando um novo grafo $G^{\text {" }}$.

E assim por diante, até no final todos os vértices do grafo tenho grau zero, e portanto todas as arestas de $G$ estão particionadas em ciclos, como na figura 5.6.

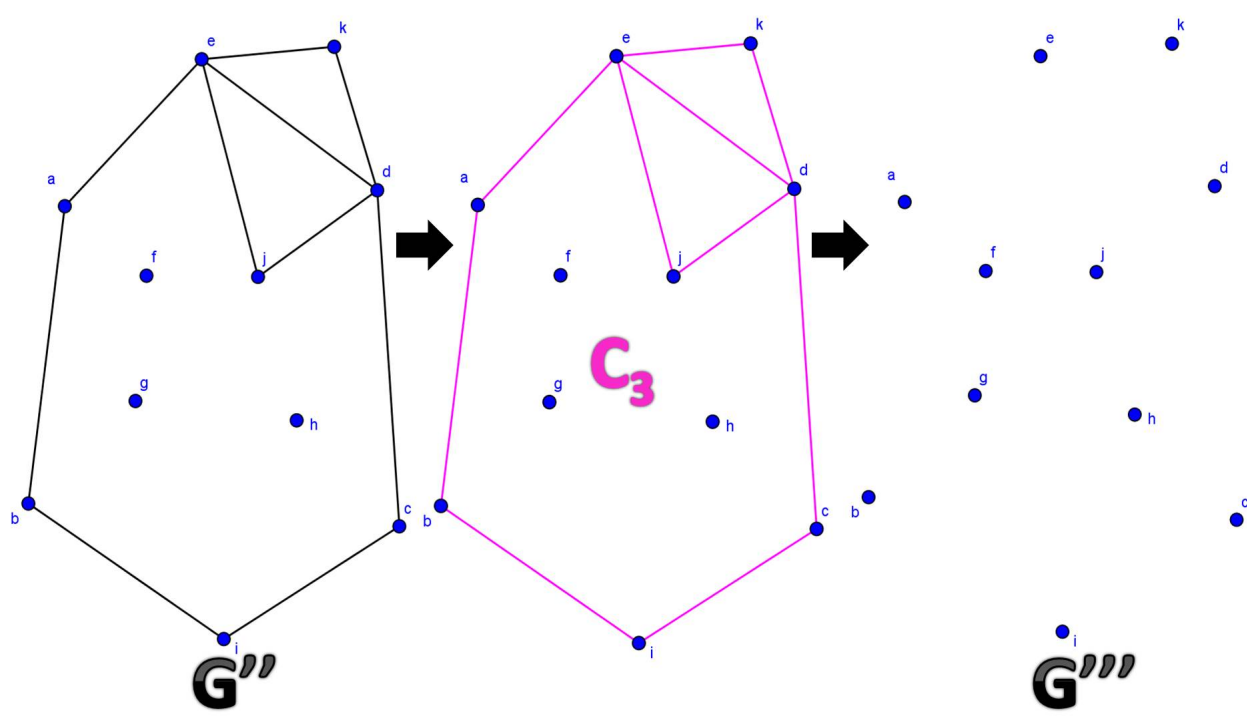

Figura 5.6: Todos os vértices passaram a ter grau zero.

Agora precisamos determina uma trilha euleriana para concluir a demonstração.

Então vamos escolher um ciclo do conjunto de ciclos de $C$. Se não existe mais ciclos em $C$ a serem analisados a demonstração está concluída. Caso contrário, escolhemos um outro ciclo de $C$ de tal forma que os ciclos escolhidos tenham um vértice em comum ( como $G$ é conexo podemos garantir essa existência). Então a união desses dois ciclos de $C$ forma uma trilha que passa por cada aresta exatamente uma vez. Por exemplo, pelo os ciclos $C_{1}$ e $C_{3}$ como mostra na figura 5.7. 


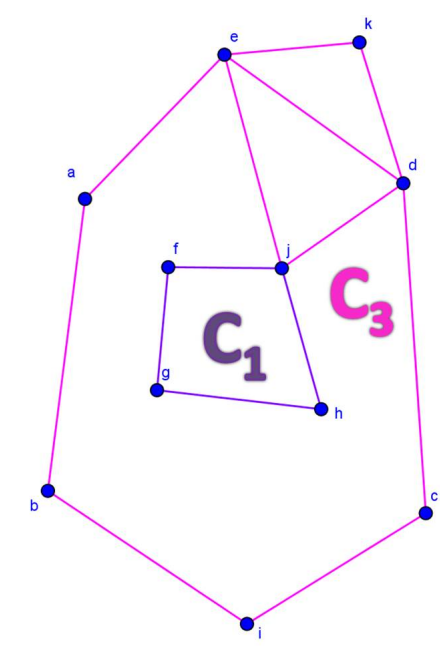

Figura 5.7: Os ciclos $C_{1}$ e $C_{3}$ possuem em comum o vértice $j$.

Depois iremos considerara um outro ciclo de $C$, que ainda não tenha sido escolhido, e que tenha vértice em comum com um dos ciclos já considerados e assim por diante. Até que tenha sido feito a união de todos os ciclos de $C$ que portanto formando uma trilha que passa por cada aresta um única vez. Logo $G$ possui uma trilha euleriana.

Teorema 3 (Grafo traçável) Um grafo simples finito e conexo admite uma trilha euleriana aberta $T_{a b}$ se e somente se tem exatamente dois vértices de grau impar. Mais precisamente, os vértices a e b são os únicos de grau ímpar.

Prova. ( $\Longrightarrow)$ "Um grafo simples finito e conexo se admite uma trilha euleriana aberta $T_{a b}$ então tem exatamente dois vértices de grau ímpar."

Seja $G$ um grafo simples finito e conexo que admite uma trilha euleriana aberta $T_{a b}$.

Como vimos na demonstração do Teorema de Euler, com exceção das arestas $a$ e $b$, cada aresta que incide em um dos vértices $v$ de $G$ aumenta em duas unidades o grau do vértices. Logo todo $v$ te grau par.

Entretanto, no vértice $a$ tem uma aresta inicial mas não possui a aresta final incidindo para fechar a trilha, logo a tem grau ímpar. E o mesmo ocorre com o vértice $b$ que tem a aresta final incidindo, porém não inciou a trilha.

$(\Longleftarrow)$ "Um grafo simples conexo se tem exatamente dois vértices de grau ímpar então admite uma trilha euleriana aberta."

Seja $G$ um grafo simples finito e conexo que tem exatamente dois vértices de grau ímpar, e sejam eles $a$ e $b$.

Vamos acrescentar ao grafo $G$ uma aresta $a b$ gerando um grafo $G^{\prime}$, como mostra a figura 5.8. 


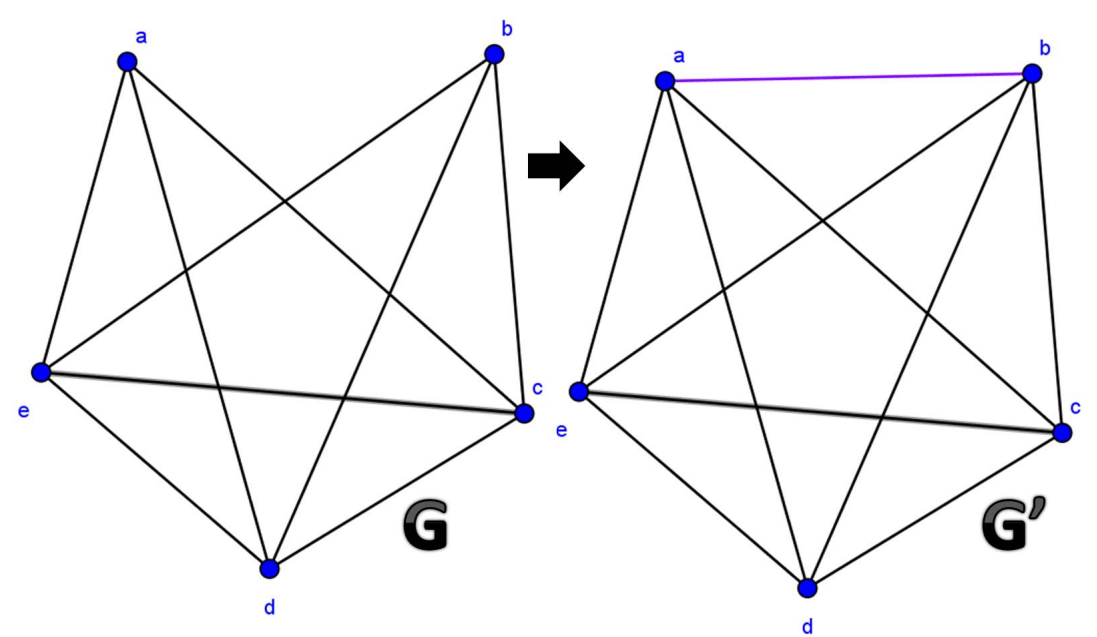

Figura 5.8: Acrescentando a aresta $a b$ ao grafo $G$ e formando o grafo $G^{\prime}$.

Agora com a aresta $a b$, o grau dos vértices $a$ e $b$ aumentou uma unidade, e com isso todos os vértices passaram a ter grau par.

Portanto pelo Teorema de Euler, o grafo $G^{\prime}$ possui uma trilha euleriana fechada, e consequente uma trilha euleriana aberta $T_{a b}$ que também pertence ao grafo $G$.

Logo, o grafo $G$ possui uma trilha euleriana aberta $T_{a b}$

Critério 1 (Dirac) Se cada um dos vértices de um grafo conexo finito $G$ (de ordem maior que 2) é vizinho de pelo menos metade dos vértices de $G$, então $G$ possui um ciclo hamiltoniano. Em outras palavras, se $|G|=n e$ $g(v) \geq \frac{n}{2} \quad \forall v \in G$, com $n \geq 3$, então $G$ possui um ciclo hamiltoniano.

Prova.

Seja G um grafo tal $|G|=n$, onde todo grafo $v$ pertencente a $G$ possui grau maior ou igual a $\frac{n}{2}$.

Suponhamos por absurdo que $G$ não possua um ciclo hamiltoniano.

Com isso, iremos acrescentar a $G$ novas arestas uma a uma, de forma a criarmos um novo grafo estendido $G^{\prime}$ ( com $G \subset G^{\prime}$ ) que contenha um ciclo hamiltoniano.

Observe que com efeito, no limite chegaremos ao grafo completo em n vértices $K_{n}$, que contém ciclos hamiltonianos. Pare o processo de adição de arestas nessa etapa e volte uma etapa, ou seja, retire a última aresta $\overline{P Q}$ adicionada que tornou possível a aparição do referido ciclo hamiltoniano, como mostra a figura 5.9. 


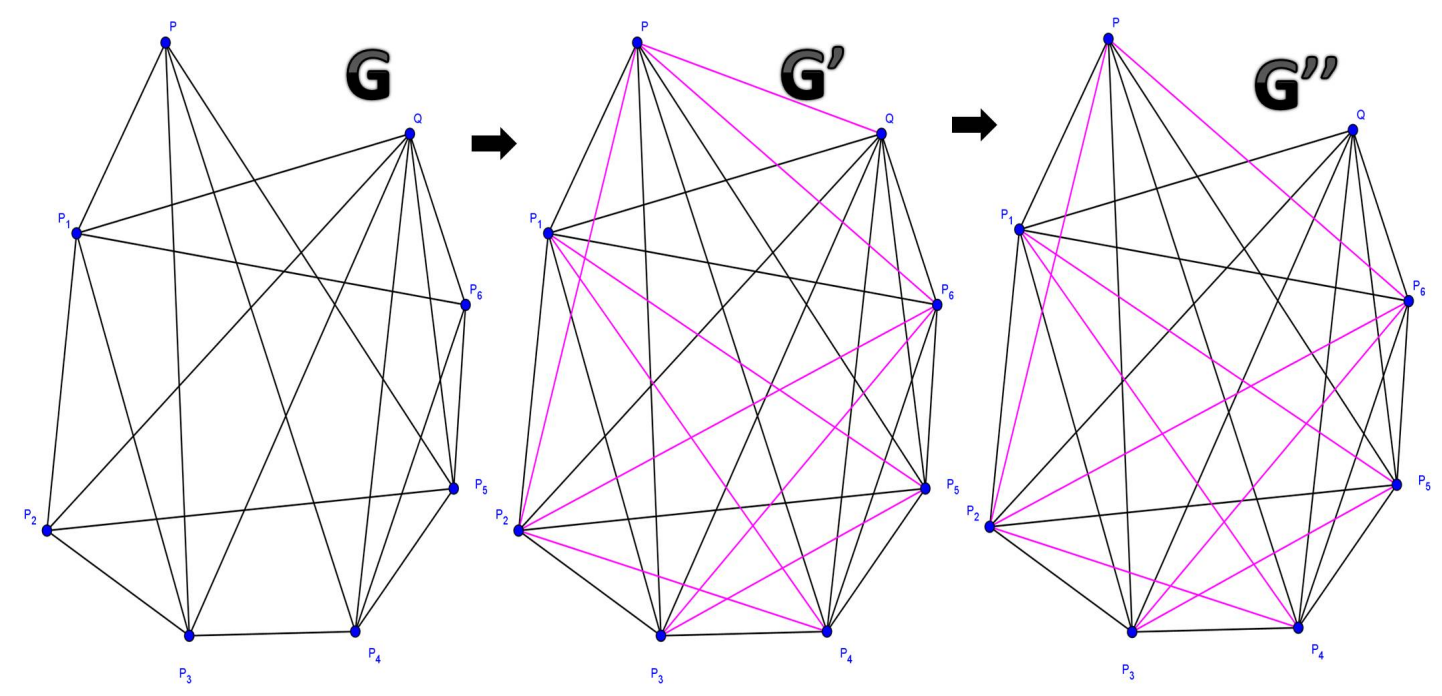

Figura 5.9: Formação de $G^{\prime}$ e $G^{\prime \prime}$ a partir de $G$. Note que já existem ciclos hamiltonianos em $G$ (é absurdamente difícil ilustrar provas por absurdo).

Ficaremos agora com o grafo estendido $G^{\prime \prime}=G^{\prime} \backslash\{\overline{P Q}\}$ que contém o caminho hamiltoniano:

$$
P=P_{1} \rightarrow P_{2} \rightarrow P_{3} \rightarrow \cdots \rightarrow P_{n-1} \rightarrow P_{n}=Q
$$

Sabemos que $\mathrm{P}$ possui ao menos $\lceil n / 2\rceil$ vizinhos dentre os vértices $P_{2}, P_{3}, \cdots, P_{n-1}$ e o mesmo ocorre com $\mathrm{Q}$.

Afirmação: existe um vizinho de $P$ que é sucessor de um vizinho de $Q$ ou vice-versa.

Prova da afirmação. Vamos escandir a seqüência $P_{2}, P_{3}, \cdots, P_{n-1}$ em $\left\lceil\frac{n}{2}-1\right\rceil$ "casas de pombo" $\left[P_{j}, P_{j+1}\right]$ contendo sucessores justapostos, possivelmente permitindo uma última "casa de pombo"contendo apenas o vértice $P_{n-1}$, caso $n$ seja ímpar, como no exemplo abaixo, $\operatorname{com} n=7$ :

$$
\left[P_{2}, P_{3}\right],\left[P_{4}, P_{5}\right],\left[P_{6}\right]
$$

Repetindo: sabemos que $P$ possui ao menos $\lceil n / 2\rceil$ vizinhos dentre os vértices $P_{2}, P_{3}, \cdots, P_{n-1}$, o mesmo valendo para $Q$. Logo, pelo Princípio da Casa de Pombos, pelo menos uma casa contém dois vizinhos de $P$. Aplicando mais uma vez o princípio, vemos que toda casa contém ao menos um vizinho de $Q$. Em particular, a casa contendo dois vizinhos de $P$ que acabamos de descobrir deve conter também um vizinho de $Q$. Das duas uma: ou o vizinho de $Q$ nessa casa é sucessor de um vizinho de $P$, ou é sucedido por um vizinho de $P$, como queríamos demonstrar. (fim da prova da afirmação)

Escolha agora um $j \in\{2,3, \cdots, n-2\}$ tal que $P_{j}$ é vizinho de $Q$ e $P_{j+1}$ é vizinho de $\mathrm{P}$. Voltando ao caminho hamiltoniano: 


$$
P=P_{1} \rightarrow P_{2} \rightarrow P_{3} \rightarrow \cdots \rightarrow P_{j} \rightarrow P_{j+1} \rightarrow \cdots \rightarrow P_{n-1} \rightarrow P_{n}=Q
$$

em $G^{\prime \prime}$, podemos então reordená-lo (usando as arestas $\overline{P_{j} Q}$ e $\overline{P_{j+1} P}$ e todas as mostradas acima, exceto $\left.\overline{P_{j} P_{j+1}}\right)$ como

$$
P \rightarrow P_{2} \rightarrow P_{3} \rightarrow \cdots \rightarrow P_{j} \rightarrow Q \rightarrow P_{n-1} \rightarrow P_{n-2} \rightarrow \cdots \rightarrow P_{j+1} \rightarrow P
$$

Ora, isso é um ciclo hamiltoniano em $G^{\prime \prime}$, que não devia existir, por construção. Essa contradição mostra que, de fato, G já possuia um ciclo hamiltoniano. Isso conclui a prova do critério. 


\section{6}

\section{Considerações Finais}

No trabalho apresentado, buscamos oferecer a alunos do Ensino Médio uma introdução aos grafos, apresentando exemplos simples de modelagem matemática de problemas do mundo real, visando fomentar a capacidade de abstração e contribuindo para o desenvolvimento de indivíduos críticos, criativos e participativos. Procuramos apresentar as noções mais básicas e alguns resultados da teoria de maneira informal e intuitiva, sempre em conexão com situações cotidianas ou puzzles, de forma a manter os alunos motivados e mostrar a aplicabilidade dos conceitos ensinados.

Apesar de a Teoria de Grafos propriamente dita ser um tema vasto, com inúmeros teoremas famosos, ela tem uma linguagem muito simples, consistindo apenas de dois tipos de objetos (vértices e arestas) e de uma única relação entre eles (a de incidência). Ademais, essas noções são modeladas por coisas tão corriqueiras como pontos no quadro-negro ou no papel e segmentos conectando eles. Tal simplicidade estrutural, aliada às inúmeras aplicações a problemas do cotidiano, torna o tema altamente palatável para uma audiência de estudantes secundaristas (ou mesmo mais jovens), visto que teorias com mais objetos e axiomas - como a Geometria Euclideana, por exemplo - são normalmente ensinadas ainda antes dessa fase. Cremos que o momento ideal para introduzir os grafos seja imediatamente após (ou mesmo durante) o estudo que tradicionalmente se faz de Análise Combinatória, pois há vários resultados desta última que podem ser usados para obter estimativas e provar teoremas em Teoria de Grafos. Um outro interesse do ensino prematuro de grafos, tal como sugerido por esta dissertação, é que ele fornece ocasião para introduzir naturalmente o conceito de algoritmo, uma das noções matemáticas mais importantes para a economia moderna.

Desejamos que o texto apresentado neste trabalho sirva como sugestão de inclusão da Teoria de Grafos em futuras remodelagens do currículo do Ensino Médio, não de modo apenas a satisfazer algum desejo - em si mesmo justificável - de trazer para a sala de aula temas mais modernos e relevantes para o estágio de desenvolvimento econômico em que nos encontramos, mas principalmente porque isso pode ser feito por meio de desafios que despertem a curiosidade e a engenhosidade próprias do aluno, em contextos tão simples e 
familiares quanto algumas situações que ele encontra no seu dia a dia. De fato, a mera linguagem da Teoria de Grafos já se mostra um poderoso aliado na organização do raciocínio, na medida em que auxilia na separação entre aquilo que é essencial e aquilo que é acidental em um problema, encaminhando assim sua solução, ou, no mínimo, uma análise mais clara do mesmo. 


\section{Referências bibliográficas}

[1] WIKIPÉDIA. Teoria dos grafos. https://pt.wikipedia.org/wiki/Teoria_dos _grafos, 2017. Acesso em: Janeiro de 2017.

[2] ORE, OYSTEIN. Graphs and their uses. The Mathematical Association of America, Washington, 1nd edition, 1963.

[3] ROSEAN, KENNETH H.. Matemática Discreta e Suas aplicações. AMGH, São Paulo, 6nd edition, 2009.

[4] FEOFILOFF,P.; KOHAYAKAWA, Y.; WAKABAYASHI, Y. . Uma introdução sucinta à teoria dos grafos. http://www.ime.usp.br/ $\sim$ pf/teoriadosgrafos/, 2011. Acesso em: Dezembro de 2016.

[5] CERIOLI, MÁRCIA R.. Notas de aulas de matemática finita: Introdução à teoria de grafo. http://www.cos.ufrj.br/ cerioli/cursos/teograf/NotasAula_MarciaCerioli2007, 2017. Acesso em: Maio de 2017.

[6] DONADELLI, JAIR. Teoria de grafo. http://professor.ufabc.edu.br/ jair.donadelli/disciplinas-ufpr/ci065/\#x150001, 2017. Acesso em: Janeiro de 2017.

[7] PISTORI, HEMERSON. Teoria de grafos. http://www.gpec.ucdb.br/pistori/disciplinas/discreta/aulas/, 2017. Acesso em: Abril de 2017. 